\title{
Dietary Patterns during Lactation and Human Milk Composition and Quantity: A Systematic Review
}

\author{
2020 Dietary Guidelines Advisory Committee, \\ Pregnancy and Lactation Subcommittee \\ Published date: July 15, 2020
}

Nutrition Evidence Systematic Review

Center for Nutrition Policy and Promotion

Food and Nutrition Service

U.S. Department of Agriculture

Braddock Metro Center II

1320 Braddock Place

Alexandria, Virginia 22314 
This systematic review was conducted by the 2020 Dietary Guidelines Advisory Committee in collaboration with the Nutrition Evidence Systematic Review (NESR) team at the Center for Nutrition Policy and Promotion, Food and Nutrition Service, U.S. Department of Agriculture (USDA). All systematic reviews from the 2020 Advisory Committee Project are available on the NESR website: https://nesr.usda.gov/2020-dietaryguidelines-advisory-committee-systematic-reviews.

Conclusion statements drawn as part of this systematic review describe the state of science related to the specific question examined. Conclusion statements do not draw implications, and should not be interpreted as dietary guidance. This portfolio provides the complete documentation for this systematic review. A summary of this review is included in the 2020 Advisory Committee's Scientific Report available at www.DietaryGuidelines.gov.

The contents of this document may be used and reprinted without permission. Endorsements by NESR, the Center for Nutrition Policy and Promotion, the Food and Nutrition Service, or the USDA of derivative products developed from this work may not be stated or implied.

Suggested citation for this systematic review: 2020 Dietary Guidelines Advisory Committee and Nutrition Evidence Systematic Review Team. Dietary Patterns during Lactation and Human Milk Composition and Quantity: A Systematic Review. 2020 Dietary Guidelines Advisory Committee Project. Alexandria, VA: U.S. Department of Agriculture, Food and Nutrition Service, Center for Nutrition Policy and Promotion, July 2020. Available at: https://nesr.usda.gov/2020-dietary-guidelines-advisory-committee-systematic-reviews.

Related citation: Dietary Guidelines Advisory Committee. 2020. Scientific Report of the 2020 Dietary Guidelines Advisory Committee: Advisory Report to the Secretary of Agriculture and the Secretary of Health and Human Services. U.S. Department of Agriculture, Agricultural Research Service, Washington, DC.

In accordance with Federal civil rights law and USDA civil rights regulations and policies, the USDA, its Agencies, offices, and employees, and institutions participating in or administering USDA programs are prohibited from discriminating based on race, color, national origin, religion, sex, gender identity (including gender expression), sexual orientation, disability, age, marital status, family/parental status, income derived from a public assistance program, political beliefs, or reprisal or retaliation for prior civil rights activity, in any program or activity conducted or funded by USDA (not all bases apply to all programs). Remedies and complaint filing deadlines vary by program or incident.

Persons with disabilities who require alternative means of communication for program information (e.g., Braille, large print, audiotape, American Sign Language, etc.) should contact the responsible Agency or USDA's TARGET Center at (202) 720-2600 (voice and TTY) or contact USDA through the Federal Relay Service at (800) 877-8339. Additionally, program information may be made available in languages other than English.

To file a program discrimination complaint, complete the USDA Program Discrimination Complaint Form, AD3027, found online at How to File a Program Discrimination Complaint and at any USDA office or write a letter addressed to USDA and provide in the letter all of the information requested in the form. To request a copy of the complaint form, call (866) 632-9992. Submit your completed form or letter to USDA by: (1) mail:

U.S. Department of Agriculture, Office of the Assistant Secretary for Civil Rights, 1400 Independence Avenue, SW, Washington, D.C. 20250-9410; (2) fax: (202) 690-7442; or (3) email: program.intake@usda.gov.

USDA is an equal opportunity provider, employer, and lender. 
Pregnancy and Lactation Subcommittee:

- Sharon Donovan, PhD, RD, University of Illinois, Urbana-Champaign, Subcommittee Chair

- Kathryn Dewey, PhD, University of California, Davis

- Rachel Novotny, PhD, RDN, LD, University of Hawaii

- Jamie Stang, PhD, MPH, RD, University of Minnesota

- Elsie Taveras, MD, MPH, Massachusetts General Hospital, Harvard Medical School, and Harvard T.H. Chan School of Public Health

- Ronald Kleinman, MD, Massachusetts General Hospital, Harvard Medical School, Vice-Chair of the 2020 Dietary Guidelines Advisory Committee

\section{Nutrition Evidence Systematic Review (NESR) Team:}

- Ramkripa Raghavan, DrPH, MPH, MSc, Analyst, Panum Group

- Julie Nevins, PhD, Analyst, Panum Groupi

- Sara Scinto-Madonich, MS, Analyst, Panum Groupi

- Julia H. Kim, PhD, MPH, RD, Analyst, Panum Groupi

- Nancy Terry, MS, MLS, Biomedical Librarian, National Institutes of Health (NIH) Library, U.S. Department of Health and Human Services (HHS)

- Gisela Butera, MLIS, MEd, Systematic Review Librarian, Panum Groupi

- Julie Obbagy, PhD, RD, Project Lead, Office of Nutrition Guidance and Analysis (ONGA), Center for Nutrition Policy and Promotion (CNPP), Food and Nutrition Service (FNS), U.S. Department of Agriculture (USDA)

\section{Federal Liaisons:}

- Jean Altman, MS, ONGA, CNPP, FNS, USDA

- Meghan Adler, MS, RDN, ONGA, CNPP, FNS, USDA

- Jenna Fahle, MSPH, RDN, ONGA, CNPP, FNS, USDA (08/2019-11/2019)

\section{Project Leadership:}

- Eve Essery Stoody, PhD, Designated Federal Officer and Director, ONGA, CNPP, FNS, USDA

- Janet de Jesus, MS, RD, Nutrition Advisor, Office of Disease Prevention and Health Promotion, Office of the Assistant Secretary for Health, HHS

USDA and HHS implemented a process to identify topics and scientific questions to be examined by the 2020 Dietary Guidelines Advisory Committee. The Committee conducted its review of evidence in subcommittees for discussion by the full Committee during its public meetings. The role of the Committee members involved establishing all aspects of the protocol, which presented the plan for how they would examine the scientific evidence, including the inclusion and exclusion criteria; reviewing all studies that met the criteria they set; deliberating on the body of evidence for each question; and writing and grading the conclusion statements to be included in

\footnotetext{
' Under contract with the Food and Nutrition Service, United States Department of Agriculture.
} 
the scientific report the 2020 Committee submitted to USDA and HHS. The NESR team with assistance from Federal Liaisons and Project Leadership, supported the Committee by facilitating, executing, and documenting the work necessary to ensure the reviews were completed in accordance with NESR methodology. More information about the 2020 Dietary Guidelines Advisory Committee, including the process used to identify topics and questions, can be found at www.DietaryGuidelines.gov. More information about NESR can be found at NESR.usda.gov.

The Committee and NESR staff thank USDA's Agricultural Research Service for coordinating the peer review of this systematic review, and the Federal scientist peer reviewers for their time and expertise.

FUNDING SOURCE: United States Department of Agriculture, Food and Nutrition Service, Center for Nutrition Policy and Promotion, Alexandria, VA 


\section{TABLE OF CONTENTS}

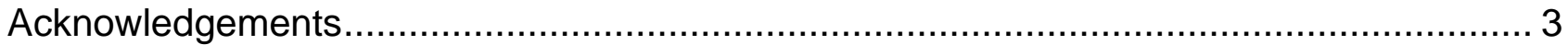

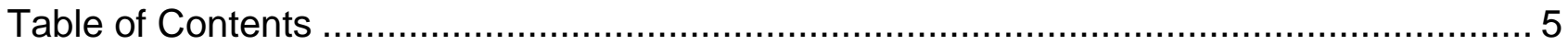

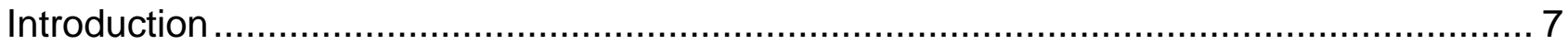

What is the relationship between dietary patterns consumed during lactation and human

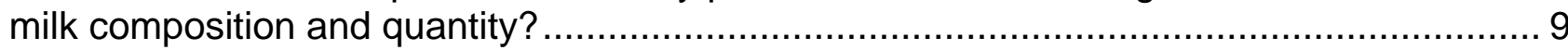

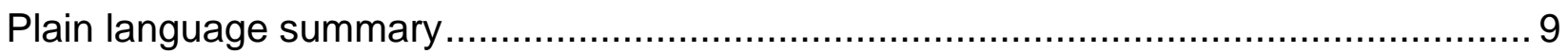

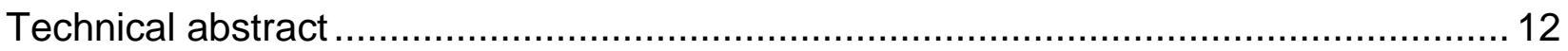

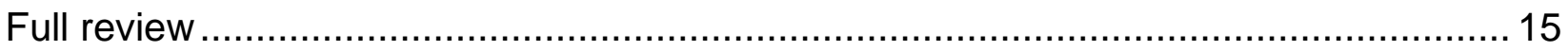

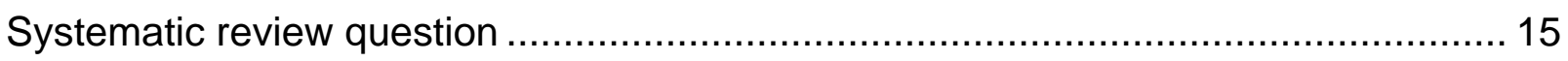

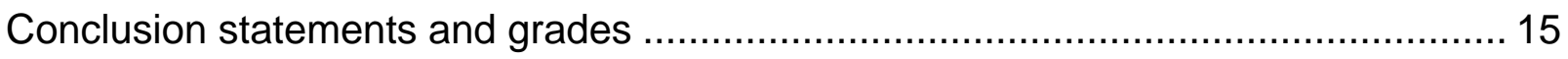

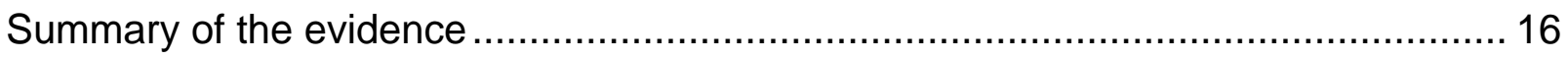

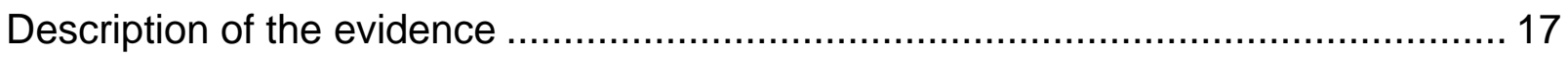

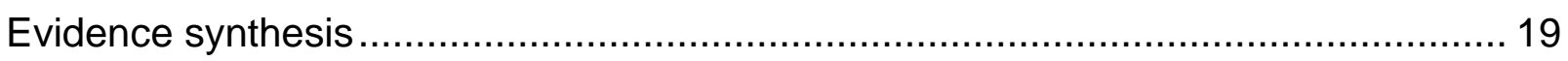

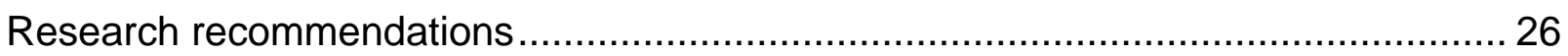

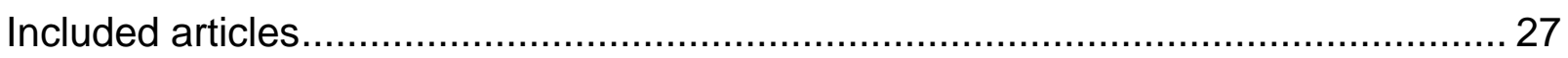

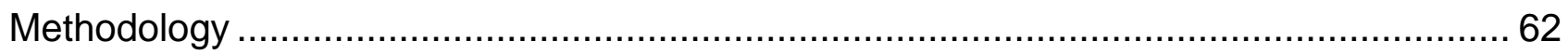

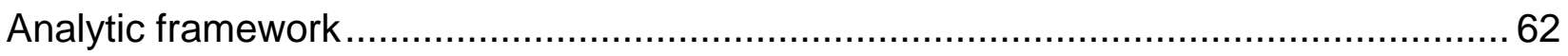

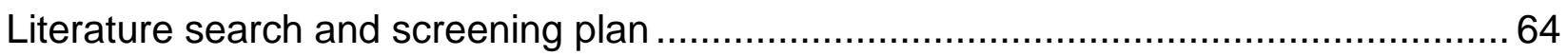

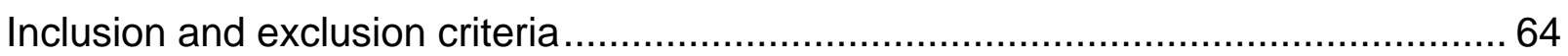

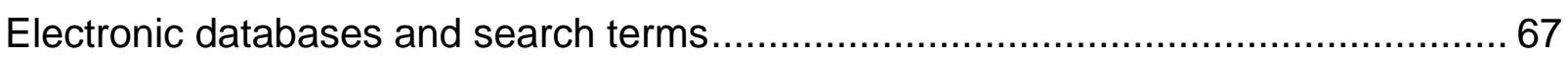

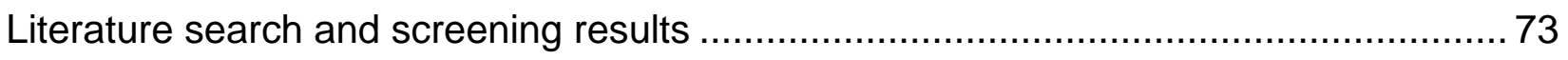

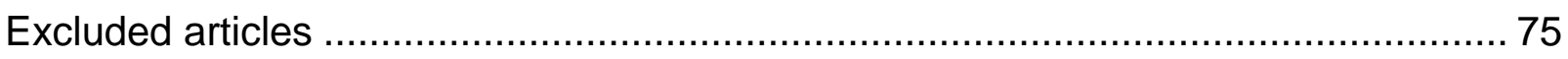

Table 1. Description of evidence on the relationship between dietary patterns during

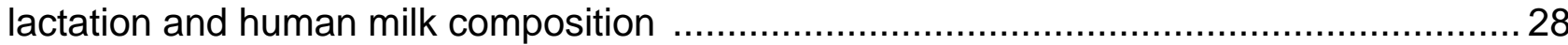
Table 2. Description of evidence on the relationship between diets based on macronutrient distributions during lactation and human milk composition and quantity ..........................40 Table 3. Results from studies that assessed the relationship between dietary patterns

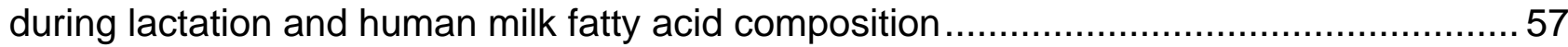
Table 4. Results from studies that assessed the relationship between diets based on macronutrient distributions during lactation and human milk composition ........................59 Table 5. Risk of bias for randomized controlled trials examining dietary patterns during lactation and human milk composition and quantity ..................................................... 61 Table 6. Risk of bias for observational studies examining dietary patterns during lactation

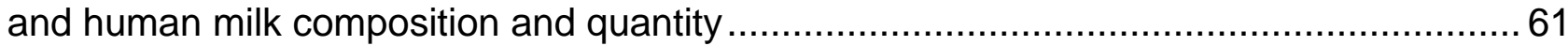

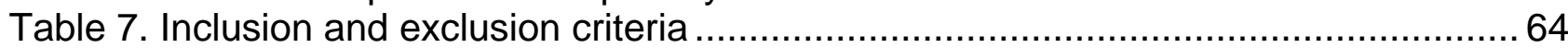

Table 8. Articles excluded after full text screening with rationale for exclusion................... 75 


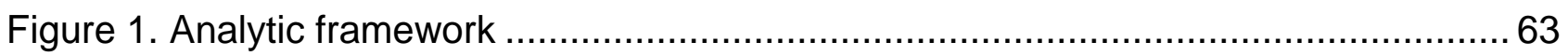

Figure 2. Flow chart of literature search and screening results................................... 74 
This document describes a systematic review conducted to answer the following question: What is the relationship between dietary patterns consumed during lactation and human milk composition and quantity? This systematic review was conducted by the 2020 Dietary Guidelines Advisory Committee, supported by USDA's Nutrition Evidence Systematic Review (NESR).

More information about the 2020 Dietary Guidelines Advisory Committee is available at the following website: www.DietaryGuidelines.gov.

NESR specializes in conducting food- and nutrition-related systematic reviews using a rigorous, protocol-driven methodology. More information about NESR is available at the following website: NESR.usda.gov.

NESR's systematic review methodology involves developing a protocol, searching for and selecting studies, extracting data from and assessing the risk of bias of each included study, synthesizing the evidence, developing conclusion statements, grading the evidence underlying the conclusion statements, and recommending future research. A detailed description of the systematic reviews conducted for the 2020 Dietary Guidelines Advisory Committee, including information about methodology, is available on the NESR website: https://nesr.usda.gov/2020-dietary-guidelines-advisory-committee-systematic-reviews. In addition, starting on page 62, this document describes the final protocol as it was applied in the systematic review. A description of and rationale for modifications made to the protocol are described in the 2020 Dietary Guidelines Advisory Committee Report, Part D: Chapter 3. Food, Beverage, and Nutrient Consumption During Lactation. 


\section{List of abbreviations}

\begin{tabular}{ll}
\hline Abbreviation & Full name \\
\hline AMDR & Acceptable Macronutrient Distribution Range \\
\hline CHO & Carbohydrate \\
\hline DHA & Docosahexaenoic acid \\
\hline EPA & Eicosapentaenoic acid \\
\hline HDI & Human Development Index \\
\hline HHS & Department of Health and Human Services \\
\hline MUFA & Monounsaturated fatty acid \\
\hline NESR & Nutrition Evidence Systematic Review \\
\hline PUFA & Polyunsaturated fatty acid \\
\hline PRO & Protein \\
\hline RCT & Randomized controlled trial \\
\hline SAT & Saturated fat \\
\hline SES & Socioeconomic status \\
\hline SIgA & Secretory immunoglobulin A \\
\hline USDA & United States Department of Agriculture \\
\hline
\end{tabular}




\section{WHAT IS THE RELATIONSHIP BETWEEN DIETARY PATTERNS CONSUMED DURING LACTATION AND HUMAN MILK COMPOSITION AND QUANTITY?}

\section{PLAIN LANGUAGE SUMMARY}

\section{What is the question?}

- The question is: What is the relationship between dietary patterns consumed during lactation and human milk composition and quantity?

\section{What is the answer to the question?}

- No evidence is available to determine the relationship between maternal dietary patterns during lactation and human milk quantity.

- Insufficient evidence is available to determine the relationship between maternal diets differing in macronutrient distributions during lactation and human milk quantity.

- Insufficient evidence is available to determine the relationship between dietary patterns during lactation and total fat in human milk.

- Limited evidence suggests that maternal consumption of diets higher in fat (>35 percent fat) and lower in carbohydrate during lactation is related to higher total fat in human milk collected in the maternal postprandial period.

- Limited evidence suggests that certain maternal dietary patterns during lactation, including diets based on macronutrient distributions, are related to the relative proportions of saturated fat and monounsaturated fatty acids in human milk, and of polyunsaturated fatty acids in human milk collected in the maternal postprandial period.

- No evidence is available to determine the relationship between maternal dietary patterns during lactation and total protein concentration in human milk.

- Insufficient evidence is available to determine the relationship between maternal diets differing in macronutrient distribution during lactation and total protein concentration in human milk.

- No evidence is available to determine the relationship between maternal dietary patterns during lactation and bioactive proteins including alpha-lactalbumin, lactoferrin, casein, alpha (1) antitrypsin, osteopontin, secretory immunoglobulin A, lysozyme in human milk.

- No evidence is available to determine the relationship between maternal dietary patterns during lactation and human milk oligosaccharides.

- Insufficient evidence is available to determine the relationship between maternal dietary patterns during lactation and vitamin $\mathrm{B}_{12}$ concentration in human milk.

- No evidence is available to determine the relationship between maternal dietary patterns during lactation and vitamin $\mathrm{C}$, choline and $\mathrm{B}$ vitamins (other than vitamin $\mathrm{B}_{12}$ ) in human milk.

- No evidence is available to determine the relationship between maternal dietary patterns during lactation and vitamins $A, D, E$ and $K$ in human milk.

- No evidence is available to determine the relationship between maternal dietary patterns during lactation and iodine and selenium in human milk. 
- This important public health question was identified by the U.S. Departments of Agriculture (USDA) and Health and Human Services (HHS) to be examined by the 2020 Dietary Guidelines Advisory Committee.

\section{How was this question answered?}

- The 2020 Dietary Guidelines Advisory Committee, Pregnancy and Lactation Subcommittee conducted a systematic review to answer this question with support from the Nutrition Evidence Systematic Review (NESR) team.

- Dietary patterns were defined as the quantities, proportions, variety, or combination of different foods, drinks, and nutrients (when available) in diets, and the frequency with which they are habitually consumed.

- Diets based on macronutrient distribution were examined when at least one macronutrient proportion was outside of the acceptable macronutrient distribution range (AMDR) for carbohydrate, fat, and/or protein, whether or not the foods/food groups consumed were provided.

\section{What is the population of interest?}

- For the question on dietary patterns and human milk composition, the population of interest is generally healthy, lactating women.

- For the question on dietary patterns and human milk quantity, the population of interest is generally healthy, lactating women who are exclusively or predominantly feeding their child human milk.

\section{What evidence was found?}

- This review includes seven articles published between 2009 and 2019.

- Two studies reported that a maternal diet higher in fat during lactation (i.e., more than 35 percent of total energy from fat, which is greater than the acceptable macronutrient distribution range resulted in higher total fat in human milk).

- Some studies showed that maternal dietary patterns during lactation were related to the relative proportions of saturated fat, monounsaturated fatty acids, and polyunsaturated fatty acids in human milk, which differed depending on whether milk samples were collected in a fed or fasted state.

- The body of evidence is limited in several ways:

- Small sample sizes of the studies.

- Inconsistencies in when and how human milk was collected across studies.

- Concerns about potential bias of the studies, including the possibility that factors other than maternal diet impacted the outcomes.

- Study populations that are not representative of the racial/ethnic or socioeconomic diversity of the U.S.

- There was insufficient or no evidence to assess the relationship between maternal dietary patterns during lactation and several outcomes, including human milk quantity and composition of total protein, water soluble vitamins $(B, C$, and choline), fat soluble vitamins (A, D, E, and K), minerals (iodine and selenium), human milk oligosaccharides, and bioactive proteins (alpha-lactalbumin, lactoferrin, casein, alpha (1) antitrypsin, osteopontin, secretory immunoglobulin A, and lysozyme). 
How up-to-date is this systematic review?

- This review searched for studies from January 2000 to November 2019. 


\section{TECHNICAL ABSTRACT}

\section{Background}

- This important public health question was identified by the U.S. Departments of Agriculture (USDA) and Health and Human Services (HHS) to be examined by the 2020 Dietary Guidelines Advisory Committee.

- The 2020 Dietary Guidelines Advisory Committee, Pregnancy and Lactation Subcommittee conducted a systematic review to answer this question with support from the Nutrition Evidence Systematic Review (NESR) team.

- The goal of this systematic review was to examine the following question: What is the relationship between dietary patterns consumed during lactation and human milk composition and quantity?

\section{Conclusion statements and grades}

- No evidence is available to determine the relationship between maternal dietary patterns during lactation and human milk quantity. (Grade: Grade not assignable)

- Insufficient evidence is available to determine the relationship between maternal $\mathrm{n}$ differing in macronutrient distributions during lactation and human milk quantity. (Grade: Grade not assignable)

- Insufficient evidence is available to determine the relationship between dietary patterns during lactation and total fat in human milk. (Grade: Grade not assignable)

- Limited evidence suggests that maternal consumption of diets higher in fat (>35 percent fat) and lower in carbohydrate during lactation is related to higher total fat in human milk collected in the maternal postprandial period. (Grade: Limited)

- Limited evidence suggests that certain maternal dietary patterns during lactation, including diets based on macronutrient distributions, are related to the relative proportions of saturated fat and monounsaturated fatty acids in human milk, and of polyunsaturated fatty acids in human milk collected in the maternal postprandial period. (Grade: Limited)

- No evidence is available to determine the relationship between maternal dietary patterns during lactation and total protein concentration in human milk. (Grade: Grade not assignable)

- Insufficient evidence is available to determine the relationship between maternal diets differing in macronutrient distribution during lactation and total protein concentration in human milk. (Grade: Grade not assignable)

- No evidence is available to determine the relationship between maternal dietary patterns during lactation and bioactive proteins including alpha-lactalbumin, lactoferrin, casein, alpha (1) antitrypsin, osteopontin, secretory immunoglobulin A, lysozyme in human milk. (Grade: Grade not assignable)

- No evidence is available to determine the relationship between maternal dietary patterns during lactation and human milk oligosaccharides. (Grade: Grade not assignable)

- Insufficient evidence is available to determine the relationship between maternal dietary patterns during lactation and vitamin $\mathrm{B}_{12}$ concentration in human milk. (Grade: Grade not assignable)

- No evidence is available to determine the relationship between maternal dietary patterns during lactation and vitamin $\mathrm{C}$, choline and $\mathrm{B}$ vitamins (other than vitamin 
$\mathrm{B}_{12}$ ) in human milk. (Grade: Grade not assignable)

- No evidence is available to determine the relationship between maternal dietary patterns during lactation and vitamins A, D, E and K in human milk. (Grade: Grade not assignable)

- No evidence is available to determine the relationship between maternal dietary patterns during lactation and iodine and selenium in human milk. (Grade: Grade not assignable)

\section{Methods}

- A literature search was conducted using four databases (PubMed, Cochrane, Embase, and CINAHL) to identify articles that evaluated the intervention or exposure of dietary patterns during lactation and the outcomes of human milk composition and quantity. A manual search was conducted to identify articles that may not have been included in the electronic databases searched. Articles were screened by two NESR analysts independently for inclusion based on predetermined criteria.

- Data extraction and risk of bias assessment were conducted for each included study, and both were checked for accuracy. The Committee qualitatively synthesized the body of evidence to inform development of conclusion statements, and graded the strength of evidence using pre-established criteria for risk of bias, consistency, directness, precision, and generalizability.

\section{Summary of the evidence}

- This systematic review includes three randomized controlled trials (RCTs) (four articles) and two cross-sectional studies (three articles) published between 2009 and 2019.

- Studies included in this review assessed one of the following maternal interventions or exposures during lactation:

- Dietary patterns (2 studies)

- Diets based on macronutrient distributions outside of the acceptable macronutrient distribution range (AMDR) (3 studies)

- Two of the three RCTs reported that a maternal diet higher in fat during lactation (i.e., $>35$ percent of total energy from fat, which is greater than the AMDR) resulted in higher total fat in human milk.

- Some, but not all studies showed that maternal dietary patterns during lactation were related to the relative proportions of saturated fat (SAT), monounsaturated fatty acids (MUFAs), and polyunsaturated fatty acids (PUFAs) in human milk, which differed depending on whether milk samples were collected in a fed or fasted state.

- This body of evidence had notable limitations:

- All RCTs had a small sample size (<20 participants) and none reported power analyses.

- The cross-sectional studies did not account for most of the confounders.

- One cross-sectional study reported that the participants differed on supplement intake during lactation, in addition to differing on dietary patterns. However, this was not controlled for in the statistical analysis or accounted for in the interpretation of the study findings.

- The timing and methods of human milk collection were heterogeneous. 
- The study populations did not represent the racial/ethnic or socioeconomic diversity of the U.S. population.

- Insufficient or no evidence was available to assess the association between dietary patterns and several other outcomes, including human milk quantity and human milk composition of total protein, water soluble vitamins (B, C, and choline), fat soluble vitamins ( $A, D, E$, and $K$ ), minerals (iodine and selenium), human milk oligosaccharides, and bioactive proteins (alpha-lactalbumin, lactoferrin, casein, alpha (1) antitrypsin, osteopontin, secretory immunoglobulin A ( $\lg A)$, and lysozyme). 


\section{FULL REVIEW}

\section{Systematic review question}

What is the relationship between dietary patterns consumed during lactation and human milk composition and quantity?

\section{Conclusion statements and grades}

No evidence is available to determine the relationship between maternal dietary patterns during lactation and human milk quantity. (Grade: Grade not assignable)

Insufficient evidence is available to determine the relationship between maternal diets differing in macronutrient distributions during lactation and human milk quantity. (Grade: Grade not assignable)

Insufficient evidence is available to determine the relationship between dietary patterns during lactation and total fat in human milk. (Grade: Grade not assignable)

Limited evidence suggests that maternal consumption of diets higher in fat $(>35$ percent fat) and lower in carbohydrate during lactation is related to higher total fat in human milk collected in the maternal postprandial period. (Grade: Limited)

Limited evidence suggests that certain maternal dietary patterns during lactation, including diets based on macronutrient distributions, are related to the relative proportions of saturated fat and monounsaturated fatty acids in human milk, and of polyunsaturated fatty acids in human milk collected in the maternal postprandial period. (Grade: Limited)

No evidence is available to determine the relationship between maternal dietary patterns during lactation and total protein concentration in human milk. (Grade: Grade not assignable)

Insufficient evidence is available to determine the relationship between maternal diets differing in macronutrient distribution during lactation and total protein concentration in human milk. (Grade: Grade not assignable)

No evidence is available to determine the relationship between maternal dietary patterns during lactation and bioactive proteins including alpha-lactalbumin, lactoferrin, casein, alpha (1) antitrypsin, osteopontin, secretory immunoglobulin A, lysozyme in human milk. (Grade: Grade not assignable)

No evidence is available to determine the relationship between maternal dietary patterns during lactation and human milk oligosaccharides. (Grade: Grade not assignable)

Insufficient evidence is available to determine the relationship between maternal dietary patterns during lactation and vitamin $\mathrm{B}_{12}$ concentration in human milk. (Grade: Grade not assignable)

No evidence is available to determine the relationship between maternal dietary patterns during lactation and vitamin $\mathrm{C}$, choline, and $\mathrm{B}$ vitamins (other than vitamin $\mathrm{B}_{12}$ ) in human milk. (Grade: Grade not assignable)

No evidence is available to determine the relationship between maternal dietary patterns during lactation and vitamins A, D, E, and K in human milk. (Grade: Grade not 
assignable)

No evidence is available to determine the relationship between maternal dietary patterns during lactation and iodine and selenium in human milk. (Grade: Grade not assignable)

\section{Summary of the evidence}

- This systematic review includes three randomized controlled trials (RCTs) (four articles) ${ }^{1-4}$ and two cross sectional studies (three articles) ${ }^{5-7}$ published between 2009 and 2019.

- Studies included in this review assessed one of the following maternal interventions or exposures during lactation:

- Dietary patterns (2 studies)

- Diets based on macronutrient distributions outside of the acceptable macronutrient distribution range (AMDR) (3 studies)

- Two of the three RCTs reported that a maternal diet higher in fat during lactation (i.e., $>35$ percent of total energy from fat, which is greater than the AMDR) resulted in higher total fat in human milk.

- Some, but not all studies showed that maternal dietary patterns during lactation were related to the relative proportions of saturated fat (SAT), monounsaturated fatty acids (MUFAs), and polyunsaturated fatty acids (PUFAs) in human milk, which differed depending on whether milk samples were collected in a fed or fasted state.

- This body of evidence had notable limitations:

- All RCTs had a small sample size (<20 participants) and none reported power analyses.

- The cross-sectional studies did not account for most of the confounders.

- One cross-sectional study reported that the participants differed on supplement intake during lactation, in addition to differing on dietary patterns. However, this was not controlled for in the statistical analysis or accounted for in the interpretation of the study findings.

- The timing and methods of human milk collection were heterogeneous.

- The study populations did not represent the racial/ethnic or socioeconomic diversity of the U.S. population.

- Insufficient or no evidence was available to assess the association between dietary patterns and several other outcomes, including human milk quantity and human milk composition of total protein, water soluble vitamins (B, C, and choline), fat soluble vitamins ( $A, D, E$, and $K$ ), minerals (iodine and selenium), human milk oligosaccharides, and bioactive proteins (alpha-lactalbumin, lactoferrin, casein, alpha (1) antitrypsin, osteopontin, secretory immunoglobulin A (slgA), and lysozyme). 


\section{Description of the evidence}

This systematic review included articles that address the relationship between dietary patterns and/or diets based on macronutrient distributions during lactation and human milk composition and quantity. The search included articles from countries categorized as high or very high on the Human Development Index (HDI)ii and published from January 2000 to November 2019. Studies included generally healthy women during lactation at the time of the intervention or exposure. The following study designs were included: RCTs, non-randomized controlled trials, prospective and retrospective cohort studies, nested case-control studies, and cross-sectional studies. Due to changes in human milk composition during the first weeks after delivery, only studies assessing milk composition in mature milk (defined as milk produced $\geq 14$ days postpartum) were included.

Dietary pattern was defined as the quantities, proportions, variety, or combination of different foods, drinks, and nutrients (when available) in diets, and the frequency with which they were habitually consumed. At a minimum, there had to be a description of the foods and beverages in the pattern. It may have been measured or derived using a variety of approaches, such as adherence to a priori patterns (indices/scores), data driven patterns (factor or cluster analysis), reduced rank regression, or other methods, including clinical trials.

Studies assessing diets based on macronutrient distributions outside of the AMDR had to include the macronutrient distribution of carbohydrate, fat, and protein of the diet, and include at least one macronutrient outside of the AMDR. Macronutrient percentages of energy outside of the AMDR are as follows:

- Carbohydrate for all age groups: $<45$ or $>65$ percent of energy;

- Protein for $\geq 19$ years: $<10$ or $>35$ percent of energy;

- Fat for $\geq 19$ years: $<20$ or $>35$ percent of energy

The outcomes considered in this review were human milk composition (specifically, macronutrients (fatty acids and total protein), water soluble vitamins (B, $C$, and choline), fat soluble vitamins ( $, D, E$, and $K$ ), selected minerals (iodine and selenium), human milk oligosaccharides, selected bioactive proteins (alpha-lactalbumin, lactoferrin, casein, alpha (1) antitrypsin, osteopontin, slgA, lysozyme) and human milk quantity.

In total, seven articles from five different studies were included in the body of evidence. The evidence in this review is presented based on the exposure: 1) Dietary patterns;

\footnotetext{
ii The Human Development classification was based on the Human Development Index (HDI) ranking from the year the study intervention occurred or data were collected (UN Development Program. HDI 1990-2017 HDRO calculations based on data from UNDESA (2017a), UNESCO Institute for Statistics (2018), United Nations Statistics Division (2018b), World Bank (2018b), Barro and Lee (2016) and IMF (2018). Available from: http://hdr.undp.org/en/data). If the study did not report the year in which the intervention occurred or data were collected, the HDI classification for the year of publication was applied. HDI values are available from 1980, and then from 1990 to present. If a study was conducted prior to 1990, the HDI classification from 1990 was applied. When a country was not included in the HDI ranking, the current country classification from the World Bank was used instead (The World Bank. World Bank country and lending groups. Available from: https://datahelpdesk.worldbank.org/knowledgebase/articles/906519-world- country-and-lending-groups).
} 
2) Diets based on macronutrient distributions.

\section{Dietary patterns}

The baseline characteristics and study findings are presented in Table 1 and Table 2. Three articles from two cross-sectional studies assessed the association between dietary patterns during pregnancy and human milk composition..$^{5-7}$ One study was conducted in the U.S. and produced two articles from the same sample ${ }^{5,6}$ and another study was conducted in China. ${ }^{7}$ The baseline sample sizes in the China ${ }^{7}$ and the U.S. studies $^{5,6}$ were 287 and 74 , respectively.

The participants in the U.S. study were predominantly White, well-educated and had a mean age of 32 years. ${ }^{5,6}$ The Chinese study participants had a mean age of 29.8 years, were 100 percent Chinese Han, and were predominantly from middle-to-higher income households. Mean prepregnancy BMI in the Chinese study was $20.6 \mathrm{~kg} / \mathrm{m}^{2}$. In the U.S. study, the mean prepregnancy BMI was higher, though mostly within the healthy range, and there was a significant difference between the comparison groups, with vegans $\left(22.8 \mathrm{~kg} / \mathrm{m}^{2}\right)$ having the lowest BMI when compared to vegetarians $(23.9$ $\left.\mathrm{kg} / \mathrm{m}^{2}\right)$ and omnivores $\left(25.8 \mathrm{~kg} / \mathrm{m}^{2}\right)$.

The Chinese study ${ }^{7}$ used a factor/cluster analysis to arrive at the following dietary patterns:

- Pattern 1: Mushroom food and algae, Meat, Marine products

- Pattern 2: Soybean products, Nuts, Dairy

- Pattern 3: Fruit, Vegetables

- Pattern 4: Grain/potato and beans, Eggs

In the U.S. study, ${ }^{5,6}$ during initial screening, participants self-identified their dietary pattern as vegan, vegetarian, or omnivore dietary patterns. Subsequently, a diet survey was administered to the enrolled participants, based on which the following dietary patterns were identified:

- Vegan: Never consumed meat and never or rarely consumed other animal products

- Vegetarian: Never or rarely consumed meat and sometimes or often consumed other animal products

- Omnivores: Consumed meat sometimes or often

All three articles assessed human milk composition. Specifically, two articles ${ }^{6,7}$ assessed fatty acid composition in human milk and one ${ }^{5}$ assessed vitamin $B_{12}$ levels in human milk. None of the articles assessed human milk quantity.

\section{Diets based on macronutrient distributions}

Three RCTs ${ }^{1-4}$ assessed the association between diets based on macronutrient distributions and human milk composition and quantity. Two studies were conducted in the U.S. ${ }^{1,2,4}$ and one in Canada. ${ }^{3}$ The sample sizes in these studies were small, with $<20$ participants in each study.

The mean age of the participants in the RCTs ranged from 27 years ${ }^{4}$ to 31.6 years. ${ }^{3}$ Maternal BMI was mostly within the healthy range, except for the study by Nasser et $\mathrm{al}^{3}{ }^{3}$ in which a mean BMl of $26 \mathrm{~kg} / \mathrm{m}^{2}$ was reported. Only Mohammad et $\mathrm{al}^{1,2}$ reported race/ethnicity, noting that the study included 2 White, 2 African American, and 3 
Hispanic mothers.

All RCTs that assessed diets based on macronutrient distributions were crossover studies that manipulated macronutrient percentage of energy above or below the AMDR for both fat and carbohydrate ${ }^{1-3}$ or fat ${ }^{4}$ only.

- Mohammad et al ${ }^{1,2}$ (baseline $\mathrm{n}=7$ ) randomized mothers to a "H-F" diet (30 percent carbohydrate, 55 percent fat, 15 percent protein) or a "H-CHO" diet (60 percent carbohydrate, 25 percent fat, 15 percent protein) for 8 days each with a washout period of 1-2 weeks. In the "H-F" diet group, the percentage of energy from carbohydrate was below the AMDR and energy from fat was above the AMDR, whereas, in the "H-CHO" diet, both carbohydrate and fat were within the percentage of energy ranges of the AMDR.

- Nasser et $\mathrm{al}^{3}$ (baseline $\mathrm{n}=14$ ) randomized mothers to a "high fat" diet (HF: 40.3 percent fat, 45.3 percent carbohydrate, 14.4 percent protein) or "low fat" diet (LF: 17.6 percent fat, 68 percent carbohydrate, 14.4 percent protein) diet for 4 days each, with a washout period of 3 days. In the "high fat" diet, percent of energy from fat was above the AMDR while percentage of energy from carbohydrates was within the AMDR; in the "low fat" diet, percentage of energy from fat was outside the AMDR and percentage of energy from carbohydrate was above the AMDR.

- Yahvah et $\mathrm{al}^{4}$ (baseline $\mathrm{n}=16$ ) randomized mothers to a "low-fat dairy" (24 percent fat) or "full-fat dairy" (36 percent fat) diet for 14 days each with a 14 day washout period. The percentage of energy from fat was above the AMDR in the "full-fat dairy group;" the percentage of energy from fat in the "low-fat dairy" group was within the AMDR and percentage of energy from both carbohydrate and protein were within the AMDR for both dairy groups.

All of the RCTs assessed human milk composition ${ }^{2-4}$ and only one study assessed both human milk composition and quantity. ${ }^{1}$ The studies primarily measured total fat and fatty acid in human milk, ${ }^{2-4}$ although one study also measured protein content. ${ }^{1}$

\section{Evidence synthesis}

With three RCTs ${ }^{1-4}$ and two cross-sectional studies, ${ }^{5-7}$ there is a smaller body of evidence available to examine the relationship between dietary patterns during lactation and human milk composition. Only one study ${ }^{1}$ assessed the relationship between diets based on macronutrient distributions during lactation and human milk quantity. Below, the results are grouped by two types of exposures - dietary patterns and diets based on macronutrient distributions.

\section{Dietary patterns}

Both studies that assessed dietary patterns were cross-sectional studies. Tian et al ${ }^{7}$ and Perrin et $\mathrm{al}^{6}$ assessed the association between dietary patterns and human milk fatty acids (Table 3). Pawlak et al ${ }^{5}$ was the only study that assessed vitamin $\mathrm{B}_{12}$ status in human milk. The findings are discussed below.

\section{Dietary patterns and human milk fatty acids}

Tian et $\mathrm{al}^{7}$ noted significant differences in proportions of certain fatty acids in human milk between women adhering to different dietary patterns. For example, women 
adhering to pattern 2 (soybean products, nuts, dairy) and pattern 4 (grain/potato and beans, eggs) had the same average amount of saturated fatty acids in human milk, which was significantly higher than the average among women who adhered to pattern 3 (fruit, vegetables) $(p<0.001)$. Among the four groups, the proportion of PUFAs in milk was the highest in women adhering to pattern 3 and lowest in those adhering to pattern $2(p=0.025)$. Similarly, the proportion of omega- 6 fatty acids in milk was highest in mothers adhering to pattern 1 (mushroom food and algae, meat, marine products) and lowest in those adhering to pattern $2(p=0.038)$. There were no statistically significant differences in omega-3 fatty acids, omega- 6 to omega-3 ratios, or proportion of MUFAs in the milk of mothers adhering to different dietary patterns, although the last of these indices approached significance $(p=0.053)$.

Perrin et $\mathrm{al}^{6}$ reported significant differences in human milk composition between mothers adhering to different dietary patterns. Specifically, milk from mothers adhering to a vegan dietary pattern, when compared to that of mothers adhering to vegetarian or non-vegetarian dietary patterns, had significantly higher unsaturated fatty acids $(p<0.001)$ and total omega-3 fatty acids $(p<0.001)$, and lower saturated fat $(p<0.001)$, trans fat $(p<0.001)$, omega- 6 to omega- 3 ratios $(p<0.001)$ and linoleic acid to $\alpha$ linolenic acid ratios $(p<0.001)$. The significant difference in omega- 3 fatty acids was driven by a higher percentage of $\alpha$-linolenic acid, with no difference noted in eicosapentaenoic acid (EPA) and docosahexaenoic acid (DHA) across different maternal dietary patterns. Similarly, there were no differences in omega- 6 fatty acids (except $y$-linolenic acid), total long chain, or total medium chain fatty acids by maternal dietary patterns.

Summary: The studies discussed above were heterogeneous in dietary patterns methodology. Specifically, Tian et $\mathrm{al}^{7}$ used factor analysis to arrive at the dietary patterns, whereas Perrin et $\mathrm{al}^{6}$ used an 'other' method that relied on grouping women into their respective patterns based on their response to a diet survey. Both studies reported that saturated fat and some of the unsaturated fat in human milk varied significantly across dietary patterns, but the heterogeneity between studies in terms of both the dietary patterns and fatty acid assessment preclude a true comparison and pooling of the study findings.

\section{Dietary patterns and human milk vitamin $B_{12}$}

Pawlak et $\mathrm{al}^{5}$ assessed human milk vitamin $\mathrm{B}_{12}$ levels in women adhering to who vegan, vegetarian and non-vegetarian dietary patterns. There were no significant differences in the vitamin $\mathrm{B}_{12}$ levels in human milk across these three groups. Thirteen of the 74 women had low vitamin $B_{12}$ concentration $(<310 \mathrm{pmol} / \mathrm{L})$ in human milk, although this did not differ by dietary pattern. Similarly, eight women had human milk vitamin $B_{12}$ above the assay detection threshold (>1122 pmol/L), and there was no significant difference between the groups. An important context to consider is that almost half of the vegan women (46.2 percent) consumed vitamin $B_{12}$ supplements, whereas only 27.3 percent and 3.9 percent of the vegetarian and non-vegetarian women, respectively, consumed supplements $(p=0.001)$. However, this was not accounted for in the analysis.

\section{Diets based on macronutrient distributions}

All studies that assessed diets based on macronutrient distributions were RCTs. In terms of outcomes, only one study assessed human milk quantity. All three studies 
looked at the association between macronutrient distribution in the diet and human milk fatty acids and the findings are discussed below by individual study, and followed by the synthesis (Table 4).

Mohammad et al, ${ }^{1}$ the only study that assessed human milk quantity, concluded that there was no significant difference in human milk production in mothers when consuming a " $\mathrm{H}-\mathrm{CHO}$ " diet (60 percent carbohydrate, 25 percent fat, 15 percent protein) vs. "H-F" diet (30 percent carbohydrates, 55 percent fat and 15 percent protein). There was also no significant effect of the diet on protein in human milk. However, the milk fat concentration and milk fat content per day was significantly higher when consuming " $\mathrm{H}-\mathrm{F}$ " diet $(\mathrm{p}<0.05)$.

Mohammad et $\mathrm{al}^{2}$ reported that the total fat in human milk was significantly higher with the "H-F" diet (30 percent carbohydrates, 55 percent fat and 15 percent protein), when compared to the " $\mathrm{H}-\mathrm{CHO}$ " diet (60 percent carbohydrate, 25 percent fat, 15 percent protein), but this was only observed in the fed state and not after overnight fasting Human milk $\sum \mathrm{C} 2: \mathrm{C} 14$ fatty acid content differed significantly and was mostly higher when women consumed the "H-CHO" vs. "H-F" diet, during both fasted and fed states. Specifically, saturated fatty acids during fed (C4:0, C6:0, C8:0, C10:0, C12:0, C14:0, C16:0 and C18:0) and fasted states (C4:0, C6:0, C8:0, C10:0, C14:0) were higher in the milk of the mothers during the "H-CHO" diet, as opposed to the "H-F" diet. Despite the differences in individual saturated fatty acids, $\Sigma$ SAT was not significantly higher when women consumed either the "H-CHO" or " $\mathrm{H}-\mathrm{F}$ " diet, irrespective of being in fed or fasted states. However, the percent total fat of $\Sigma$ SAT in human milk was significantly higher during the "H-CHO" diet in the fed state only.

Human milk $\sum$ MUFA was significantly higher when women consumed the "H-F" diet as opposed to the "H-CHO" diet, in the fed state. There was, however, no difference in the fasted state. The percent total fat of $\sum$ MUFA was significantly higher during the " $\mathrm{H}$ F" diet in both fed and fasted states. Similarly, women during their " $\mathrm{H}-\mathrm{F}$ " diet had higher milk $\Sigma$ PUFA (specifically C20:2, C20:3, C20:4, C20:5, C22:6) when compared to the "H-CHO" diet. This difference was noted only in the fed state and not in the fasted state. No statistically significant differences were observed in the percent total fat of $\Sigma$ PUFA when consuming "H-CHO" vs. "H-F" diets, in both fed and fasted states.

Nasser et $\mathrm{al}^{3}$ noted no significant differences in the mean total concentrations of saturated fatty acids, MUFA, and PUFA when women were consuming the "low fat" (68 percent carbohydrate, 17.6 percent fat, 14.4 percent protein) vs. "high fat" diet (45.3 percent carbohydrate, 40.3 percent fat 14.4 percent protein). However, the concentrations of total medium chain fatty acids (C8:0-C14:0) were significantly higher during the "low fat" vs. "high fat" diet $(p=0.01)$. Similarly, certain $n-6$ fatty acids $(\gamma-$ linolenic acid, dihomo- $y$-linolenic acid, and arachidonic acid) were significantly higher with the "low fat" diet when compared to the "high fat" diet. a-linolenic acid (C18:3n-3) in milk was higher when mothers consumed the "high fat" vs. "low fat" diet.

Yahvah et al ${ }^{4}$ reported that the total lipids in human milk were significantly higher with a "full-fat dairy" diet (48 percent carbohydrate, 36 percent fat, 17 percent protein) when compared to a "low-fat dairy" diet (57 percent carbohydrates, 24 percent fat, 20 percent protein). Saturated fat was higher in the milk of women consuming a "full-fat dairy" diet vs. "low-fat dairy" diet (specifically, C12:0, C13:0, iso-C14:0, C15:0, isoC15:0, anteiso-C15:0, C16:0, iso-C16:0, C17:0, iso-C17:0, anteiso-C17:0, C18:0, 
anteiso 18:0, iso-18:0, C20:0). Many of the MUFAs in the milk did not differ based on the intervention, with the exception of C14:1, C16:1t9, and C18:1t11, which were higher in the milk of women consuming the full-fat dairy diet. Most of the PUFAs varied with the dietary intervention, with $\mathrm{C} 16: 2$ and $\mathrm{C} 18: 2 \mathrm{c} 9, \mathrm{t} 11$ higher in milk after women had the "full-fat dairy" diet; on the other hand, a-linolenic acid was higher in milk after women had the "low-fat dairy" diet.

Summary: Across four articles, Mohammad et al ${ }^{1}$ was the only study that reported human milk quantity and there was no statistically significant relationship between diet macronutrient distribution and human milk volume. Mohammad et al (2009) ${ }^{1}$ and Mohammad et al (2014) ${ }^{2}$ (both from the same trial) and Yahvah et al ${ }^{4}$ reported that total milk fat was higher after consuming the " $\mathrm{H}-\mathrm{F}$ " diet or the "full-fat dairy" diet.

- Saturated fatty acid: Both Mohammad et $\mathrm{al}^{2}$ and Nasser et $\mathrm{al}^{3}$ reported no differences in total saturated fatty acids. However, when mothers consumed a " $\mathrm{H}-\mathrm{CHO}$ " diet (60 percent carbohydrate, 25 percent fat, 15 percent protein $)^{2}$ or a "low fat" diet (68 percent carbohydrate, 17.6 percent fat, 14.4 percent protein) ${ }^{3}$, their milk was higher in certain individual saturated fatty acids (Table 4).

Yahvah et al ${ }^{4}$ did not report total saturated fatty acids, but noted that certain saturated fatty acids were higher when mothers consumed the "low-fat dairy" diet (57 percent carbohydrate, 24 percent fat, 20 percent protein) and others were higher when they consumed the "full-fat dairy" diet (48 percent carbohydrate, 36 percent fat, 17 percent protein).

- MUFAs: Mohammad et $\mathrm{al}^{2}$ reported that after the "H-F" diet (30 percent carbohydrates, 55 percent fat and 15 percent protein), human milk was significantly higher in MUFAs. Nasser et $\mathrm{al}^{3}$ reported no differences in total MUFAs in milk when mothers consumed the "low fat" (68 percent carbohydrate, 17.6 percent fat, 14.4 percent protein) vs. "high fat" diet (45.3 percent carbohydrate, 40.3 percent fat 14.4 percent protein), but noted that palmitoleic acid (C16:0) was higher during the "low fat" diet and arachidic acid (C20:0) was higher during the "high fat" diet. Yahvah et al ${ }^{4}$ did not report total MUFAs, but noted that when mothers consumed the "full-fat dairy" diet (48 percent carbohydrate, 36 percent fat, 17 percent protein), their milk was higher in certain MUFAs (C14:1, C16:1t, C18:1t11), whereas C12:0 and iso-17:0 was higher with the "low-fat dairy" diet (57 percent carbohydrates, 24 percent fat, 20 percent protein).

- PUFAs: Mohammad et $\mathrm{al}^{2}$ reported that after mothers consumed the " $\mathrm{H}-\mathrm{F}$ " diet (30 percent carbohydrate, 55 percent fat and 15 percent protein), human milk was significantly higher in PUFAs. Nasser et $\mathrm{al}^{3}$ reported no differences in total PUFAs in human milk when mothers consumed the "low fat" (68 percent carbohydrate, 17.6 percent fat, 14.4 percent protein) vs. "high fat" diet (45.3 percent carbohydrate, 40.3 percent fat, 14.4 percent protein), but noted that mothers had higher $\alpha$-linolenic acid $(\mathrm{C} 18: 3 \mathrm{n}-3)$ in milk when consuming the latter diet. On the other hand, $y$-linoleic acid (C18:3n-6), dihomo $y$-linoleic acid (C20:3n-6), and arachidonic acid (C20:4n-6) were higher when mothers consumed the "low fat" diet. Yahvah et al ${ }^{4}$ did not report total PUFAs, but noted that the milk of mothers consuming the "low-fat dairy" diet (57 percent carbohydrate, 24 percent fat, 20 percent protein) had higher linoleic acid (C18:2) and $\alpha$-linolenic acid (C18:3n:3). 


\section{Assessment of the evidence ${ }^{\mathrm{iii}}$}

The following conclusion statement was supported by three RCTs and was graded "limited." The individual grading elements are discussed below and summarized in Table 5.

"Limited evidence suggests that maternal consumption of diets higher in fat (>35 percent fat) and lower in carbohydrate during lactation is related to higher total fat in human milk collected in the maternal postprandial period."

As outlined and described below, the body of evidence examining diets based on macronutrient distributions during lactation and human milk composition was assessed for the following elements used when grading the strength of evidence.

- Risk of bias was graded as limited

- Study Design: All studies included in this body of evidence were RCTs, but minimal information on participant randomization methods was reported. Other factors such as maternal BMI and nutritional status prior to enrollment could have influenced the study findings, but are not discussed or accounted for in the articles.

- Intervention/Exposure: Although all 3 RCTs were designed to assess the impact of maternal diet (manipulating outside of AMDR) on human milk fat composition, articles reported minimal information on the foods and types of fat in the intervention diets. Little information was provided on supplement use and the potential influence on the study findings.

- Outcome: There was variability across studies in how and when milk was collected. For example, Mohammad et al ${ }^{1,2}$ collected milk when mothers were in fed and fasted states and Mohammad et al ${ }^{2}$ presented the results stratified by those two states. However, none of the other studies clarified the maternal fed state during milk collection, thus making it difficult to compare the study findings. Studies also differed on how milk was collected. For example, Nasser $\mathrm{et} \mathrm{al}^{3}$ reported that hind milk was collected, Yahvah et al ${ }^{4}$ reported complete extraction of milk from one breast, and Mohammad et $\mathrm{al}^{1,2}$ noted that 2.5 milliliters was extracted at the beginning, middle, and end of each feeding.

- Timing: The stage of lactation was somewhat different between the studies. While lactation stage of women in the Mohammad et $\mathrm{al}^{1,2}$ and Nasser et al ${ }^{3}$ studies overlapped ( 6 to 14 weeks and 2 to 6 months postpartum, respectively), Yahvah et al ${ }^{4}$ recruited women who were at least 4 months postpartum and the upper bound was not specified.

- Consistency was graded as moderate. Two of the three RCTs noted a significant relationship between a higher fat diet and higher total fat in human milk. The remaining study ${ }^{3}$ noted that the average fat content (assessed in the hind milk) was non-significantly greater in the higher fat diet, which is consistent

\footnotetext{
iii A detailed description of the methodology used for grading the strength of the evidence is available on the NESR website: https://nesr.usda.gov/2020-dietary-guidelines-advisory-committee-systematicreviews and in Part $\mathrm{C}$ of the following reference: Dietary Guidelines Advisory Committee. 2020. Scientific Report of the 2020 Dietary Guidelines Advisory Committee: Advisory Report to the Secretary of Agriculture and the Secretary of Health and Human Services. U.S. Department of Agriculture, Agricultural Research Service, Washington, DC.
} 
with other findings.

- Directness was graded as strong. These RCTs were designed to address the question on the relationship between diets with macronutrient distributions outside of the AMDR and human milk composition and quantity. Thus, the primary objectives of the studies aligned well with the systematic review question.

- Precision was graded as limited. All the three RCTs each had a small sample size (<20 participants) and none reported power analyses. Despite this, the magnitude and direction of the results were consistent across studies (as discussed above). None of the studies unduly influenced the findings of this systematic review and removing a single study from the body of evidence would unlikely change the conclusions.

- Generalizability was graded as limited. The studies included in this body of evidence were conducted in the U.S. and Canada. However, none of them reported the socioeconomic status (SES) of the participants and Nasser et al ${ }^{3}$ and Yahvah et al ${ }^{4}$ did not report the race/ethnicity of participants. Considering the small sample size of the RCTs and lack of information on SES and race/ethnicity, it is unclear whether the studies were representative of the general U.S. population.

The following conclusion statement is supported by three RCTs and two crosssectional studies. The individual grading elements are discussed below and summarized in Table 5 and Table 6.

"Limited evidence suggests that certain maternal dietary patterns during lactation, including diets based on macronutrient distributions, are related to the relative proportions of saturated fat and monounsaturated fatty acids in human milk, and of polyunsaturated fatty acids in human milk collected in the maternal postprandial period."

As outlined and described below, the body of evidence examining dietary patterns during lactation, including diets based on macronutrient distributions, and human milk composition was assessed for the following elements used when grading the strength of evidence.

- Risk of bias was graded limited for the RCTs and limited for the cross-sectional studies. The following bullets address the risk of bias for the 2 cross-sectional studies. For the RCTs, the readers are referred to the risk of bias in the previous section, as the same RCTs contributed to the evidence for both conclusion statements.

- Study Design: Both Tian et $\mathrm{al}^{7}$ and Perrin et $\mathrm{al}^{6}$ selected participants using convenience sampling, which may have introduced selection bias. Related to participant selection, Perrin et $\mathrm{al}^{6}$ noted that nearly half of the participants (approximately 43 percent) who were invited to participate did not respond and it is unclear whether their baseline characteristics were different from those of women who participated. The mothers in the Perrin et al ${ }^{6}$ study also differed significantly by diet group in baseline $\mathrm{BMI}$, which could have influenced the study findings. Tian et $\mathrm{al}^{7}$ did not adjust for a majority of key confounders and Perrin et al ${ }^{6}$ accounted for none of the key confounders identified in the analytic framework. 
- Exposure: Both studies assessed diet at a single time point. In the study by Perrin et al, ${ }^{6}$ participants self-reported their dietary data based on a questionnaire that collected information on certain foods and food groups. Also, it is unclear if the questionnaires used in either study were validated. In the Perrin et al study ${ }^{6}$, there were statistically significant differences in maternal DHA/EPA supplement intake between groups (vegan: 26.9 percent, vegetarian: 9.1 percent, omnivore: 3.9 percent), in addition to consuming different dietary patterns. However, this was not accounted for in the analysis and made it difficult to determine the effect of the dietary pattern.

- Outcome: Milk was collected at a single time point. Although milk was collected mid-morning in both the studies, it is unclear whether mothers were in fed or fasted states at the time of collection. Similar to RCTs, both studies differed on how milk was collected. For example, Perrin et al ${ }^{6}$ noted that participants provided samples by complete expression of a single breast, whereas, Tian et $\mathrm{al}^{7}$ reported that 30 milliliters of milk was collected from study participants.

- Timing: The stage of lactation within and between studies varied widely. For example, mothers in the Tian et al ${ }^{7}$ study were 22 days to 6 months postpartum at the time of data collection. Perrin et al ${ }^{6}$ reported a statistically significant difference in the stage of lactation between exposure groups, ranging from 27.5 to 54.6 weeks postpartum.

- Consistency was graded as moderate for the RCTs and the cross-sectional studies were given a 'grade not assignable' rating. While the studies consistently noted associations between maternal dietary patterns/diets based on macronutrient distributions and human milk fatty acids, the findings were heterogeneous regarding the magnitude and directionality of associations for saturated fat, MUFAs, and PUFAs. For this reason, this element was rated 'grade not assignable.'

- Directness was graded as strong for the RCTs and moderate for the crosssectional studies. As discussed previously, the primary objective of the RCTs aligned well with the systematic review question. For the cross-sectional studies, the study by Tian et $\mathrm{al}^{7}$ seems to have been designed to assess the association between maternal dietary patterns during lactation and composition of fatty acids in human milk. However, it is less clear for Perrin et al ${ }^{6}$ because the other article from this study (Pawlak et al ${ }^{5}$ ) reported that the power calculations were based on detecting differences in vitamin $B_{12}$ in human milk, suggesting that the Perrin et al ${ }^{6}$ article could have been a secondary analysis.

- Precision was graded as limited for both RCTs and cross-sectional studies. The cross-sectional studies each had a reasonable sample size $\left(n=274^{7}\right.$ and $\mathrm{n}=74^{6}$ ), although neither reported power calculations. The RCTs had small sample sizes (<20 participants). None of the studies unduly influenced the findings of this systematic review and removing one or more studies would not likely influence the conclusions.

- Generalizability was graded as limited for both RCTs and cross-sectional studies. Although the RCTs were conducted in the U.S. and Canada, the studies reported minimal data on SES and race/ethnicity of the participants. The study by Perrin et al ${ }^{6}$ was conducted in the U.S. and most of the participants 
were highly educated White women. The study by Tian et $\mathrm{al}^{7}$ was conducted in China, with 100 percent Han Chinese women from mid-to-upper SES. Based on these characteristics, it is unclear if the findings would apply to a diverse sample of U.S. mothers.

The bodies of evidence that assessed the relationship between 1) maternal dietary patterns and vitamin $\mathrm{B}_{12}$ in human milk, 2) maternal diets differing in macronutrient distributions and total protein concentration or human milk quantity were rated 'grade not assignable' primarily because only one study met the inclusion criteria.

Publication bias is always a concern; however, given that these studies were smaller in size and many of them had null findings, publication bias did not seem to be a serious concern in this evidence.

\section{Research recommendations}

- Include diverse populations from the U.S. and elsewhere with varying age groups and different racial/ethnic and socioeconomic backgrounds.

- Foster collaborative efforts to score dietary patterns consistently, so that they can be compared and reproduced across studies.

- Assess other nutrients (particularly water- and fat-soluble vitamins), human milk oligosaccharides, and bioactive proteins in human milk.

- Use a consistent methodology for human milk collection and assessment.

- Include well-designed and sufficiently powered RCTs.

- Adjust for key confounding factors in observational studies including age, race/ethnicity, SES, anthropometry, smoking, parity, gestational age, and supplement intake during pregnancy and lactation. 


\section{Included articles}

1. Mohammad MA, Sunehag AL, Haymond MW. Effect of dietary macronutrient composition under moderate hypocaloric intake on maternal adaptation during lactation. Am J Clin Nutr. 2009;89(6):1821-1827. doi:10.3945/ajcn.2008.26877

2. Mohammad MA, Sunehag AL, Haymond MW. De novo synthesis of milk triglycerides in humans. Am J Physiol Endocrinol Metab. 2014;306(7):E838847. doi:10.1152/ajpendo.00605.2013

3. Nasser R, Stephen AM, Goh YK, Clandinin MT. The effect of a controlled manipulation of maternal dietary fat intake on medium and long chain fatty acids in human breast milk in Saskatoon, Canada. Int Breastfeed J. 2010;5:3. doi:10.1186/1746-4358-5-3

4. Yahvah KM, Brooker SL, Williams JE, Settles M, McGuire MA, McGuire MK. Elevated dairy fat intake in lactating women alters milk lipid and fatty acids without detectible changes in expression of genes related to lipid uptake or synthesis. Nutr Res. 2015;35(3):221-228. doi:10.1016/j.nutres.2015.01.004

5. Pawlak R, Vos P, Shahab-Ferdows S, Hampel D, Allen LH, Perrin MT. Vitamin $\mathrm{B}-12$ content in breast milk of vegan, vegetarian, and nonvegetarian lactating women in the United States. Am J Clin Nutr. 2018;108(3):525-531. doi:10.1093/ajcn/nqy104

6. Perrin MT, Pawlak R, Dean LL, Christis A, Friend L. A cross-sectional study of fatty acids and brain-derived neurotrophic factor (BDNF) in human milk from lactating women following vegan, vegetarian, and omnivore diets. Eur J Nutr. 2019;58(6):2401-2410. doi:10.1007/s00394-018-1793-z

7. Tian HM, Wu YX, Lin YQ, et al. Dietary patterns affect maternal macronutrient intake levels and the fatty acid profile of breast milk in lactating Chinese mothers. Nutrition. 2019;58:83-88. doi:10.1016/j.nut.2018.06.009 
Table 1. Description of evidence on the relationship between dietary patterns during lactation and human milk composition ${ }^{\mathrm{iv}, \mathrm{v}}$

\begin{tabular}{|c|c|c|c|c|}
\hline $\begin{array}{l}\text { Study and Participant } \\
\text { Characteristics }\end{array}$ & $\begin{array}{l}\text { Intervention/Exposure } \\
\text { and Outcomes }\end{array}$ & Results & $\begin{array}{l}\text { Confounding and Study } \\
\text { Limitations }\end{array}$ & Summary of findings \\
\hline \multicolumn{5}{|l|}{ Factor/Cluster Analysis } \\
\hline 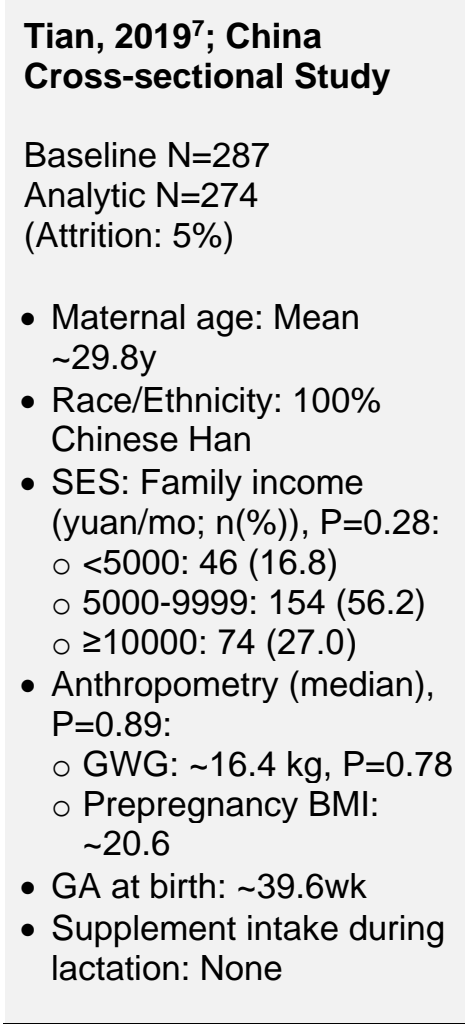 & $\begin{array}{l}\text { Dietary Pattern(s): } \\
\text { - Pattern 1: Mushroom food } \\
\text { and algae, Meat, Marine } \\
\text { products ( } n=66) \\
\text { - Pattern 2: Soybean } \\
\text { products, Nuts, Dairy } \\
\text { ( } n=63 \text { ) } \\
\text { - Pattern 3: Fruit, } \\
\text { Vegetables ( } n=73 \text { ) } \\
\text { - Pattern 4: Grain/potato } \\
\text { and beans, Eggs ( } n=72 \text { ) } \\
\text { Dietary assessment } \\
\text { methods: } \\
\text { Data was collected using a } \\
\text { 24-h dietary recall } \\
\text { questionnaire and } 176 \text { item } \\
\text { FFQ by a trained } \\
\text { investigator to estimate } \\
\text { dietary patterns. The foods } \\
\text { were combined to make } 10 \\
\text { groups: grains/potatoes and } \\
\text { beans, soy bean products, } \\
\text { mushrooms and algae, } \\
\text { fruits, vegetables, nuts, }\end{array}$ & $\begin{array}{l}\text { Significant: } \\
\text { Human milk fatty acid } \\
\text { proportions (\%), Median } \\
\text { (25th, 75th) } \\
\text { - SAT, Kruksal-Wallis, } \\
\text { P<0.001 } \\
\text { o Pattern 1: } 40.38 \text { (37.41, } \\
\text { 44.25) } \\
\text { ○ Pattern 2: } 42.92 \text { (38.61, } \\
\text { 49.62) } \\
\text { ○ Pattern 3: } 39.10 \text { (34.65, } \\
\text { 45.04) } \\
\text { ○ Pattern 4: } 42.92 \text { (40.31, } \\
\text { 49.93) } \\
\text { - PUFAs, Kruksal-Wallis, } \\
\text { P=0.025 } \\
\text { ○ Pattern 1: } 24.49 \text { (21.73, } \\
\text { 28.43) } \\
\text { ○ Pattern 2: } 22.09 \text { (19.92, } \\
\text { 27.08) } \\
\text { ○ Pattern 3: } 24.63 \text { (20.37, } \\
\text { 29.17) } \\
\text { o Pattern 4: } 22.77 \text { (19.49, } \\
\text { 26.38) }\end{array}$ & $\begin{array}{l}\text { Key confounders } \\
\text { accounted for: } \\
\text { Race/ethnicity, } \\
\text { Anthropometry, GA } \\
\text { Limitations: } \\
\text { - Time of exposure } \\
\text { measurement relative to } \\
\text { outcome is not clear } \\
\text { - Lactation stage varies (22 } \\
\text { d to } 6 \text { mo) } \\
\text { - Single measurement of } \\
\text { exposure and outcome } \\
\text { - Power calculation NR }\end{array}$ & $\begin{array}{l}\text { Maternal dietary patterns } \\
\text { were associated with } \\
\text { human milk saturated fatty } \\
\text { acids, PUFAs, and n-6 } \\
\text { PUFA proportions, but not } \\
\text { with MUFAs, n-3 PUFAs, or } \\
\text { n-6/n-3 PUFA proportions. }\end{array}$ \\
\hline
\end{tabular}

iv \pm indicates values of Mean \pm SD unless otherwise noted

$\checkmark$ AA: arachidonic acid, ALA: alpha-linolenic acid, ANOVA: analysis of variance, BMI: body mass index, d: day(s) DHA: docosahexaenoic acid, EPA: eicosapentaenoic acid, FFQ: food frequency questionnaire, GA: gestational age, GWG: gestational weight gain, h: hour, IQR: interquartile range, kg: kilogram(s), LA: linoleic acid, mo: month(s), MUFA: monounsaturated fatty acid, n-\#: omega-\#, NR: not reported, PUFA: polyunsaturated fatty acid, SAT: saturated fat, SES: socioeconomic status, wk: week(s), y: year(s) 


\begin{tabular}{|c|c|c|c|c|}
\hline $\begin{array}{l}\text { Study and Participant } \\
\text { Characteristics }\end{array}$ & $\begin{array}{l}\text { Intervention/Exposure } \\
\text { and Outcomes }\end{array}$ & Results & $\begin{array}{l}\text { Confounding and Study } \\
\text { Limitations }\end{array}$ & Summary of findings \\
\hline & $\begin{array}{l}\text { meat, eggs, marine } \\
\text { products, and dairy } \\
\text { products. These groups } \\
\text { were assigned to } 1 \text { of } 4 \\
\text { dietary patterns using a } \\
\text { rotated component matrix. } \\
\text { Outcomes: } \\
\text { Human milk composition: } \\
\text { Macronutrients: Fatty acid } \\
\text { once during } 22 d \text { to } 6 \text { mo } \\
\text { postpartum } \\
\text { Outcome assessment } \\
\text { methods: } \\
\text { After discarding the first few } \\
\text { drops, a total of } 30 \text { mL of } \\
\text { milk was collected.The } \\
\text { profile of fatty acid in human } \\
\text { milk was detected by } \\
\text { capillary gas } \\
\text { chromatography and } \\
\text { calculated with fatty acid } \\
\text { methylesters (FAME) using } \\
\text { the internal standard } \\
\text { method. }\end{array}$ & 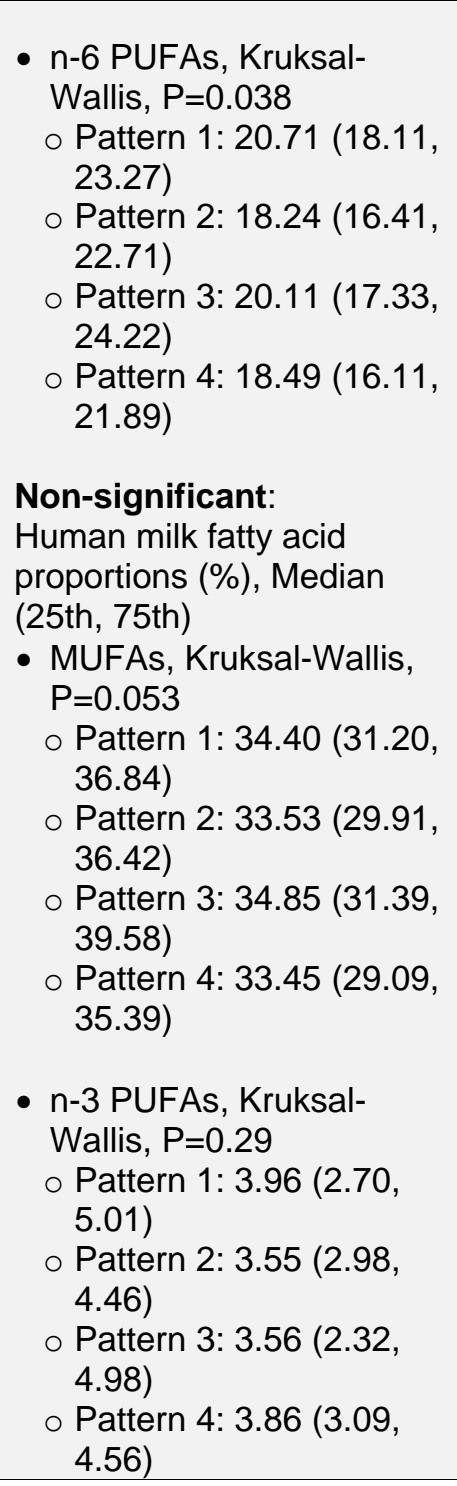 & & \\
\hline
\end{tabular}




\begin{tabular}{|c|c|c|c|c|}
\hline $\begin{array}{l}\text { Study and Participant } \\
\text { Characteristics }\end{array}$ & $\begin{array}{l}\text { Intervention/Exposure } \\
\text { and Outcomes }\end{array}$ & Results & $\begin{array}{l}\text { Confounding and Study } \\
\text { Limitations }\end{array}$ & Summary of findings \\
\hline & & $\begin{array}{l}\text { n-6/n-3 PUFAs, Kruksal- } \\
\text { Wallis, P=0.34 } \\
\text { o Pattern 1: } 4.83(3.80 \\
\text { 7.32) } \\
\text { o Pattern 2: } 4.76(4.14, \\
\text { 6.30) } \\
\text { O Pattern 3: } 5.34(3.74 \\
\text { 9.39) } \\
\text { o Pattern 4: } 4.69(3.85 \\
\text { 5.74) }\end{array}$ & & \\
\hline \multicolumn{5}{|c|}{ Other Dietary Pattern Analysis } \\
\hline $\begin{array}{l}\text { Pawlak, 20185; U.S. } \\
\text { Cross-sectional Study } \\
\text { Baseline } \mathrm{N}=74 \\
\text { Analytic } \mathrm{N}=74 \\
\text { (Attrition: } 0 \% \text { ) } \\
\text { - Maternal age: Mean 32y } \\
\text { - Race/Ethnicity: } \\
\circ \text { White=85.1\% } \\
\circ \text { Mixed/Other=9.4\% } \\
\circ \text { Hispanic=4\% } \\
\circ \text { Asian=1.4\% } \\
\circ \text { Black=0\% } \\
\text { - SES: Education: } \\
\circ \text { HS/GED/other: } 2.7 \% \\
\circ \text { Some college/ technical: } \\
\text { 16.2\% } \\
\circ 4 y \text { college: } 37.8 \% \\
\circ \text { Graduate: } 43.2 \% \\
\text { - Anthropometry: BMI } \\
\text { (mean } \pm \text { SD), } \mathrm{P}=0.02: \\
\text { V Vegan: } 22.8 \pm 3.1\end{array}$ & $\begin{array}{l}\text { Dietary Pattern(s): } \\
\text { - Vegan: Never consumed } \\
\text { meat and never or rarely } \\
\text { consumed other animal } \\
\text { products (1 time/mo) } \\
\text { ( } \mathrm{n}=26) \\
\text { - Vegetarian: Never } \\
\text { consumed meat and } \\
\text { regularly consumed other } \\
\text { animal products ( } \mathrm{n}=22) \\
\text { - Nonvegetarian: } \\
\text { Consumed meat } \\
\text { sometimes or often ( } \mathrm{n}=26 \text { ) } \\
\text { Dietary assessment } \\
\text { methods: } \\
\text { Diet survey; Unclear timing } \\
\text { and validation } \\
\text { Outcomes: } \\
\text { Human milk composition: } \\
\text { Vitamin } \mathrm{B}_{12} \text { assessment } \\
\text { once at } ~ 38.8 w k \text { postpartum }\end{array}$ & $\begin{array}{l}\text { Significant: None } \\
\text { Non-significant: } \\
\text { Human milk } B_{12} \text { (pmol/L), } \\
\text { Median (quartile 1, quartile } \\
\text { 3): } \\
\text { Unadjusted: ANOVA } \\
\text { P=0.89, Kruskal-Wallis } \\
\text { P=0.94 } \\
\text { - Vegan: } 558 \text { (331, 759); } \\
\text { - Vegetarian: } 509 \text { (368, } 765 \\
\text { pmol/L); } \\
\text { - Nonvegetarian: } 444(355, \\
\text { 777) } \\
\text { Adjusted (BMI, lactation } \\
\text { stage) ANOVA: P=0.89 } \\
\text { Human milk B } 12>1122 \\
\text { pmol/L (\%), P=0.72 } \\
\text { - Vegan: } 15.4 \\
\text { - Vegetarian: } 9.1 \\
\text { - Nonvegetarian: } 7.7\end{array}$ & $\begin{array}{l}\text { Key confounders } \\
\text { accounted for: } \\
\text { Anthropometry } \\
\text { Limitations: } \\
\text { - Baseline differences in } \\
\text { maternal BMI, lactation } \\
\text { stage and supplement use } \\
\text { - Majority of the participants } \\
\text { (77.4\%) reported using } \\
\text { vitamin B12 supplements } \\
\text { - Only one time point of } \\
\text { exposure and outcome } \\
\text { measurement } \\
\text { - No validation of exposure } \\
\text { assessment } \\
\text { - Unclear why } 61 \text { eligible } \\
\text { participants did not } \\
\text { respond and whether their } \\
\text { characteristics were } \\
\text { different from the } \\
\text { participants that enrolled }\end{array}$ & $\begin{array}{l}\text { There was no significant } \\
\text { difference between vitamin } \\
\mathrm{B}_{12} \text { levels in human milk } \\
\text { between } 3 \text { dietary patterns } \\
\text { (vegan, vegetarian and } \\
\text { nonvegetarian) }\end{array}$ \\
\hline
\end{tabular}




\begin{tabular}{|c|c|c|c|c|}
\hline $\begin{array}{l}\text { Study and Participant } \\
\text { Characteristics }\end{array}$ & $\begin{array}{l}\text { Intervention/Exposure } \\
\text { and Outcomes }\end{array}$ & Results & $\begin{array}{l}\text { Confounding and Study } \\
\text { Limitations }\end{array}$ & Summary of findings \\
\hline 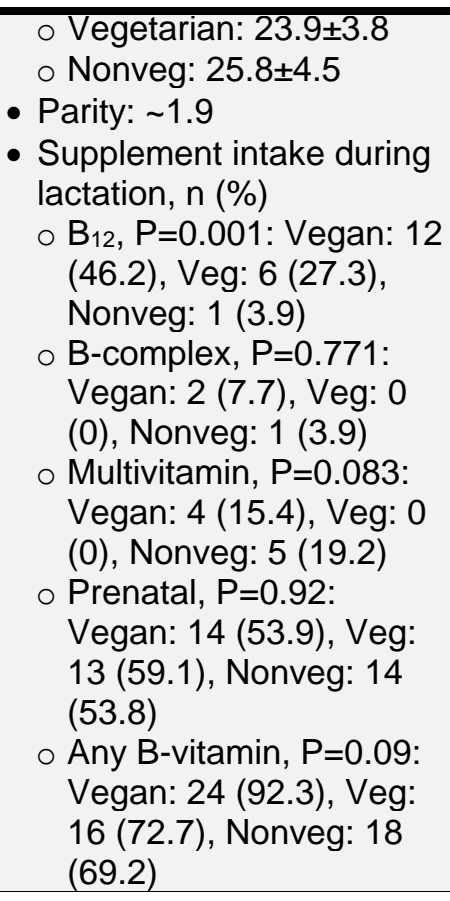 & $\begin{array}{l}\text { - Vegan: } 36.6 \pm 27.7 \mathrm{wk} \\
\text { - Vegetarian: } 54.6 \pm 46.0 \mathrm{wk} \\
\text { - Nonvegetarian: } 27.5 \pm \\
19.8 \mathrm{wk} \\
\text { o Vegetarian vs } \\
\text { Nonvegetarian, } \mathrm{P}<0.05 \\
\text { Outcome assessment } \\
\text { methods: } \\
\text { Completely express the } \\
\text { content of } 1 \text { breast in the } \\
\text { morning ( } \geq 2 \mathrm{~h} \text { since the } \\
\text { previous feeding). } \\
\text { Competitive } \\
\text { chemiluminescent enzyme } \\
\text { immunoassay. Milk samples } \\
\text { with vitamin } \mathrm{B}_{12} \\
\text { concentrations above upper } \\
\text { detection limit assigned max } \\
\text { value (1122 pmol/L) and } \\
\text { flagged. }\end{array}$ & $\begin{array}{l}\text { Human milk } B_{12}<310 \\
\text { pmol/L }(\%), P=1.00 \\
\text { - Vegan: } 19.2 \\
\text { - Vegetarian: } 18.2 \\
\text { - Nonvegetarian: } 15.4\end{array}$ & $\begin{array}{l}\text { - Stage of lactation was } \\
\text { significantly different } \\
\text { between the three groups }\end{array}$ & \\
\hline $\begin{array}{l}\text { Perrin, 20196; U.S. } \\
\text { Cross-sectional Study } \\
\text { Baseline } \mathrm{N}=74 \\
\text { Analytic } \mathrm{N}=74 \\
\text { (Attrition: } 0 \% \text { ) } \\
\text { - Maternal age: Mean } \\
\text { - } 31.95 \mathrm{y} \\
\text { - Race/Ethnicity: } \\
\circ \text { White }=85.1 \% \\
\circ \text { Mixed/Other=9.4\% } \\
\circ \text { Hispanic=4\% } \\
\circ \text { Asian }=1.4 \%\end{array}$ & $\begin{array}{l}\text { Dietary Pattern(s): } \\
\text { - Vegan: Never consumed } \\
\text { meat and never or rarely } \\
\text { consumed other animal } \\
\text { products ( } 1 \text { time/mo) } \\
(n=26) \\
\text { - Vegetarian: Never } \\
\text { consumed meat and } \\
\text { regularly consumed other } \\
\text { animal products }(n=22) \\
\text { - Nonvegetarian: } \\
\text { Consumed meat } \\
\text { sometimes or often }(n=26)\end{array}$ & $\begin{array}{l}\text { Significant: } \\
\text { Data are median (IQR); } \\
\text { Significance } P \leq 0.001 \\
\text { \% SAT, ANOVA, } P<0.001 \\
\text { - Vegan: } 33.1(6.2) ; \\
\text { - Vegetarian: } 40.0(8.6) ; \\
\text { - Nonvegetarian: } 42.3(8.4) \\
\text { \% C15:0, Kruskal-Wallis, } \\
\text { P<0.001 } \\
\text { - Vegan: } 0.06(0.08) \\
\text { - Vegetarian: } 0.24(0.20) \\
\text { - Nonvegetarian: } 0.26 \\
\text { (0.16) }\end{array}$ & $\begin{array}{l}\text { Key confounders } \\
\text { accounted for: None } \\
\text { Limitations: } \\
\text { - Baseline differences in } \\
\text { maternal BMI, lactation } \\
\text { stage and supplement use } \\
\text { - Only one time point of } \\
\text { exposure and outcome } \\
\text { measurement } \\
\text { - No validation of exposure } \\
\text { assessment }\end{array}$ & $\begin{array}{l}\text { Human milk from vegans } \\
\text { had significantly higher } \\
\text { unsaturated fat and total n-3 } \\
\text { PUFAs, and lower saturated } \\
\text { fatty acids, trans fats, and n- } \\
6 / n-3 \text { PUFA ratio than their } \\
\text { vegetarian and } \\
\text { nonvegetarian counterparts. } \\
\text { DHA concentrations in } \\
\text { human milk were low } \\
\text { regardless of maternal } \\
\text { dietary pattern, and were } \\
\text { reflective of low seafood } \\
\text { intake and supplement use. }\end{array}$ \\
\hline
\end{tabular}




\begin{tabular}{|c|c|c|c|c|}
\hline $\begin{array}{l}\text { Study and Participant } \\
\text { Characteristics }\end{array}$ & $\begin{array}{l}\text { Intervention/Exposure } \\
\text { and Outcomes }\end{array}$ & Results & $\begin{array}{l}\text { Confounding and Study } \\
\text { Limitations }\end{array}$ & Summary of findings \\
\hline 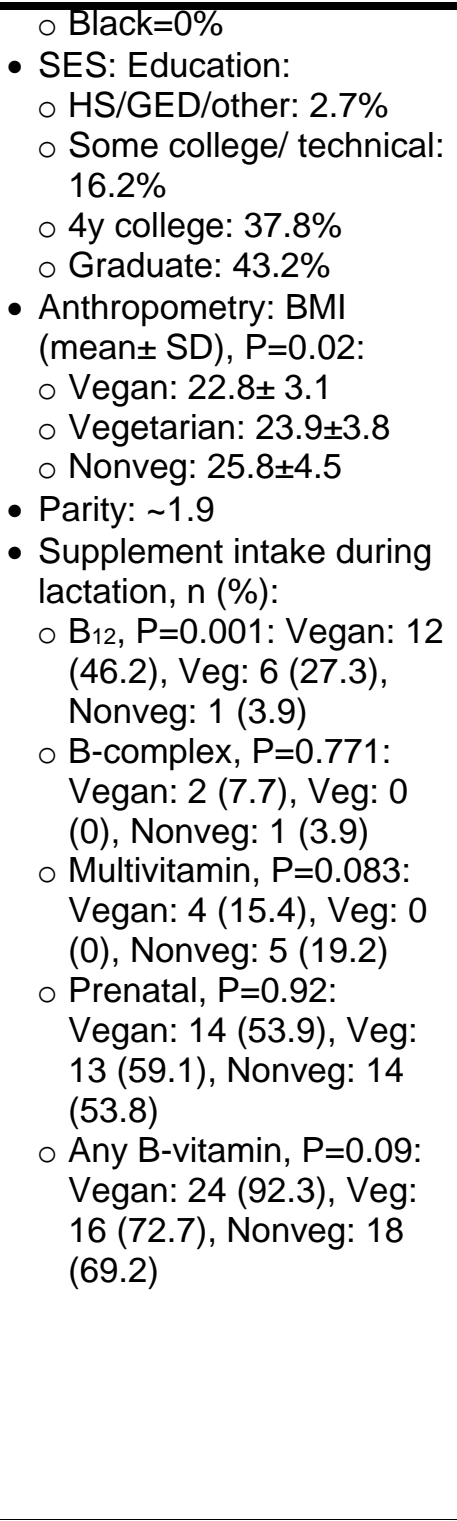 & $\begin{array}{l}\text { Dietary assessment } \\
\text { methods: } \\
\text { Diet survey; Unclear timing } \\
\text { and validation } \\
\text { Outcomes: } \\
\text { Human milk composition: } \\
\text { Fatty acid } \\
\text { once at } 38.8 w k \text { postpartum } \\
\text { - Vegan: } 36.6 \pm 27.7 w k \\
\text { - Vegetarian: } 54.6 \pm 46.0 w k \\
\text { - Nonvegetarian: } 27.5 \pm \\
19.8 w k \\
\text { O Vegetarian vs } \\
\text { Nonvegetarian, P<0.05 } \\
\text { Outcome assessment } \\
\text { methods: } \\
\text { Completely express the } \\
\text { content of } 1 \text { breast in the } \\
\text { morning ( } \geq 2 \mathrm{~h} \text { since the } \\
\text { previous feeding). } \\
\text { Total fat measured by } \\
\text { creamatocrit. The fatty acid } \\
\text { present in the samples } \\
\text { measured as fatty acid } \\
\text { methyl esters according to } \\
\text { Bannon et al method }\end{array}$ & 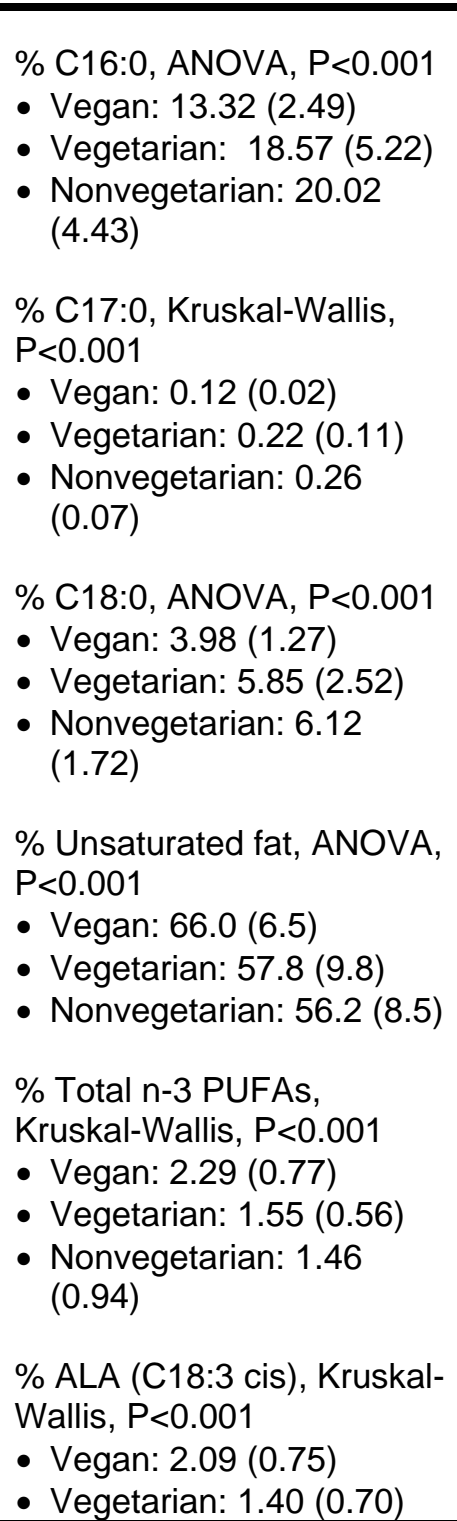 & $\begin{array}{l}\text { - Dietary patterns not fully } \\
\text { defined using a priori/ } \\
\text { posteriori methods } \\
\text { - Unclear why } 61 \text { eligible } \\
\text { participants did not } \\
\text { respond and whether their } \\
\text { characteristics were } \\
\text { different from the } \\
\text { participants that enrolled } \\
\text { - Power calculation was } \\
\text { based on detecting } \\
\text { differences in milk } B_{12}\end{array}$ & \\
\hline
\end{tabular}


Study and Participant

Characteristics
Intervention/Exposure and Outcomes
Confounding and Study

Limitations
Summary of findings

\% C18:3 cis, y, Kruskal-

Wallis, $\mathrm{P}<0.001$

- Vegan: $0.0(0.0)$

- Vegetarian: 0.0 (0.15)

- Nonvegetarian; 0.08

(0.19)

LA:ALA, Kruskal-Wallis,

$\mathrm{P}<0.001$

- Vegan: 9.3 (2.1)

- Vegetarian: 12.2 (4.9)

- Nonvegetarian: 12.7 (6.2)

n-6: n-3 PUFAs, Kruskal-

Wallis, $P<0.001$

- Vegan: 8.8 (2.4)

- Vegetarian: 11.4 (3.7)

- Nonvegetarian: 11.2 (3.8)

\% C14:1 cis, Kruskal-Wallis, $\mathrm{P}<0.001$

- Vegan: $0.00(0.07)$

- Vegetarian: $0.20(0.13)$

- Nonvegetarian: 0.23

(0.15)

\% C16:1 cis 9, Kruskal-

Wallis, $\mathrm{P}<0.001$

- Vegan: $1.01(0.89)$

- Vegetarian: $1.44(0.86)$

- Nonvegetarian: 2.04

(0.63) 


\begin{tabular}{|c|c|c|c|c|}
\hline $\begin{array}{l}\text { Study and Participant } \\
\text { Characteristics }\end{array}$ & $\begin{array}{l}\text { Intervention/Exposure } \\
\text { and Outcomes }\end{array}$ & Results & $\begin{array}{l}\text { Confounding and Study } \\
\text { Limitations }\end{array}$ & Summary of findings \\
\hline & & $\begin{array}{l}\text { \% C17:1 cis, Kruskal-Wallis, } \\
\text { P<0.001 } \\
\text { - Vegan: } 0.03(0.08) \\
\text { - Vegetarian: } 0.12(0.09) \\
\text { - Nonvegetarian: } 0.16 \\
\text { (0.06) } \\
\text { \% C18:1 cis, ANOVA, } \\
\text { P<0.001 } \\
\text { - Vegan: } 39.86(7.56) \\
\text { - Vegetarian: } 35.09(7.96) \\
\text { - Nonvegetarian: } 33.09 \\
\text { (8.50) } \\
\text { \% Total trans fat, Kruskal- } \\
\text { Wallis, P<0.001 } \\
\text { - Vegan: } 0.44(0.19) \\
\text { - Vegetarian: } 0.66(0.71) \\
\text { - Nonvegetarian: } 1.09 \\
\text { (0.55) } \\
\text { \% C18:1 trans, Kruskal- } \\
\text { Wallis, P<0.001 } \\
\text { - Vegan: } 0.00(0.07) \\
\text { - Vegetarian: } 0.14(0.61) \\
\text { - Nonvegetarian: } 0.62 \\
\text { (0.45) } \\
\text { Non-significant: } \\
\text { Data are median (IQR); } \\
\text { Significance P } \leq 0.001 \\
\text { Total fat (g/dL), Kruskal- } \\
\text { Wallis, P=0.041 } \\
\text { - Vegan: } 3.0(1.7) \\
\text { - Vegetarian: } 4.0(2.9) \\
\text { - Nonvegetarian: } 4.0(2.9)\end{array}$ & 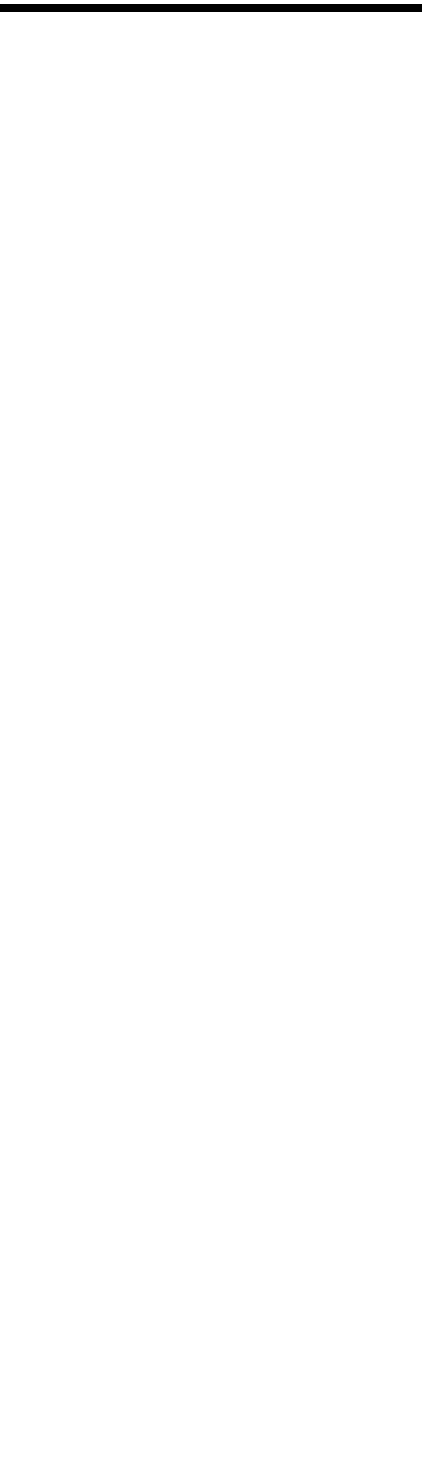 & \\
\hline
\end{tabular}




\begin{tabular}{|c|c|c|c|c|}
\hline $\begin{array}{l}\text { Study and Participant } \\
\text { Characteristics }\end{array}$ & $\begin{array}{l}\text { Intervention/Exposure } \\
\text { and Outcomes }\end{array}$ & Results & $\begin{array}{l}\text { Confounding and Study } \\
\text { Limitations }\end{array}$ & Summary of findings \\
\hline & & $\begin{array}{l}\text { \% C8:0, ANOVA, P=0.052 } \\
\text { - Vegan: } 0.21(0.13) \\
\text { - Vegetarian: } 0.18(0.15) \\
\text { - Nonvegetarian: } 0.17 \\
\text { (0.18) } \\
\text { \% C10:0, Kruskal-Wallis, } \\
\text { P=0.332 } \\
\text { - Vegan: } 1.46(0.71) \\
\text { - Vegetarian: } 1.50(0.74) \\
\text { - Nonvegetarian: } 1.65 \\
\text { (0.43) } \\
\% \text { C12:0, Kruskal-Wallis, } \\
\text { P=0.186 } \\
\text { - Vegan: } 7.12(3.63) \\
\text { - Vegetarian: } 5.88(2.01) \\
\text { - Nonvegetarian: } 6.22 \\
\text { (3.07) } \\
\text { \% C14:0, Kruskal-Wallis, } \\
\text { P=0.571 } \\
\text { - Vegan: } 5.55(3.89) \\
\text { - Vegetarian: } 6.81(3.06) \\
\text { - Nonvegetarian: } 6.56 \\
\text { (3.36) } \\
\text { \% C20:0, Kruskal-Wallis, } \\
\text { P=0.002 } \\
\text { - Vegan: } 0.16(0.14) \\
\text { - Vegetarian: } 0.20(0.16) \\
\text { - Nonvegetarian: } 0.09 \\
\text { (0.15) } \\
\text { \% C22:0, Kruskal-Wallis, } \\
\text { P=0.015 } \\
\text { - Vegan: } 0.06(0.09) \\
\text { - Vegetarian: } 0.05(0.08)\end{array}$ & 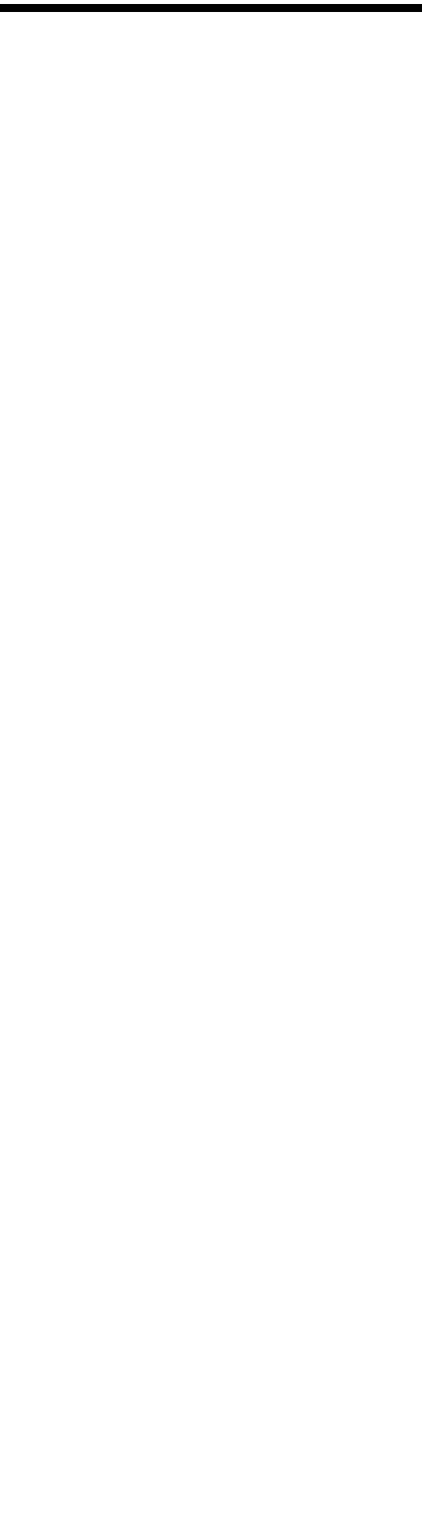 & \\
\hline
\end{tabular}


Study and Participant

Characteristics
Intervention/Exposure and Outcomes
Confounding and Study

Limitations
Summary of findings

- Nonvegetarian: 0.00

(0.04)

\% C24:0, Kruskal-Wallis,

$\mathrm{P}=0.765$

- Vegan: 0.00 (0.07)

- Vegetarian: 0.06 (0.08)

- Nonvegetarian: 0.00

(0.08)

\% EPA (C20:5 cis), Kruskal-

Wallis, $\mathrm{P}=0.057$

- Vegan: 0.0 (0.05)

- Vegetarian: 0.0 (0.05)

- Nonvegetarian: 0.04

(0.18)

\% DHA (C22:6 cis),

Kruskal-Wallis, $\mathrm{P}=0.543$

- Vegan: 0.14 (0.09)

- Vegetarian: 0.17 (0.14)

- Nonvegetarian: 0.18

(0.18)

\% Total n-6 PUFAs,

ANOVA, $\mathrm{P}=0.492$

- Vegan: 19.65 (2.88)

- Vegetarian: 18.69 (6.76)

- Nonvegetarian: 17.11

(6.39)

$\%$ LA (C18:2 cis), ANOVA,

$\mathrm{P}=0.366$

- Vegan: 18.86 (2.29)

- Vegetarian: 17.98 (6.91)

- Nonvegetarian: 16.28

(6.40) 
Study and Participant

Characteristics
Intervention/Exposure and Outcomes

\section{Confounding and Study}

Limitations

$\%$ C20:3 cis, Kruskal-Wallis,

$\mathrm{P}=0.106$

- Vegan: $0.27(0.09)$

- Vegetarian: 0.34 (0.11)

- Nonvegetarian: 0.31

(0.13)

$\%$ AA (C20:4), ANOVA,

$\mathrm{P}=0.014$

- Vegan: $0.38(0.21)$

- Vegetarian: 0.38 (0.13)

- Nonvegetarian: 0.45

(0.16)

\% C15:1 cis, Kruskal-Wallis,

$\mathrm{P}=0.002$

- Vegan: $0.00(0.00)$

- Vegetarian: 0.00 (0.05)

- Nonvegetarian 0.00

(0.04)

\% C20:1 cis, Kruskal-Wallis,

$\mathrm{P}=0.003$

- Vegan: $0.38(0.16)$

- Vegetarian: $0.33(0.10)$

- Nonvegetarian: 0.29

(0.12)

\% C20:2 cis, Kruskal-Wallis,

$\mathrm{P}=0.873$

- Vegan: $0.26(0.15)$

- Vegetarian: 0.26 (0.08)

- Nonvegetarian: 0.27

(0.11) $(\mathrm{P}=0.873)$ 


\begin{tabular}{|c|c|c|c|c|}
\hline $\begin{array}{l}\text { Study and Participant } \\
\text { Characteristics }\end{array}$ & $\begin{array}{l}\text { Intervention/Exposure } \\
\text { and Outcomes }\end{array}$ & Results & $\begin{array}{l}\text { Confounding and Study } \\
\text { Limitations }\end{array}$ & Summary of findings \\
\hline & & $\begin{array}{l}\text { \% C22:1 cis, Kruskal-Wallis, } \\
\text { P=0.278 } \\
\text { - Vegan: } 0.00(0.09) \\
\text { - Vegetarian: } 0.05(0.07) \\
\text { - Nonvegetarian: } 0.00 \\
\text { (0.05) (P=0.278) } \\
\text { \% C24:1 cis, Kruskal-Wallis, } \\
\text { P=0.430 } \\
\text { - Vegan: } 0.00(0.01) \\
\text { - Vegetarian: } 0.00(0.03) \\
\text { - Nonvegetarian: } 0.00(0.0) \\
\text { \% C14:1 trans, Kruskal- } \\
\text { Wallis, P=0.108 } \\
\text { - Vegan: } 0.00(0.00) \\
\text { - Vegetarian: } 0.00(0.03) \\
\text { - Nonvegetarian: } 0.00 \\
\text { (0.00) } \\
\text { \% C16:1 trans, ANOVA, } \\
\text { P=0.863 } \\
\text { - Vegan: } 0.36(0.17) \\
\text { - Vegetarian: } 0.34(0.10) \\
\text { - Nonvegetarian: } 0.36 \\
\text { (0.10) } \\
\% \text { C18:2 trans, Kruskal- } \\
\text { Wallis, P=0.021 } \\
\text { - Vegan: } 0.00(0.07) \\
\text { - Vegetarian: } 0.14(0.34) \\
\text { - Nonvegetarian: } 0.15 \\
\text { (0.29) } \\
\text { Medium chain (\%), Kruskal- } \\
\text { Wallis, P=0.897 } \\
\text { - Vegan: } 14.9 \text { (6.3) }\end{array}$ & 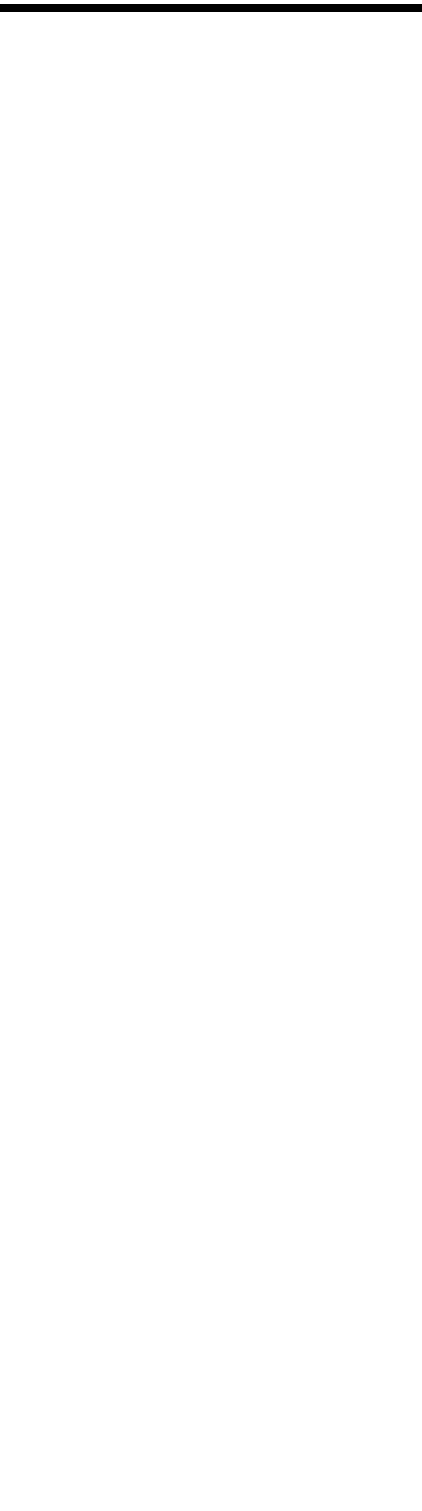 & \\
\hline
\end{tabular}


Study and Participant

Characteristics
Intervention/Exposure and Outcomes
Confounding and Study

Limitations
Summary of findings

\section{- Vegetarian: 14.6 (5.6)}

- Nonvegetarian: 14.9 (6.7)

Long chain (\%), Kruskal-

Wallis, 0.906

- Vegan: $85.1(6.9)$

- Vegetarian: 85.4 (5.9)

- Nonvegetarian: 85.6 (6.7) 
Table 2. Description of evidence on the relationship between diets based on macronutrient distributions during lactation and human milk composition and quantityvivii

\begin{tabular}{|c|c|c|c|c|}
\hline $\begin{array}{l}\text { Study and Participant } \\
\text { Characteristics }\end{array}$ & $\begin{array}{l}\text { Intervention/Exposure } \\
\text { and Outcomes }\end{array}$ & Results & $\begin{array}{l}\text { Confounding and Study } \\
\text { Limitations }\end{array}$ & Summary of findings \\
\hline \multicolumn{5}{|c|}{ Randomized Controlled Trials } \\
\hline 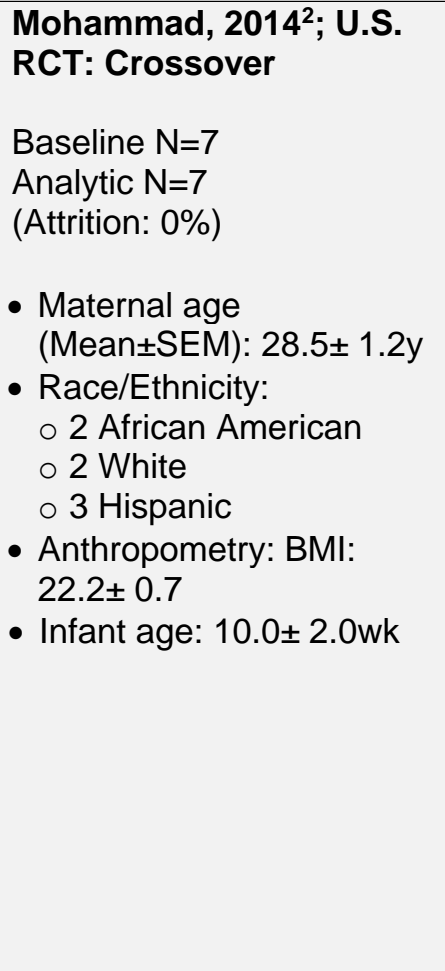 & $\begin{array}{l}\text { Macronutrient } \\
\text { Proportion(s): } \\
\text { - 'H-FAT': } 30 \% \mathrm{CHO}, 55 \% \\
\text { FAT, 15\% PRO } \\
\text { - 'H-CHO': } 60 \% \text { CHO, } 25 \% \\
\text { FAT, 15\% PRO } \\
\text { for } 8 d \text { on each diet with 1- } \\
\text { 2wk washout during 6-14wk } \\
\text { postpartum } \\
\text { Dietary assessment } \\
\text { methods: } \\
\text { Diets were created to } \\
\text { achieve the designed } \\
\text { macronutrient composition. } \\
\text { Total energy intake and } \\
\text { distribution of energy from } \\
\text { CHO, FAT, and PRO were } \\
\text { analyzed by using NDSR. } \\
\text { Outcomes: } \\
\text { Human milk composition: } \\
\text { Fatty acids }\end{array}$ & $\begin{array}{l}\text { Significant: } \\
\text { All values are Mean g/L } \\
\text { Total fatty acid } \\
\text { - Feeding: } \mathrm{H}-\mathrm{CHO}: 42.239 \text {, } \\
\text { H-FAT: } 46.893, \mathrm{P}<0.05 \\
\text { C4:0 } \\
\text { - Fasting: } \mathrm{H}-\mathrm{CHO}: 0.102 \text {, } \\
\text { H-FAT: } 0.071, \mathrm{P}<0.05 \\
\text { - Feeding: } \mathrm{H}-\mathrm{CHO}: 0.148 \text {, } \\
\text { H-FAT: } 0.087, \mathrm{P}<0.05 \\
\text { C6:0 } \\
\text { - Fasting: } \mathrm{H}-\mathrm{CHO}: 0.202 \text {, } \\
\text { H-FAT: } 0.131, \mathrm{P}<0.01 \\
\text { - Feeding: } \mathrm{H}-\mathrm{CHO}: 0.333 \text {, } \\
\text { H-FAT: } 0.183, \mathrm{P}<0.05 \\
\text { C8:0 } \\
\text { - Fasting: } \mathrm{H}-\mathrm{CHO}: 0.357 \text {, } \\
\text { H-FAT: } 0.246, \mathrm{P}<0.01 \\
\text { - Feeding: } \mathrm{H}-\mathrm{CHO}: 0.530 \text {, } \\
\text { H-FAT: } 0.381, \mathrm{P}<0.01\end{array}$ & $\begin{array}{l}\text { Key confounders } \\
\text { accounted for: None } \\
\text { Limitations: } \\
\text { - Unclear baseline } \\
\text { imbalances } \\
\text { - No adjustment for multiple } \\
\text { comparisons } \\
\text { - No information on } \\
\text { randomization, blinding, or } \\
\text { carry-over effects } \\
\text { - Power calculation NR }\end{array}$ & $\begin{array}{l}\text { Total milk fat was } \\
\text { significantly higher during } \\
\text { H-FAT diet, when compared } \\
\text { to H-CHO diet. Total } \\
\text { MUFAs and PUFAs in } \\
\text { human milk was } \\
\text { significantly higher during } \\
\text { H-FAT diet vs H-CHO diet. } \\
\text { These findings were } \\
\text { relevant only during } \\
\text { (maternal) fed state. }\end{array}$ \\
\hline
\end{tabular}

vi \pm indicates values of Mean $\pm S D$ unless otherwise noted

vii AA: arachidonic acid, ALA: alpha-linolenic acid, BMI: body mass index, CHO: carbohydrate, CLA: conjugated linoleic acid, d: day(s), DHA:

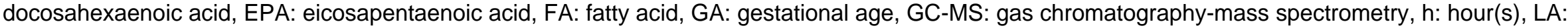
linoleic acid, mo: month(s), MUFA: monounsaturated fatty acid, n-\#: omega-\#, NDSR: Nutrition Data System for Research, NR: not reported, NS: nonsignificant, PUFA: polyunsaturated fatty acid, PRO: protein, RCT: randomized controlled trial, SAT: saturated fat, SEM: standard error of the mean, wk: week(s), y: year(s) 


\begin{tabular}{|c|c|c|c|c|}
\hline $\begin{array}{l}\text { Study and Participant } \\
\text { Characteristics }\end{array}$ & $\begin{array}{l}\text { Intervention/Exposure } \\
\text { and Outcomes }\end{array}$ & Results & $\begin{array}{l}\text { Confounding and Study } \\
\text { Limitations }\end{array}$ & Summary of findings \\
\hline & $\begin{array}{l}\text { Every } 3 \mathrm{~h} \text { collected during } \\
\text { the } 3 \mathrm{~d} \text { inpatient stay. } \\
\text { Outcome assessment } \\
\text { methods: } \\
\text { During human milk feeding, } \\
\text { once every } 3 \mathrm{~h}, 2.5 \mathrm{~mL} \text { of } \\
\text { milk from each breast was } \\
\text { collected at the beginning, } \\
\text { middle and after the feeding } \\
\text { (total of } 15 \mathrm{~mL} \text { ). Milk } \\
\text { samples for each collection } \\
\text { time were pooled for } \\
\text { analyses. After human milk } \\
\text { feeding, mothers were } \\
\text { asked to empty the breast } \\
\text { and milk was weighed. } \\
\text { The } 13 \mathrm{C} \text { enrichment and } \\
\text { quantification of fatty acid in } \\
\text { milk performed on samples } \\
\text { using the PFBBr } \\
\text { derivatization and GC-MS } \\
\text { negative chemical } \\
\text { ionization. }\end{array}$ & $\begin{array}{l}\text { C10:0 } \\
\text { - Fasting: } \mathrm{H}-\mathrm{CHO}: 1.313 \text {, } \\
\text { H-FAT: } 1.112, \mathrm{P}<0.05 \\
\text { - Feeding: } \mathrm{H}-\mathrm{CHO}: 1.920 \text {, } \\
\text { H-FAT: } 1.547, \mathrm{P}<0.05 \\
\text { C12:0: } \\
\text { - Feeding: } \mathrm{H}-\mathrm{CHO}: 3.569 \text {, } \\
\text { H-FAT: } 3.078, \mathrm{P}<0.05 \\
\text { C14:0: } \\
\text { - Fasting: } \mathrm{H}-\mathrm{CHO}: 2.632 \text {, } \\
\text { H-FAT: } 2.320, \mathrm{P}<0.01 \\
\text { - Feeding: } \mathrm{H}-\mathrm{CHO}: 3.915 \text {, } \\
\text { H-FAT: } 3.427, \mathrm{P}<0.01 \\
\text { Total C2: } \mathrm{C} 14: \\
\text { - Fasting: } \mathrm{H}-\mathrm{CHO}: 7.230, \\
\text { H-FAT: } 6.269, \mathrm{P}<0.01 \\
\text { - Feeding: } \mathrm{H}-\mathrm{CHO}: 10.423 \text {, } \\
\text { H-FAT: } 8.712, \mathrm{P}<0.01 \\
\text { C16:0: } \\
\text { - Feeding: } \mathrm{H}-\mathrm{CHO}: 4.846 \text {, } \\
\text { H-FAT: } 5.620, \mathrm{P}<0.05 \\
\text { C18:0: } \\
\text { - Feeding: } \mathrm{H}-\mathrm{CHO}: 2.944 \text {, } \\
\text { H-FAT: } 4.034, \mathrm{P}<0.01 \\
\text { C18:1: } \\
\text { - Feeding: } \mathrm{H}-\mathrm{CHO}: 10.110 \text {, } \\
\text { H-FAT: } 13.230, \mathrm{P}<0.01 \\
\text { Total MUFAs: }\end{array}$ & & \\
\hline
\end{tabular}




\begin{tabular}{|c|c|c|c|c|}
\hline $\begin{array}{l}\text { Study and Participant } \\
\text { Characteristics }\end{array}$ & $\begin{array}{l}\text { Intervention/Exposure } \\
\text { and Outcomes }\end{array}$ & Results & $\begin{array}{l}\text { Confounding and Study } \\
\text { Limitations }\end{array}$ & Summary of findings \\
\hline & & 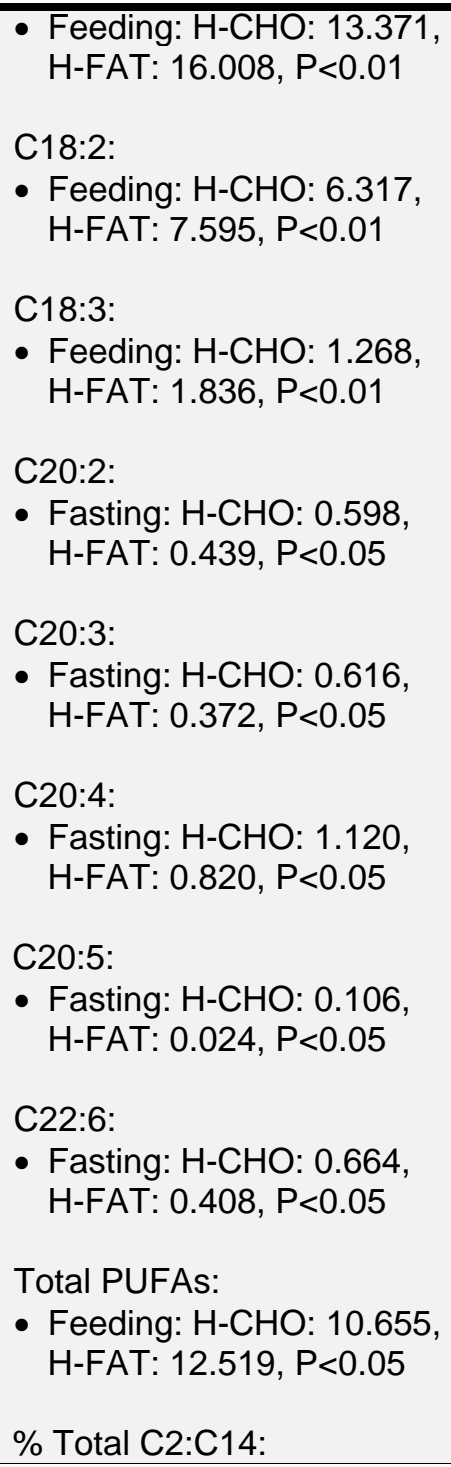 & 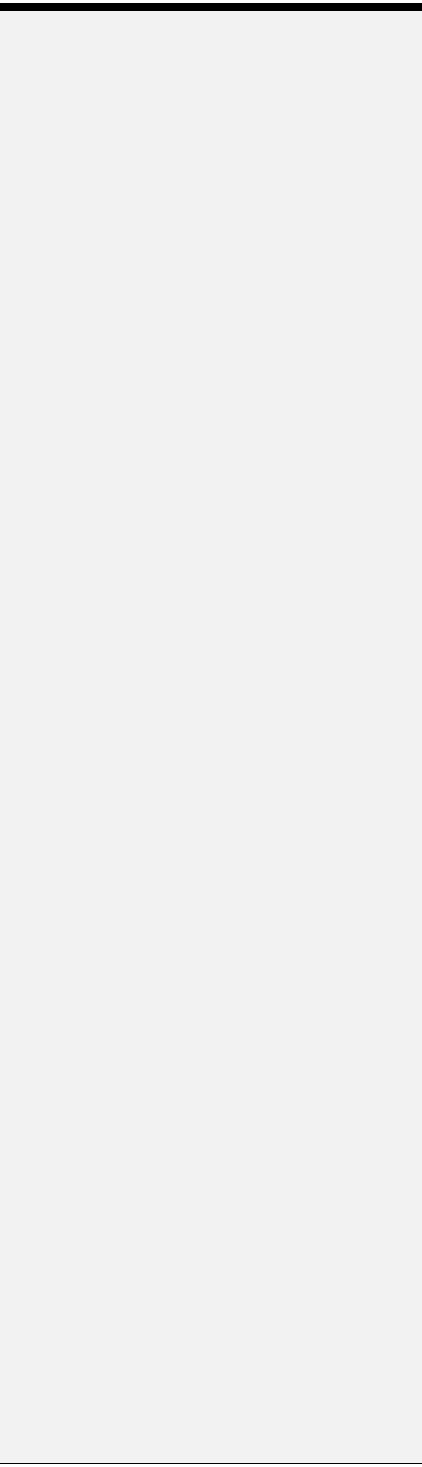 & \\
\hline
\end{tabular}




\begin{tabular}{|c|c|c|c|c|}
\hline $\begin{array}{l}\text { Study and Participant } \\
\text { Characteristics }\end{array}$ & $\begin{array}{l}\text { Intervention/Exposure } \\
\text { and Outcomes }\end{array}$ & Results & $\begin{array}{l}\text { Confounding and Study } \\
\text { Limitations }\end{array}$ & Summary of findings \\
\hline & & 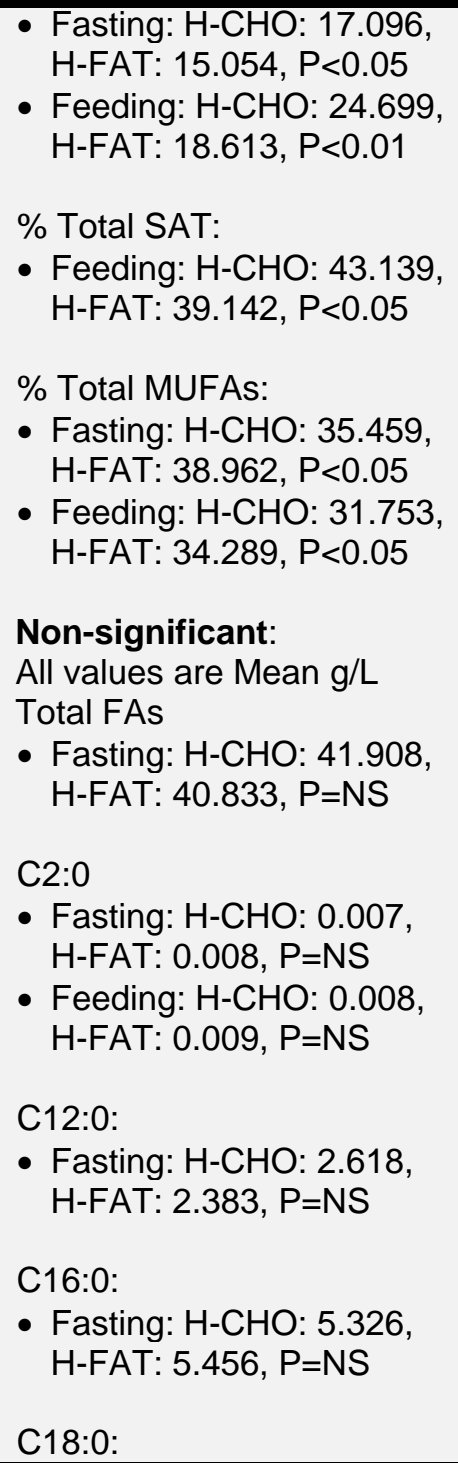 & 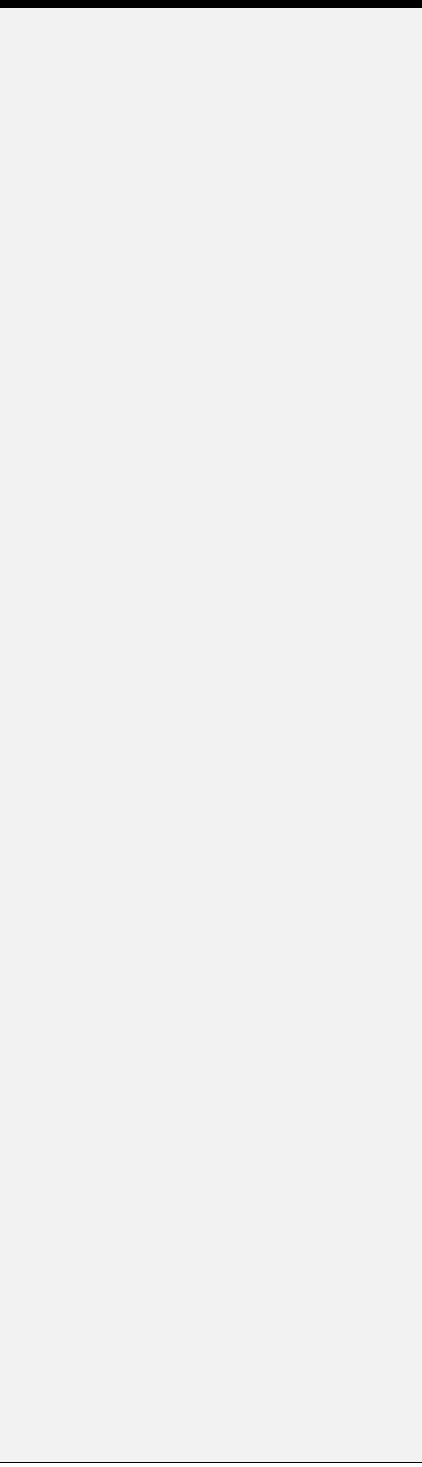 & \\
\hline
\end{tabular}




\begin{tabular}{|c|c|c|c|c|}
\hline $\begin{array}{l}\text { Study and Participant } \\
\text { Characteristics }\end{array}$ & $\begin{array}{l}\text { Intervention/Exposure } \\
\text { and Outcomes }\end{array}$ & Results & $\begin{array}{l}\text { Confounding and Study } \\
\text { Limitations }\end{array}$ & Summary of findings \\
\hline & & 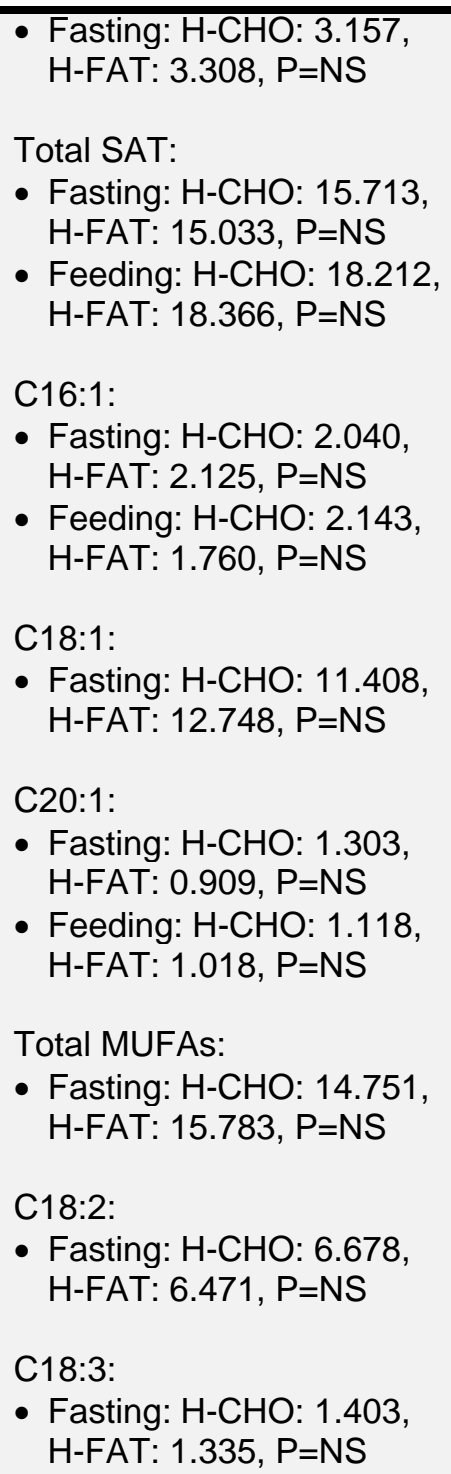 & 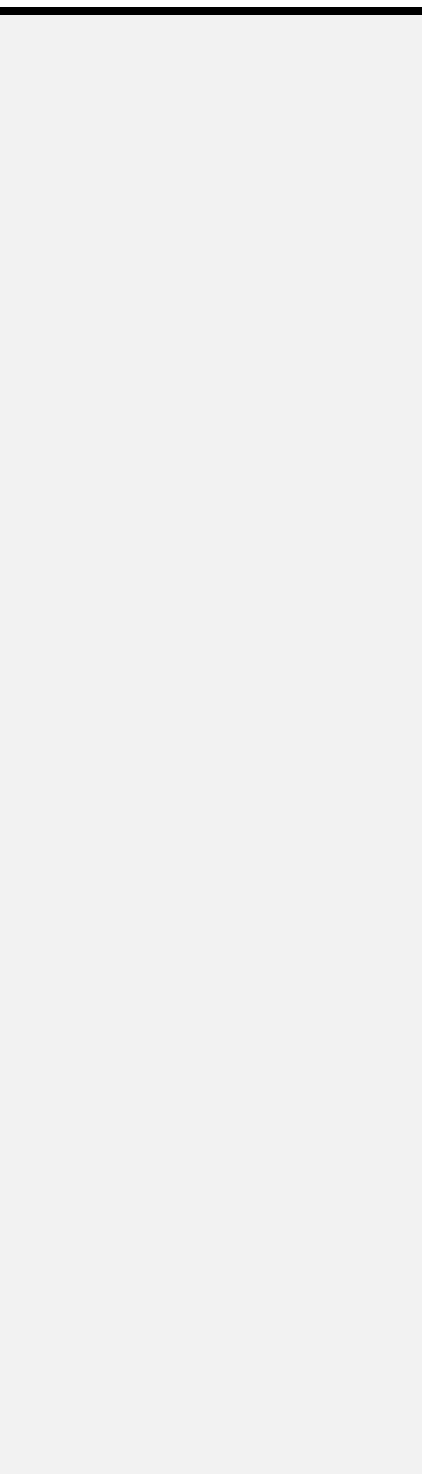 & \\
\hline
\end{tabular}




\begin{tabular}{|c|c|c|c|c|}
\hline $\begin{array}{l}\text { Study and Participant } \\
\text { Characteristics }\end{array}$ & $\begin{array}{l}\text { Intervention/Exposure } \\
\text { and Outcomes }\end{array}$ & Results & $\begin{array}{l}\text { Confounding and Study } \\
\text { Limitations }\end{array}$ & Summary of findings \\
\hline & & $\begin{array}{l}\text { C20:2: } \\
\text { - Feeding: } \mathrm{H}-\mathrm{CHO}: 0.493 \text {, } \\
\text { H-FAT: } 0.532, \mathrm{P}=\mathrm{NS} \\
\text { C20:3: } \\
\text { - Feeding: } \mathrm{H}-\mathrm{CHO}: 0.657 \text {, } \\
\text { H-FAT: } 0.563, \mathrm{P}=\mathrm{NS} \\
\text { C20:4: } \\
\text { - Feeding: } \mathrm{H}-\mathrm{CHO}: 1.020 \text {, } \\
\text { H-FAT: } 1.173, \mathrm{P}=\mathrm{NS} \\
\text { C20:5: } \\
\text { - Feeding: } \mathrm{H}-\mathrm{CHO}: 0.083 \text {, } \\
\text { H-FAT: } 0.056, \mathrm{P}=\mathrm{NS} \\
\text { C22:5: } \\
\text { - Fasting: } \mathrm{H}-\mathrm{CHO}: 0.261 \text {, } \\
\text { H-FAT: } 0.148, \mathrm{P}=\mathrm{NS} \\
\text { - Feeding: } \mathrm{H}-\mathrm{CHO}: 0.234 \text {, } \\
\text { H-FAT: } 0.229, \mathrm{P}=\mathrm{NS} \\
\text { C22:6: } \\
\text { - Feeding: } \mathrm{H}-\mathrm{CHO}: 0.582 \text {, } \\
\text { H-FAT: } 0.535, \mathrm{P}=\mathrm{NS} \\
\text { Total PUFAs: } \\
\text { - Fasting: } \mathrm{H}-\mathrm{CHO}: 11.445 \text {, } \\
\text { H-FAT: } 10.017, \mathrm{P}=\mathrm{NS} \\
\text { \% Total SAT: } \\
\text { - Fasting: } \mathrm{H}-\mathrm{CHO}: 37.198 \text {, } \text { Fasting: } \mathrm{H}-\mathrm{CHO}: 27.342 \text {, } \\
\text { H-FAT: } 24.809, \mathrm{P}=\mathrm{NS} \\
\text { H-FAT: } 36.230, \mathrm{P}=\mathrm{NS} \\
\end{array}$ & 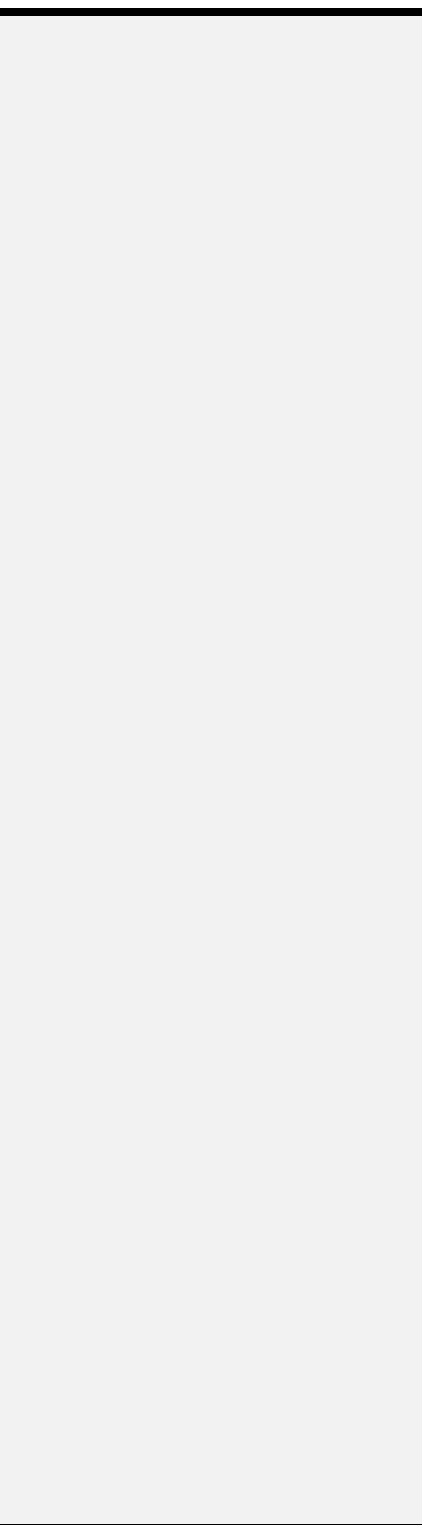 & \\
\hline
\end{tabular}




\begin{tabular}{|c|c|c|c|c|}
\hline $\begin{array}{l}\text { Study and Participant } \\
\text { Characteristics }\end{array}$ & $\begin{array}{l}\text { Intervention/Exposure } \\
\text { and Outcomes }\end{array}$ & Results & $\begin{array}{l}\text { Confounding and Study } \\
\text { Limitations }\end{array}$ & Summary of findings \\
\hline & & $\begin{array}{l}\text { - Feeding: H-CHO: } 25.108 \text {, } \\
\text { H-FAT: } 26.569, \mathrm{P}=\mathrm{NS}\end{array}$ & & \\
\hline 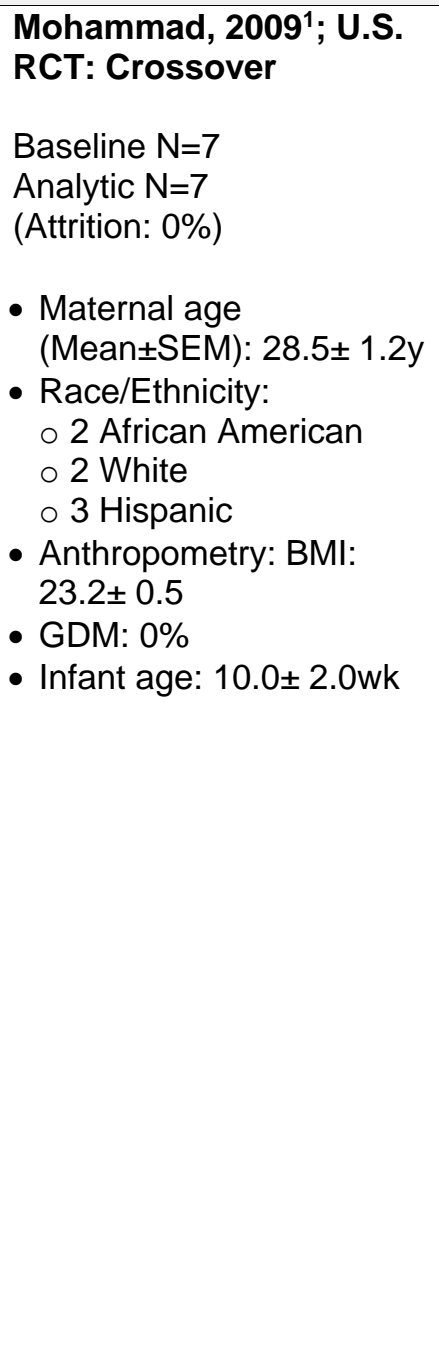 & $\begin{array}{l}\text { Macronutrient } \\
\text { Proportion(s): } \\
\text { - 'H-FAT': } 30 \% \mathrm{CHO}, 55 \% \\
\text { FAT, 15\% PRO } \\
\text { - 'H-CHO': } 60 \% \mathrm{CHO}, 25 \% \\
\text { FAT, 15\% PRO } \\
\text { for } 8 d \text { on each diet with 1- } \\
\text { 2wk washout during 6-14wk } \\
\text { postpartum } \\
\text { Dietary assessment } \\
\text { methods: } \\
\text { Crossover design: } \\
\text { Intervention } 1 \text { (8d), } \\
\text { Washout (1-2wk), } \\
\text { Intervention } 2 \text { (8d). Diets } \\
\text { created to achieve designed } \\
\text { macronutrient composition. } \\
\text { Total energy intake and } \\
\text { distribution of energy from } \\
\text { CHO, FAT, and PRO } \\
\text { analyzed using NDSR. } \\
\text { During each study period, } \\
\text { women consumed study- } \\
\text { provided diet for } 4 d \text { in their } \\
\text { homes, and then consumed } \\
\text { the same diet for } 4 d \text { and } 3 \\
\text { nights in the research } \\
\text { center. } \\
\text { Outcomes: } \\
\text { Human milk composition: } \\
\text { Protein, Fat }\end{array}$ & $\begin{array}{l}\text { Significant: } \\
\text { Composition (Mean } \pm \text { SEM), } \\
\text { Paired t-test } \\
\text { Fat (g/dL), } \mathrm{P}<0.05 \\
\text { - H-CHO: } 4.3 \pm 0.3 \\
\text { - H-FAT: } 4.8 \pm 0.3 \\
\text { Fat (g/d), P<0.05 } \\
\text { - H-CHO: } 34 \pm 2 \\
\text { - H-FAT: } 39 \pm 2 \\
\text { Non-significant: } \\
\text { Composition (Mean } \pm \mathrm{SEM}) \text {, } \\
\text { Paired t-test } \\
\text { Protein (g/dL), P=NS } \\
\text { - H-CHO: } 1.8 \pm 0.1 \\
\text { - H-FAT: } 1.9 \pm 0.1 \\
\text { Protein (g/d), P=NS } \\
\text { - H-CHO: } 15 \pm 0.9 \\
\text { - H-FAT: } 16 \pm 0.8 \\
\text { Milk volume (mL/d, Mean } \pm \\
\text { SEM), Paired t-test, P=NS } \\
\text { - H-CHO: } 829 \pm 41 \\
\text { - H-FAT: } 821 \pm 33\end{array}$ & $\begin{array}{l}\text { Key confounders } \\
\text { accounted for: None } \\
\text { Limitations: } \\
\text { - No adjustment for multiple } \\
\text { comparisons } \\
\text { - Unclear baseline } \\
\text { imbalances } \\
\text { - No information on } \\
\text { randomization, blinding, or } \\
\text { carry-over effects } \\
\text { - Power calculation NR }\end{array}$ & $\begin{array}{l}\text { Consuming a reduced- } \\
\text { calorie H-FAT diet } \\
\text { compared to an isocaloric, } \\
\text { isonitrogenous H-CHO } \\
\text { increased total fat milk } \\
\text { concentration, but did not } \\
\text { affect milk protein } \\
\text { concentrations or volume. }\end{array}$ \\
\hline
\end{tabular}


Study and Participant

Characteristics

\section{Intervention/Exposure}

and Outcomes

Results

Every 3 h collected during

the $3 d$ inpatient stay, which

occurred twice during 6-

14 wk postpartum

Human milk quantity

Every $3 \mathrm{~h}$ collected during

the $3 d$ inpatient stay, which

occurred twice during 6-

14wk postpartum

\section{Outcome assessment}

methods:

During human milk feeding, once every $3 \mathrm{~h}, 2.5 \mathrm{~mL}$ of

milk from each breast was

collected at the beginning,

middle and after the feeding

(total of $15 \mathrm{~mL}$ ). Milk

samples for each collection

time were pooled for

analyses. After human milk

feeding, mothers were

asked to empty the breast

and the milk was weighed.

Total lipid content was

quantified gravimetrically;

protein was measured by

using a bicinchoninic acid

protein assay kit.

The daily intake of the

infants was determined on

the basis of the milk volume

consumed and the energy

content of the milk.
Confounding and Study

Limitations 


\begin{tabular}{|c|c|c|c|c|}
\hline $\begin{array}{l}\text { Study and Participant } \\
\text { Characteristics }\end{array}$ & $\begin{array}{l}\text { Intervention/Exposure } \\
\text { and Outcomes }\end{array}$ & Results & $\begin{array}{l}\text { Confounding and Study } \\
\text { Limitations }\end{array}$ & Summary of findings \\
\hline $\begin{array}{l}\text { Nasser, 20103; Canada } \\
\text { RCT: Crossover } \\
\text { Baseline } \mathrm{N}=14 \\
\text { Analytic } \mathrm{N}=14 \\
\text { (Attrition: } 0 \% \text { ) } \\
\text { - Maternal age: } 31.6 \text { y } \\
\text { (range 24-37) } \\
\text { - Anthropometry: BMI: } 26 \\
\text { - Smoking status: } 0 \% \\
\text { - Parity: } 6 \text { primiparae, } 8 \\
\text { multiparae } \\
\text { - GA at birth: } 100 \% \text { Full- } \\
\text { term } \\
\text { - Infant age (Mean } \pm \text { SEM): } \\
2.8 \pm 0.9 m 0 \text { (range 2-6mo) }\end{array}$ & $\begin{array}{l}\text { Macronutrient } \\
\text { Proportion(s): } \\
\text { - HF: } 40.3 \% \text { FAT, } 14.4 \% \\
\text { PRO, 45.3\% CHO } \\
\text { - LF: } 17.6 \% \text { FAT, } 14.4 \% \\
\text { PRO, } 68 \% \text { CHO } \\
\text { for 4d on each diet with 3d } \\
\text { washout during 2-6mo } \\
\text { postpartum } \\
\text { Dietary assessment } \\
\text { methods: } \\
\text { Women randomly assigned } \\
\text { to receive each dietary } \\
\text { intervention (low fat and } \\
\text { high fat), with equal } \\
\text { numbers of participants for } \\
\text { each order of treatment. } \\
\text { Women were provided with } \\
\text { prepared meals and snacks } \\
\text { meeting their daily energy } \\
\text { requirement, as determined } \\
\text { by the dietary assessment } \\
\text { prior to the period of diet } \\
\text { control. } \\
\text { Outcomes: } \\
\text { Human milk composition: } \\
\text { fatty acids } \\
\text { Once during } 2-6 m o \\
\text { postpartum } \\
\text { Outcome assessment } \\
\text { methods: } \\
\text { Each mother espressed } 20- \\
50 \text { mL of human milk }\end{array}$ & $\begin{array}{l}\text { Significant: } \\
\text { Human milk fat composition } \\
\text { (g/100 g total fatty acids), } \\
\text { Mean } \pm \text { SEM } \\
\text { Capric acid (C10:0), } \mathrm{P}= \\
0.01 \\
\text { - LF: } 0.87 \pm 0.04 \\
\text { - HF: } 0.68 \pm 0.03 \\
\text { Lauric acid (C12:0), } \mathrm{P}=0.01 \\
\text { - LF: } 5.38 \pm 1.16 \\
\text { - HF: } 3.98 \pm 0.37 \\
\text { Total medium chain fatty } \\
\text { acids, } \mathrm{P}=0.01 \\
\text { - LF: } 13.56 \pm 0.66 \\
\text { - HF: } 11.42 \pm 0.86 \\
\text { Stearic acid }(\mathrm{C} 18: 0), \mathrm{P}=0.01 \\
\text { - LF: } 5.00 \pm 0.11 \\
\text { - HF: } 6.08 \pm 0.14 \\
\text { Arichidic acid (C20:0), } \\
\mathrm{P}=0.02 \\
\text { - LF: } 0.08 \pm 0.07 \\
\text { - HF: } 0.12 \pm 0.01 \\
\text { Palmitoleic acid }(\mathrm{C} 16: 1 \mathrm{n}-7) \text {, } \\
\mathrm{P}=0.046 \\
\text { - LF: } 1.95 \pm 0.29 \\
\text { - HF: } 1.31 \pm 0.23 \\
\text { Eicosenoic acid (C20:1n-9), } \\
\mathrm{P}=0.01\end{array}$ & $\begin{array}{l}\text { Key confounders } \\
\text { accounted for: } \\
\text { Smoking Status, GA } \\
\text { Limitations: } \\
\text { - No adjustment for multiple } \\
\text { comparisons } \\
\text { - Short study duration } \\
\text { - Power calculation NR }\end{array}$ & $\begin{array}{l}\text { No significant difference in } \\
\text { human milk concentrations } \\
\text { of total saturated, MUFAs, } \\
\text { and PUFAs during high fat } \\
\text { or low fat diet. }\end{array}$ \\
\hline
\end{tabular}




\begin{tabular}{|c|c|c|c|c|}
\hline $\begin{array}{l}\text { Study and Participant } \\
\text { Characteristics }\end{array}$ & $\begin{array}{l}\text { Intervention/Exposure } \\
\text { and Outcomes }\end{array}$ & Results & $\begin{array}{l}\text { Confounding and Study } \\
\text { Limitations }\end{array}$ & Summary of findings \\
\hline & $\begin{array}{l}\text { between 1-2pm. Milk was } \\
\text { pumped from a breast after } \\
\text { the baby latched and fed for } \\
2-5 \text { minutes. Average fat } \\
\text { content was assessed in the } \\
\text { hind milk. } \\
\text { Milk samples were } \\
\text { extracted for medium and } \\
\text { long chain fatty acids using } \\
\text { a modified Folch procedure. }\end{array}$ & $\begin{array}{l}\text { - LF: } 0.27 \pm 0.02 \\
\text { - HF: } 0.38 \pm 0.02 \\
\text { ALA (C18:3n-3), P=0.01 } \\
\text { - LF: } 1.22 \pm 0.04 \\
\text { - HF:1.69 } 0.06 \\
\text { Y-linoenic acid (C18:3n-6), } \\
\text { P=0.02 } \\
\text { - LF: } 0.12 \pm 0.01 \\
\text { - HF: } 0.09 \pm 0.01 \\
\text { Dihomo-y-linolenic acid } \\
\text { (C20:3n-6), P=0.03 } \\
\text { - LF: } 0.27 \pm 0.02 \\
\text { - HF: } 0.24 \pm 0.02 \\
\text { AA (C20:4n-6), P=0.02 } \\
\text { - LF: } 0.34 \pm 0.01 \\
\text { - HF: } 0.30 \pm 0.02 \\
\text { Non-significant: } \\
\text { Human milk fat composition } \\
\text { (g/100 g total fatty acids), } \\
\text { Mean } \pm \text { SEM } \\
\text { Total SAT, P=0.46 } \\
\text { - LF: } 41.1 \pm 0.82 \\
\text { - HF: } 40.40 \pm 0.85 \\
\text { Caprylic acid (C8:0) } \\
\text { - LF: Trace } \\
\text { - HF: Trace }\end{array}$ & 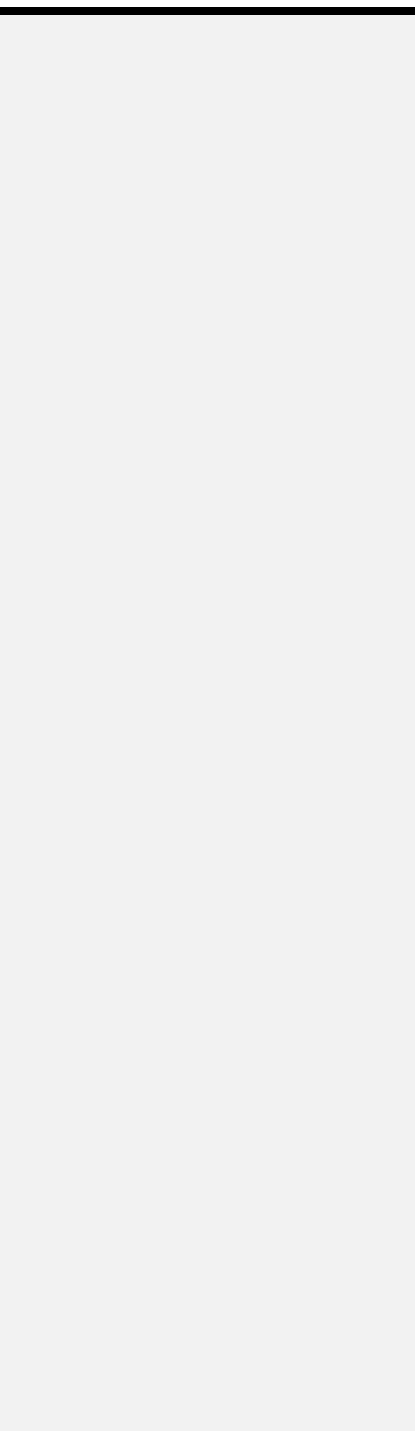 & \\
\hline
\end{tabular}




\begin{tabular}{|c|c|c|c|c|}
\hline $\begin{array}{l}\text { Study and Participant } \\
\text { Characteristics }\end{array}$ & $\begin{array}{l}\text { Intervention/Exposure } \\
\text { and Outcomes }\end{array}$ & Results & $\begin{array}{l}\text { Confounding and Study } \\
\text { Limitations }\end{array}$ & Summary of findings \\
\hline & & $\begin{array}{l}\text { Myristic acid (C14:0), } \\
\text { P=0.07 } \\
\text { - LF: } 7.31 \pm 0.35 \\
\text { - HF: } 6.76 \pm 0.48 \\
\text { Palmitic acid (C16:0), } \\
\text { P=0.43 } \\
\text { - LF: } 22.70 \pm 0.45 \\
\text { - HF: } 23.43 \pm 0.24 \\
\text { Total MUFAs, } P=0.10 \\
\text { - LF: } 38.70 \pm 0.80 \\
\text { - HF: } 39.90 \pm 0.65 \\
\text { Myristoleic acid (C14:1n-5), } \\
\text { P=0.27 } \\
\text { - LF: } 0.35 \pm 0.01 \\
\text { - HF: } 0.41 \pm 0.05 \\
\text { Oleic acid (C18:1n-9), } \\
\text { P=0.08 } \\
\text { - LF: } 36.16 \pm 0.86 \\
\text { - HF: } 37.81 \pm 0.67 \\
\text { Total PUFAs, } P=0.54 \\
\text { - LF: } 16.90 \pm 0.66 \\
\text { - HF: } 16.40 \pm 0.48 \\
\text { LA (C18:2n-6), P=0.27 } \\
\text { - LF: } 14.65 \pm 0.62 \\
\text { - HF: } 13.82 \pm 0.45 \\
\text { Eicosadienoic acid (C20:2n- } \\
6), P=0.51 \\
\text { - LF: } 0.19 \pm 0.02\end{array}$ & 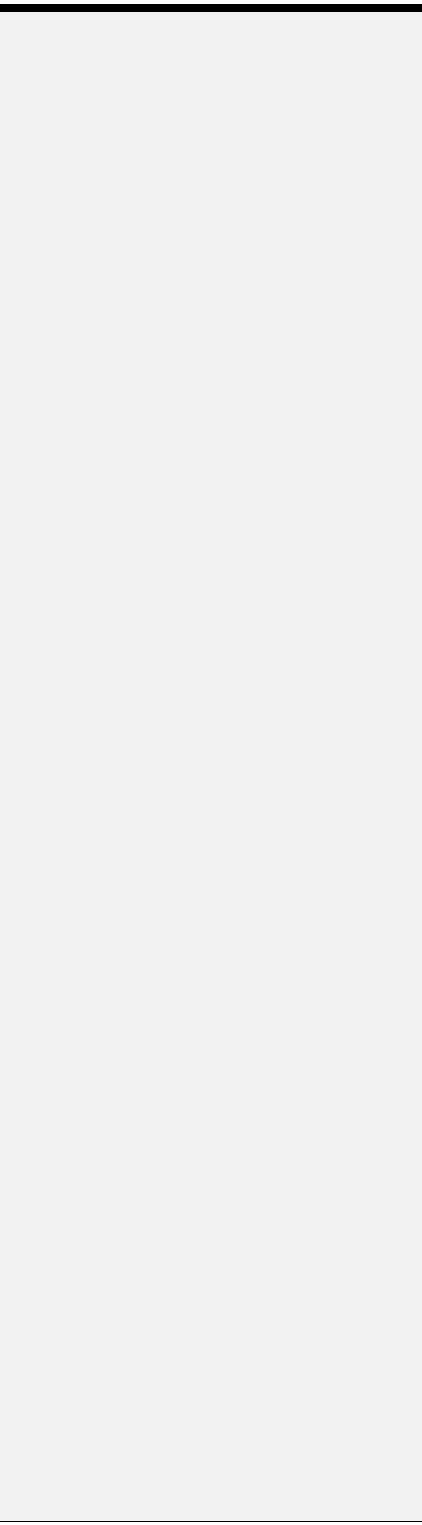 & \\
\hline
\end{tabular}




\begin{tabular}{|c|c|c|c|c|}
\hline $\begin{array}{l}\text { Study and Participant } \\
\text { Characteristics }\end{array}$ & $\begin{array}{l}\text { Intervention/Exposure } \\
\text { and Outcomes }\end{array}$ & Results & $\begin{array}{l}\text { Confounding and Study } \\
\text { Limitations }\end{array}$ & Summary of findings \\
\hline & & $\begin{array}{l}\text { - HF: } 0.18 \pm 0.01 \\
\text { EPA (C20:5n-3) } \\
\text { - LF: Trace } \\
\text { - HF: Trace } \\
\text { Docasapentaenoic acid } \\
\text { (C22:5n-3) } \\
\text { - LF: Trace } \\
\text { - HF: Trace } \\
\text { DHA (C22:6n-3), P=0.77 } \\
\text { - LF: } 0.12 \pm 0.02 \\
\text { - HF: } 0.14 \pm 0.04\end{array}$ & & \\
\hline $\begin{array}{l}\text { Yahvah, 20154; U.S. } \\
\text { RCT: Crossover } \\
\text { Baseline } \mathrm{N}=16 \\
\text { Analytic } \mathrm{N}=15 \\
\text { (Attrition: } 6 \%) \\
\text { All baseline characteristics: } \\
\text { ( } \mathrm{N}=15, \text { Mean } \pm \text { SEM) } \\
\text { - Maternal age: } 27 \pm 1 \mathrm{y} \\
\text { - Anthropometry: } \\
\text { Prepregnancy BMI: } 24 \pm 1 \\
\text { - Parity: } 1.7 \pm 0.2\end{array}$ & $\begin{array}{l}\text { Macronutrient } \\
\text { Proportion(s): } \\
\text { - Low-fat dairy (LFD): } 24 \% \\
\text { FAT, } \sim 20 \% \text { PRO, } 57 \% \\
\text { CHO (Ref, } n=15) ; \\
\text { - Full-fat dairy (FFD): } ~ 36 \% \\
\text { FAT, } 17 \% \text { PRO, } 48 \% \\
\text { CHO ( } n=15 \text { ) } \\
\text { Maternal intake of } 4 \text { full-fat } \\
\text { or low-fat dairy products/d } \\
\text { for } 14 d \text { with } 14 d \text { washout at } \\
\geq 4 \text { mo postpartum } \\
\text { Dietary assessment } \\
\text { methods: } \\
\text { Dairy products delivered } \\
\text { weekly to participants' } \\
\text { homes with reminders of } \\
\text { study guidelines and } \\
\text { sampling dates. } 3 \mathrm{~d} \text { weighed }\end{array}$ & $\begin{array}{l}\text { Significant: } \\
\text { Mean } \pm \text { SEM, Paired t-tests: } \\
\text { Total lipids (g/100 g milk), } \\
\text { P<0.05 } \\
\text { - FFD: } 3.35 \pm 0.28 \\
\text { - LFD: } 2.41 \pm 0.31 \\
4: 0 \text { (g/100 g lipid), P<0.05 } \\
\text { (questioning this } \mathrm{p}-\mathrm{value}) \\
\text { - FFD: } 0.05 \pm 0.00 \\
\text { - LFD: } 0.05 \pm 0.00 \\
\text { 12:0 (g/100 g lipid), P<0.05 } \\
\text { - FFD: } 4.58 \pm 0.36 \\
\text { - LFD: } 5.26 \pm 0.44 \\
\text { 13:0 (g/100 g lipid), P<0.001 } \\
\text { - FFD: } 0.04 \pm 0.00 \\
\text { - LFD: } 0.02 \pm 0.00\end{array}$ & $\begin{array}{l}\text { Key confounders } \\
\text { accounted for: } \\
\text { None } \\
\text { Limitations: } \\
\text { - No adjustment for multiple } \\
\text { comparisons } \\
\text { - No information on } \\
\text { randomization, blinding, or } \\
\text { carry-over effects } \\
\text { - Power calculation NR }\end{array}$ & $\begin{array}{l}\text { Consuming a diet rich in } \\
\text { full-fat versus low-fat dairy } \\
\text { products during lactation } \\
\text { was associated with } \\
\text { different lipid content and } \\
\text { fatty acid profiles in human } \\
\text { milk. }\end{array}$ \\
\hline
\end{tabular}




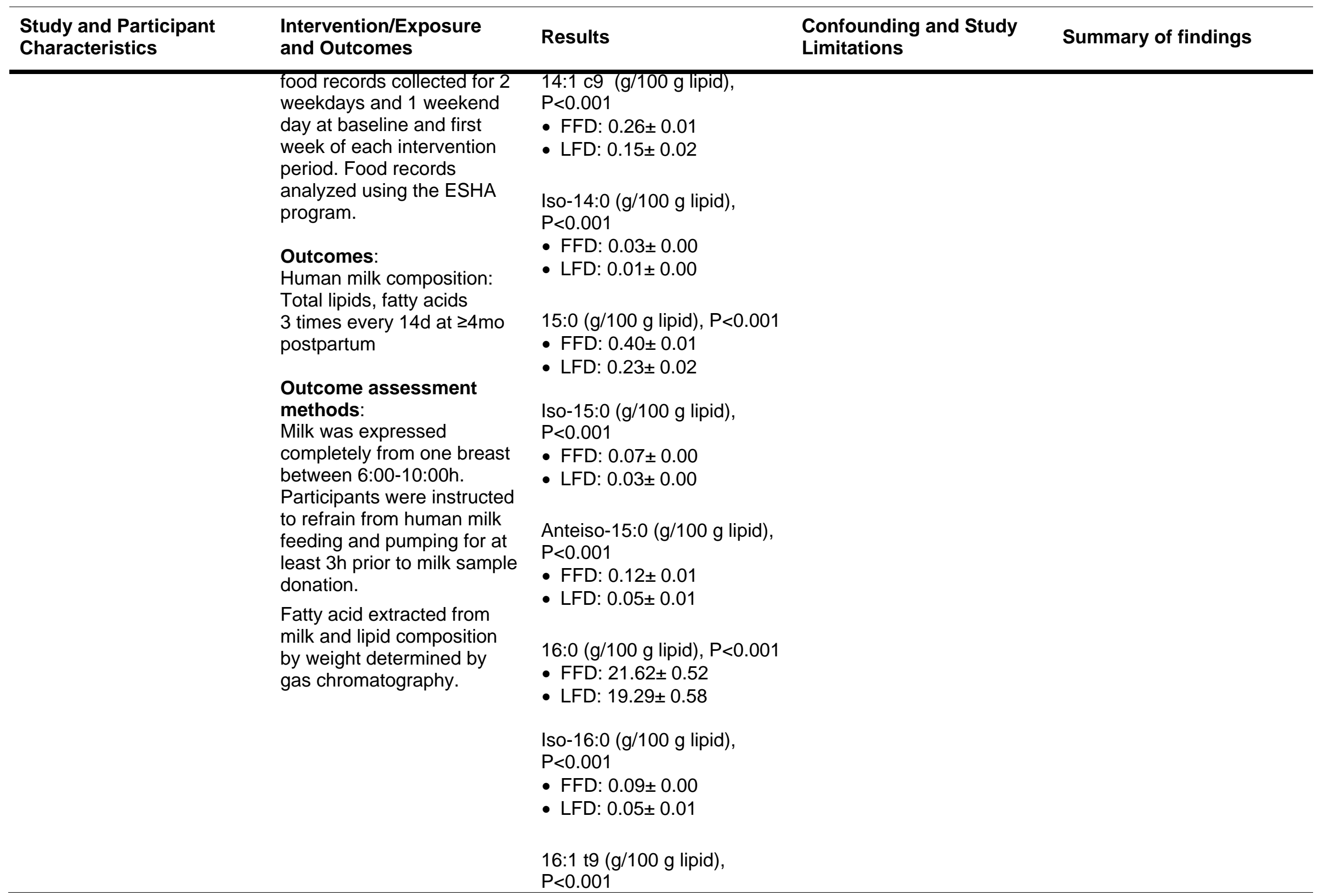


Study and Participant

Characteristics
Intervention/Exposure and Outcomes
Confounding and Study

Limitations
Summary of findings

- FFD: $0.14 \pm 0.01$

$16: 2 \mathrm{c9}, \mathrm{c12}$ (g/100 g lipid),

$\mathrm{P}<0.05$

- FFD: $0.22 \pm 0.01$

- LFD: $0.18 \pm 0.01$

17:0 (g/100 g lipid), $P<0.001$

- FFD: $0.37 \pm 0.01$

- LFD: $0.27 \pm 0.01$

Iso-17:0 (g/100 g lipid),

$\mathrm{P}<0.05$

- FFD: $0.36 \pm 0.01$

- LFD: $0.41 \pm 0.01$

Anteiso-17:0 (g/100 g lipid), $\mathrm{P}<0.001$

- FFD: $0.21 \pm 0.01$

- LFD: $0.11 \pm 0.01$

18:0 ( $\mathrm{g} / 100 \mathrm{~g}$ lipid), $\mathrm{P}<0.001$

- FFD: $7.54 \pm 0.27$

- LFD: $5.75 \pm 0.27$

Anteiso-18:0 (g/100 g lipid), $\mathrm{P}<0.001$

- FFD: $0.05 \pm 0.00$

- LFD: $0.03 \pm 0.00$

Iso-18:0 (g/100 g lipid),

$\mathrm{P}<0.001$

- FFD: $0.05 \pm 0.01$

- LFD: $0.03 \pm 0.00$ 


\begin{tabular}{|c|c|c|c|c|}
\hline $\begin{array}{l}\text { Study and Participant } \\
\text { Characteristics }\end{array}$ & $\begin{array}{l}\text { Intervention/Exposure } \\
\text { and Outcomes }\end{array}$ & Results & $\begin{array}{l}\text { Confounding and Study } \\
\text { Limitations }\end{array}$ & Summary of findings \\
\hline & & $\begin{array}{l}\text { 18:1 c11 (g/100 g lipid), } \\
\text { P<0.05 } \\
\text { - FFD: } 1.17 \pm 0.15 \\
\text { - LFD: } 1.32 \pm 0.18\end{array}$ & & \\
\hline & & $\begin{array}{l}18: 1 \mathrm{t} 11 \text { (g/100 g lipid), } \\
\text { P<0.001 } \\
\text { - FFD: } 0.54 \pm 0.03 \\
\text { - LFD: } 0.34 \pm 0.03\end{array}$ & & \\
\hline & & $\begin{array}{l}18: 2 \text { c9,c12 (g/100 g lipid), } \\
\text { P<0.001 } \\
\text { - FFD: } 14.27 \pm 0.75 \\
\text { - LFD: } 18.80 \pm 0.91\end{array}$ & & \\
\hline & & $\begin{array}{l}18: 2 \mathrm{c}, \mathrm{t} 11(\mathrm{CLA})(\mathrm{g} / 100 \mathrm{~g} \\
\text { lipid), } \mathrm{P}<0.001 \\
\text { - FFD: } 0.33 \pm 0.01 \\
\text { - LFD: } 0.24 \pm 0.01\end{array}$ & & \\
\hline & & $\begin{array}{l}18: 3 \alpha \mathrm{c} 9, \mathrm{c} 12, \mathrm{c} 15(\mathrm{~g} / 100 \mathrm{~g} \\
\text { lipid), } \mathrm{P}<0.05 \\
\text { - FFD: } 1.60 \pm 0.12 \\
\text { - LFD: } 1.97 \pm 0.16\end{array}$ & & \\
\hline & & $\begin{array}{l}20: 0 \text { (g/100 g lipid), } P<0.001 \\
\text { - FFD: } 0.21 \pm 0.02 \\
\text { - LFD: } 0.16 \pm 0.01\end{array}$ & & \\
\hline & & $\begin{array}{l}\text { Non-significant: } \\
\text { Mean } \pm \text { SEM, Paired t-tests: } \\
\text { 6:0 (g/100 g lipid), P=NS } \\
\text { - FFD: } 0.08 \pm 0.00 \\
\text { - LFD: } 0.08 \pm 0.01\end{array}$ & & \\
\hline & & $\begin{array}{l}\text { 8:0 (g/100 g lipid), } P=N S \\
\text { - FFD: } 0.17 \pm 0.01\end{array}$ & & \\
\hline
\end{tabular}


Study and Participant

Characteristics
Intervention/Exposure and Outcomes
Confounding and Study

Limitations

- LFD: $0.17 \pm 0.01$

10:0 (g/100 g lipid), $P=N S$

- FFD: $1.11 \pm 0.06$

- LFD: $1.14 \pm 0.06$

14.0 ( $\mathrm{g} / 100 \mathrm{~g}$ lipid), $P=\mathrm{NS}$

- FFD: $6.37 \pm 0.38$

- LFD: $5.94 \pm 0.54$

$16: 1 \mathrm{c9}$ (g/100 g lipid),

$\mathrm{P}=\mathrm{NS}$

- FFD: $2.08 \pm 0.15$

- LFD: $2.21 \pm 0.16$

$17: 1 \mathrm{c9}$ (g/100 g lipid),

$\mathrm{P}=\mathrm{NS}$

- FFD: $0.04 \pm 0.00$

- LFD: $0.04 \pm 0.00$

18:1 c9 (g/100 g lipid),

$\mathrm{P}=\mathrm{NS}$

- FFD: $30.77 \pm 0.80$

- LFD: $30.51 \pm 0.59$

18:1 c12 (g/100 g lipid),

$\mathrm{P}=\mathrm{NS}$

- FFD: $0.66 \pm 0.14$

- LFD: $0.69 \pm 0.17$

18:1 t7-8 (g/100 g lipid),

$\mathrm{P}=\mathrm{NS}$

- FFD: $0.31 \pm 0.03$

- LFD: $0.29 \pm 0.05$

$18: 1$ t9 (g/100 g lipid), $P=N S$ 


\begin{tabular}{|c|c|c|c|c|}
\hline $\begin{array}{l}\text { Study and Participant } \\
\text { Characteristics }\end{array}$ & $\begin{array}{l}\text { Intervention/Exposure } \\
\text { and Outcomes }\end{array}$ & Results & $\begin{array}{l}\text { Confounding and Study } \\
\text { Limitations }\end{array}$ & Summary of findings \\
\hline & & $\begin{array}{l}\text { - FFD: } 0.32 \pm 0.02 \\
\text { - LFD: } 0.31 \pm 0.03 \\
\text { 18:1 } 110 \text { (g/100 g lipid), } \\
\text { P=NS } \\
\text { - FFD: } 0.52 \pm 0.05 \\
\text { - LFD: } 0.42 \pm 0.05 \\
\text { 18:3 y c6,c9,c12 (g/100 g } \\
\text { lipid), P=NS } \\
\text { - FFD: } 0.11 \pm 0.01 \\
\text { - LFD: } 0.13 \pm 0.02 \\
21: 0 \text { (g/100 g lipid), P=NS } \\
\text { - FFD: } 0.05 \pm 0.00 \\
\text { - LFD: } 0.05 \pm 0.01 \\
\text { 22:0 (g/100 g lipid), P=NS } \\
\text { - FFD: } 0.07 \pm 0.01 \\
\text { - LFD: } 0.06 \pm 0.01\end{array}$ & & \\
\hline
\end{tabular}


Table 3. Results from studies that assessed the relationship between dietary patterns during lactation and human milk fatty acid composition viii

\begin{tabular}{l} 
Articles $^{\mathrm{ix}}$ \\
\hline Tian, 20197 \\
- Pattern 1: Mushroom food and \\
algae, Meat, Marine products \\
- Pattern 2: Soybean products, \\
Nuts, Dairy \\
- Pattern 3: Fruit, Vegetables \\
- Pattern 4: Grain/potato and \\
beans, Eggs
\end{tabular}

Total milk fat

NR

R

\section{Perrin, 20196}

- Vegan: Never/rarely consumed animal products

- Vegetarian: Never consumed meat; regularly consumed other animal products

- Non-vegetarian: Consumed meat sometimes/often

\section{Total Fat NS}

Trans fat higher among women with Nonvegetarian $>$ Vegetarian $>$ Vegan diets $(p<0.001)$

\section{Saturated Fat} 3: 39.10, Pattern 4: $42.92(p<0.001)$
SAT: Pattern 1: 40.38

Pattern 2: 42.92, Pattern

\section{Monounsaturated fatty acids}

MUFAs: Pattern 1: 34.40,

Pattern 2: 33.53, Pattern 3: 34.85, Pattern 4: 33.45 $(\mathrm{p}=0.053)$

\section{Polyunsaturated fatty acids}

PUFAs: Pattern 1: 24.49,

Pattern 2: 22.09, Pattern 3 24.63, Pattern 4: 22.77 $(\mathrm{p}=0.025)$

n-6 PUFAs: Pattern 1: 20.71, Pattern 2: 18.24, Pattern 3: 20.11, Pattern 4: 18.49 $(\mathrm{p}=0.038)$

n-3 PUFAs: Pattern 1: 3.96, Pattern 2: 3.55, Pattern 3: 3.56, Pattern 4: $3.86(p=0.29)$

n-6: n-3 PUFA ratio: Pattern 1: 4.83, Pattern 2: 4.76, Pattern 3: 5.34, Pattern 4: $4.69(p=0.34)$

Data not reported as total SAT: Vegan: 33.1, Vegetarian: 40.0, Nonvegetarian: 42.3 $(p<0.001)$

C15:0, C16:0, C17:0, and $\mathrm{C} 18: 0$ higher among women with Nonvegetarian $>$ Vegetarian $>$ Vegan diets $(p<0.001)$
Data not reported as total MUFAs

PUFAs

C14:1 cis, C16:1 cis, C17:1 cis higher among women with Non-vegetarian > Vegetarian $>$ Vegan diets $(p<0.001)$

\section{C18:1 cis higher among} women with Vegan > n-6 PUFAs: Vegan: 19.65, Vegetarian: 18.69, Nonvegetarian: 17.11 (NS)

n-3 PUFAs: Vegan: 2.29, Vegetarian: 1.55 , Nonvegetarian: $1.46(p<0.001)$

viii AA: arachidonic acid, ALA: alpha-linolenic acid, DHA: docosahexaenoic acid, EPA: eicosapentaenoic acid, LA: linoleic acid, MUFA: monounsaturated fatty acid, n-\#: omega-\#, NR: not reported, NS: non-significant, PUFA: polyunsaturated fatty acid, SAT: saturated fat

ix Data are Median \% fatty acid proportions unless otherwise specified 


\begin{tabular}{|c|c|c|c|c|}
\hline Articles $^{i x}$ & Total milk fat & Saturated Fat & $\begin{array}{l}\text { Monounsaturated } \\
\text { fatty acids }\end{array}$ & $\begin{array}{l}\text { Polyunsaturated fatty } \\
\text { acids }\end{array}$ \\
\hline & & $\begin{array}{l}\mathrm{C} 8: 0, \mathrm{C} 10: 0, \mathrm{C} 12: 0 \\
\mathrm{C} 14: 0, \mathrm{C} 20: 0, \mathrm{C} 22: 0, \\
\text { and C24:0 NS }\end{array}$ & $\begin{array}{l}\text { Vegetarian }>\text { Non- } \\
\text { vegetarian diets }(p<0.001)\end{array}$ & $\begin{array}{l}n-6: n-3 \text { PUFA ratio: Vegan: } \\
8.8, \text { Vegetarian: } 11.4, \text { Non- } \\
\text { vegetarian: } 11.2(p<0.001)\end{array}$ \\
\hline & & & $\begin{array}{l}\text { C15:1 cis, C20:1 cis, C22:1 } \\
\text { cis, C24:1 cis, C14:1 trans, } \\
\text { C16:1 trans NS }\end{array}$ & $\begin{array}{l}\text { LA:ALA ratio higher in Non- } \\
\text { vegetarian }>\text { Vegetarian }> \\
\text { Vegan diet }\end{array}$ \\
\hline & & & & $\begin{array}{l}\text { C18:3 cis y higher in Non- } \\
\text { vegetarian > Vegetarian = } \\
\text { Vegan }\end{array}$ \\
\hline & & & & $\begin{array}{l}\text { ALA, and unsaturated fat higher } \\
\text { among women with Vegan > } \\
\text { Vegetarian > Non-vegetarian } \\
\text { diets }\end{array}$ \\
\hline & & & & $\begin{array}{l}\text { LA (C18:2 cis), C18:2 trans } \\
\text { C20:2 cis, C20:3 cis, AA } \\
\text { (C20:4), EPA (C20:5 cis), and } \\
\text { DHA (C22:6 cis) NS }\end{array}$ \\
\hline
\end{tabular}


Table 4. Results from studies that assessed the relationship between diets based on macronutrient distributions during lactation and human milk composition ${ }^{x}$

\begin{tabular}{|c|c|c|c|c|}
\hline Articles & Total milk fat & Saturated fat & $\begin{array}{l}\text { Monounsaturated } \\
\text { fatty acids }\end{array}$ & $\begin{array}{l}\text { Polyunsaturated fatty } \\
\text { acids }\end{array}$ \\
\hline $\begin{array}{l}\text { Mohammad, } 2009{ }^{1} \\
\text { High CHO } \\
(60 \% \mathrm{CHO}, 25 \% \text { FAT, 15\% PRO) } \\
\text { vs. } \\
\text { High Fat } \\
\text { ( } 30 \% \mathrm{CHO}, 55 \% \text { FAT, } 15 \% \text { PRO) }\end{array}$ & $\begin{array}{l}\text { Milk fat concentration } \\
\text { and milk fat content/day } \\
\text { higher after high fat diet } \\
(p<0.05)\end{array}$ & NR & NR & NR \\
\hline $\begin{array}{l}\text { Mohammad, 2014 } \\
\text { High } \mathrm{CHO} \\
\text { (60\% CHO, 25\% FAT, 15\% PRO) } \\
\text { vs. } \\
\text { High Fat } \\
\text { ( } 30 \% \mathrm{CHO}, 55 \% \text { FAT, } 15 \% \text { PRO) }\end{array}$ & $\begin{array}{l}\text { Total milk fat higher in } \\
\text { high fat diet }(p<0.05) \\
\text { only in a fed state }\end{array}$ & $\begin{array}{l}\text { ESAT: Fasting: H-CHO: } \\
\text { 15.71, H-FAT: } 15.03 \text { (NS) } \\
\text { Feeding: H-CHO: 18.21, H- } \\
\text { FAT: 18.37 (NS) } \\
\text { Women during H-CHO diet } \\
\text { had higher \%total SAT (fed } \\
\text { only p<0.05) and } \sum \text { C2:C14 } \\
\text { (both fed and fasting } \\
\text { p<0.05) } \\
\text { Women during H-CHO diet } \\
\text { had higher C4:0, C6:0, } \\
\text { C8:0, C10:0, C12:0 (fed } \\
\text { only), C14:0, } \sum \mathrm{C} 2: \mathrm{C} 14, \\
\text { C16:0 (fed only), C18:0 (fed } \\
\text { only) in human milk } \\
\text { (p<0.05) than H-FAT. } \\
\text { C2:0 NS }\end{array}$ & 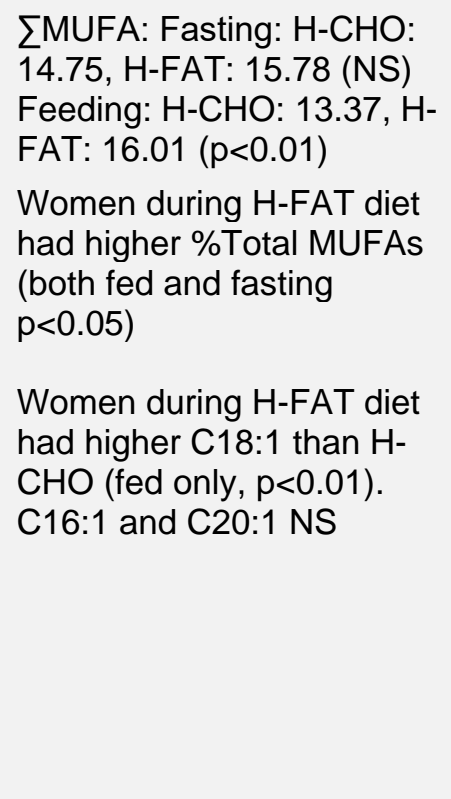 & 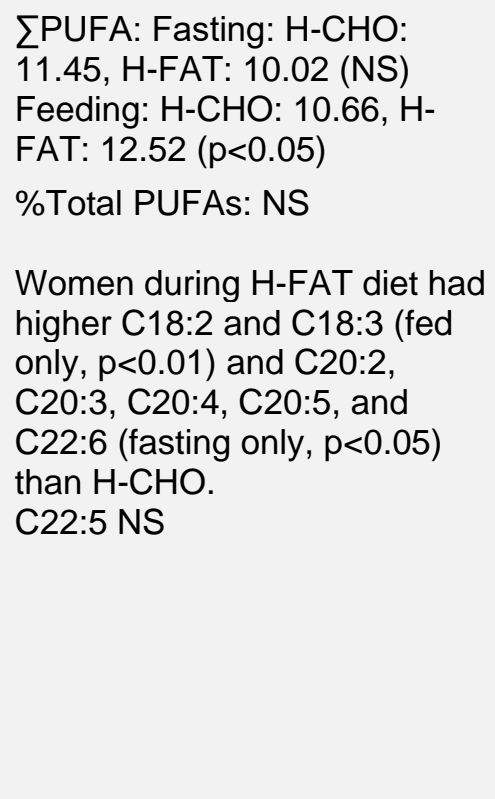 \\
\hline
\end{tabular}

× AA: arachidonic acid, ALA: alpha-linolenic acid, CHO: carbohydrate, DHA: docosahexaenoic acid, EPA: eicosapentaenoic acid, LA: linoleic acid, MUFA: monounsaturated fatty acid, n-\#: omega-\#, NR: not reported, NS: non-significant, PRO: protein, PUFA: polyunsaturated fatty acid, SAT: saturated fat, xi Units $\mathrm{g} / \mathrm{L}$ 


\section{Articles}

Total milk fat

Saturated fat

Monounsaturated

fatty acids

Polyunsaturated fatty

acids

Nasser, 20103xii

High Fat

(45.3\% CHO, 40.3\% FAT, $14.4 \%$

PRO)

Low Fat

(68\% CHO, 17.6\% FAT, $14.4 \%$

PRO)

NR

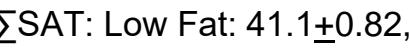
High Fat: $40.4 \pm 0.85$

$(p=0.46)$

Women during low fat diet had higher total medium chain FA, C10:0 and C12:0 $(p=0.01)$ in human milk than high fat. C18:0 and C20:0 higher in high fat diet than low fat diet $(p=0.01)$. C14:0 and C16:0 NS

Total lipids was higher after a full-fat dairy diet compared to low-fat dairy diet

\section{Yahvah, 2015 ${ }^{\text {xiii }}$}

Low fat dairy

(57\% CHO, 24\% FAT, 20\% PRO) vS

Full-fat dairy (48\% CHO, 36\%

FAT, 17\% PRO)
Data not reported as total

saturated fat

Women during full-fat dairy

diet had higher

C13:0, iso-14:0, C15:0, iso-

15:0, anteiso-15:0, C16:0,

iso-C16:0, C17:0, anteiso

17:0, C18:0, anteiso 18:0, iso-18:0, C20:0 ( $p<0.05)$

Women during low fat dairy diet had higher C12:0 and iso-17:0 in their milk $(p<0.05)$

C4:0, C6:0, C8:0, C10:0,

C14:0, C21:0, C22:0 NS
¿MUFA: Low Fat: $38.7 \pm 0.8, \quad \sum$ PUFA: Low Fat: $16.9 \pm 0.66$ High Fat: 39.9+0.65 $(p=0.10)$

C16:1: Milk from women during low fat diet higher than high fat $(p=0.046)$ C20:1: Milk from women during high fat diet higher than low fat $(p=0.01)$

C14:1 and C18:1 NS High Fat: $16.4+0.48(p=0.54)$

Women during low fat diet had higher C18:3n-6, C20:3 and AA (C20:4n-6) in human milk than high fat milk $(p<0.05)$. ALA (C18:3n:3) was higher in milk of mothers with high fat diet $(p=0.01)$

LA (C18:2n-6), C20:2n-6, C22:5n-3, EPA (C20:5n-3) DHA (C22:6n-3) NS

Data not reported as total MUFAs

Data not reported as total PUFAs

Women during full-fat dairy diet had higher $\mathrm{C} 14: 1$,

C16:1t9, C18:1t11 $(p<0.001)$

Women during low-fat dairy diet had higher C18:1c11 $(p<0.05)$

C16:1, C17:1, C18:1 C18:1, C18:1t7-8, C18:1t9, C18:1t10 NS
Women during full-fat dairy diet had higher C16:2 and C18:2 $c 9, t 11(p<0.05)$ in human milk than low-fat dairy diet

Women during low-fat dairy diet had higher C18:2 c9,c12 and C18:3 $\alpha$ c9,c12,c15 than full-fat dairy diet $(p<0.05)$

C18:3 y c6,c9,c12 NS

\footnotetext{
xii Units $\mathrm{g} / 100 \mathrm{~g}$ total fatty acids

xiii Units $\mathrm{g} / 100 \mathrm{~g}$ lipids
} 
Table 5. Risk of bias for randomized controlled trials examining dietary patterns during lactation and human milk composition and quantityxiv, $x v$

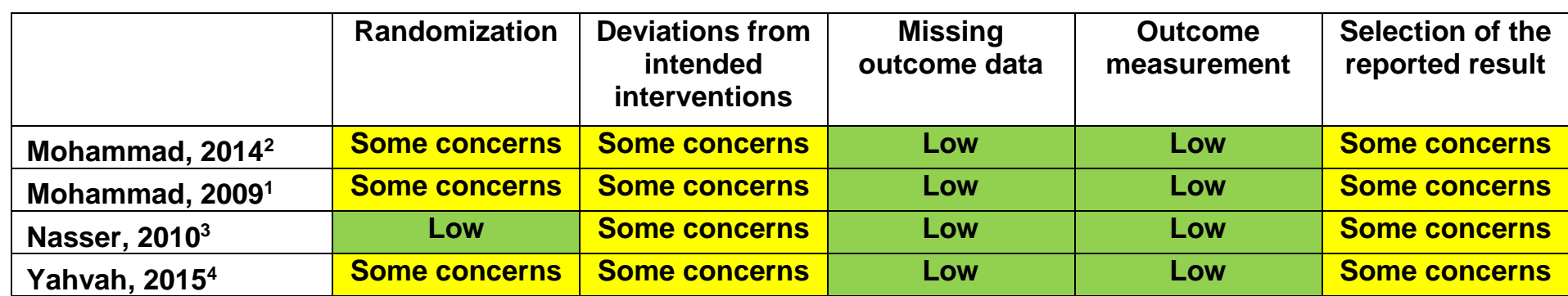

Table 6. Risk of bias for observational studies examining dietary patterns during lactation and human milk composition and quantity ${ }^{\mathrm{xvi}}$

\begin{tabular}{|l|c|c|c|c|c|c|c|}
\hline & Confounding & $\begin{array}{c}\text { Selection of } \\
\text { participants }\end{array}$ & $\begin{array}{c}\text { Classification } \\
\text { of exposures }\end{array}$ & $\begin{array}{c}\text { Deviations from } \\
\text { intended } \\
\text { exposures }\end{array}$ & Missing data & $\begin{array}{c}\text { Outcome } \\
\text { measurement }\end{array}$ & $\begin{array}{l}\text { Selection of the } \\
\text { reported result }\end{array}$ \\
\hline Tian, 20197 & Serious & Serious & Moderate & Low & Low & Low & Moderate \\
\hline Pawlak, 2018 & Critical & Serious & Serious & Critical & Low & Low & Moderate \\
\hline Perrin, 20196 & Critical & Serious & Serious & Critical & Low & Low & Moderate \\
\hline
\end{tabular}

${ }^{x i v}$ A detailed description of the methodology used for assessing risk of bias is available on the NESR website: https://nesr.usda.gov/2020-dietary-guidelinesadvisory-committee-systematic-reviews and in Part C of the following reference: Dietary Guidelines Advisory Committee. 2020. Scientific Report of the 2020 Dietary Guidelines Advisory Committee: Advisory Report to the Secretary of Agriculture and the Secretary of Health and Human Services. U.S. Department of Agriculture, Agricultural Research Service, Washington, DC.

xv Possible ratings of low, some concerns, or high determined using the "Cochrane Risk-of-bias 2.0" (RoB 2.0) (August 2016 version)" (Higgins JPT, Sterne JAC, Savović J, Page MJ, Hróbjartsson A, Boutron I, Reeves B, Eldridge S. A revised tool for assessing risk of bias in randomized trials In: Chandler J, McKenzie J, Boutron I, Welch V (editors). Cochrane Methods. Cochrane Database of Systematic Reviews 2016, Issue 10 (Suppl 1). dx.doi.org/10.1002/14651858.CD201601.)

xvi Possible ratings of low, moderate, serious, critical, or no information determined using the "Risk of Bias for Nutrition Observational Studies" tool (RoBNObs) (Dietary Guidelines Advisory Committee. 2020. Scientific Report of the 2020 Dietary Guidelines Advisory Committee: Advisory Report to the Secretary of Agriculture and the Secretary of Health and Human Services. U.S. Department of Agriculture, Agricultural Research Service, Washington, DC.) 
The NESR team used its rigorous, protocol-driven methodology to support the 2020 Dietary Guidelines Advisory Committee in conducting this systematic review.

NESR's systematic review methodology involves:

- Developing a protocol,

- Searching for and selecting studies,

- Extracting data from and assessing the risk of bias of each included study,

- Synthesizing the evidence,

- Developing conclusion statements,

- Grading the evidence underlying the conclusion statements, and

- Recommending future research.

A detailed description of the methodology used in conducting this systematic review is available on the NESR website: https://nesr.usda.gov/2020-dietary-guidelines-advisory-committee-systematicreviews, and can be found in the 2020 Dietary Guidelines Advisory Committee Report, Part C: Methodology.xvii This systematic review was peer reviewed by Federal scientists, and information about the peer review process can also be found in the Committee's Report, Part C. Methodology. Additional information about this systematic review, including a description of and rationale for any modifications made to the protocol can be found in the 2020 Dietary Guidelines Advisory Committee Report, Chapter 3. Food, Beverage, and Nutrient Consumption During Lactation.

Below are details of the final protocol for the systematic review described herein, including the:

- Analytic framework

- Literature search and screening plan

- Literature search and screening results

\section{ANALYTIC FRAMEWORK}

The analytic framework (Figure 1) illustrates the overall scope of the systematic review, including the population, the interventions and/or exposures, comparators, and outcomes of interest. It also includes definitions of key terms and identifies key confounders considered in the systematic review. The inclusion and exclusion criteria that follow provide additional information about how parts of the analytic framework were defined and operationalized for the review.

xvii Dietary Guidelines Advisory Committee. 2020. Scientific Report of the 2020 Dietary Guidelines Advisory Committee: Advisory Report to the Secretary of Agriculture and the Secretary of Health and Human Services. U.S. Department of Agriculture, Agricultural Research Service, Washington, DC. 


\section{Figure 1. Analytic framework}

\section{Systematic review question: What is the relationship between dietary patterns consumed during lactation}

and human milk composition and quantity?

Intervention/exposure

Consumption of and/or adherence to a dietary pattern vs

\section{Comparator}

- Consumption of and/or adherence to a different dietary pattern

- Different levels of consumption of and/or adherence to a dietary pattern

Population: Human milk composition: Women during lactation; healthy and/or at risk for chronic disease

Human milk quantity: Exclusively or predominantly human milk feeding women; healthy and/or at riskfor chronic disease

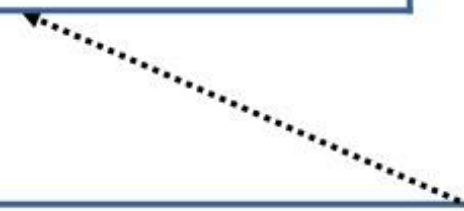

Outcomes

Human milk composition assessed in milk collected ¿ 14 days postpartum

- Macronutrients: Fatty acids, total protein

- Water soluble vitamins: B, C and choline

- Fat soluble vitamins: A, D, E, and K

- Minerals: Iodine and Selenium

- Human milk oligosaccharides

- Bioactive proteins (alpha-lactalbumin, lactoferrin, casein, alpha (1) antitrypsin, osteopontin, slgA, lysozyme)

Human milk quantity assessed in milk collected $\approx 14$ days postpartum

Population: Human milk composition: Women during lactation; healthy and/or at riskfor chronic disease

Human milk quantity: Exclusively or predominantly human milkfeeding women; healthy and/or at riskfor chronic disease

Key Confounders: Age, Race/ethnicity, Socioeconomic status, Anthropometry (obesity status during lactation and gestational weight gain), Smoking, Parity, Gestational age, Supplementintake during lactation

\section{Key definitions}

Dietary Pattern - The quantities, proportions, variety, or combination of different foods, drinks, and nutrients (when available) in diets, and the frequency with which they are habitually consumed.

Exclusive human milk feeding - Infant receives no other food or drink, not even water, except breast milk (including milk expressed or from a wet nurse). Infants may receive oral rehydration solution, drops and syrups (vitamins, minerals and medicines). (WHO, 2001)

Predominant human milk feeding - Breast milk (including milk expressed or from a wet nurse) is infant's predominant source of nourishment. Infants may also receive liquids (water and waterbased drinks, fruit juices) ritual fluids and oral rehydration solution, drops or syrups (vitamins, minerals and medicines). (WHO, 2001)

\section{Legend}

$\longrightarrow$ The relationship of interest in the systematic review

....... Factors that may impact the relationship of interest in the systematic review 


\section{LITERATURE SEARCH AND SCREENING PLAN}

\section{Inclusion and exclusion criteria}

This table provides the inclusion and exclusion criteria for the systematic review. The inclusion and exclusion criteria are a set of characteristics used to determine which articles identified in the literature search were included in or excluded from the systematic review.

\section{Table 7. Inclusion and exclusion criteria}

\begin{tabular}{|c|c|c|}
\hline Category & Inclusion Criteria & Exclusion Criteria \\
\hline $\begin{array}{l}\text { Study } \\
\text { design }\end{array}$ & $\begin{array}{l}\text { - Randomized controlled trials } \\
\text { - Non-randomized controlled trials } \\
\text { including quasi-experimental and } \\
\text { controlled before-and-after studies } \\
\text { - Prospective cohort studies } \\
\text { - Retrospective cohort studies } \\
\text { - Nested case-control studies } \\
\text { - Cross-sectional studies }\end{array}$ & 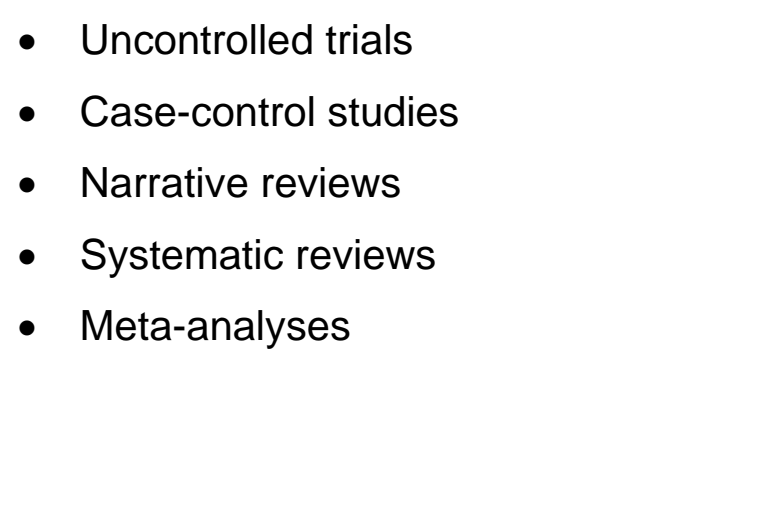 \\
\hline $\begin{array}{l}\text { Intervention/ } \\
\text { exposure }\end{array}$ & $\begin{array}{l}\text { - Studies that examine consumption } \\
\text { of and/or adherence to a } \\
\text { 1. Dietary pattern [i.e., the } \\
\text { quantities, proportions, variety, } \\
\text { or combination of different } \\
\text { foods, drinks, and nutrients } \\
\text { (when available) in diets, and } \\
\text { the frequency with which they } \\
\text { are habitually consumed] } \\
\text { including, at a minimum, a } \\
\text { description of the foods and } \\
\text { beverages in the pattern } \\
\text { and/or } \\
\text { 2. Diet based on macronutrient } \\
\text { distribution outside of the } \\
\text { AMDR and } \\
\text { - Include the macronutrient } \\
\text { distribution of carbohydrate, } \\
\text { fat, and protein of the diet, } \\
\text { and } \\
\text { - Include at least one } \\
\text { macronutrient outside of the } \\
\text { acceptable macronutrient }\end{array}$ & $\begin{array}{l}\text { 2a. Examine consumption of and/or } \\
\text { adherence to a diet based on } \\
\text { macronutrient proportion in which all } \\
\text { macronutrients are within the AMDR } \\
\text { 2b. Do not describe the entire } \\
\text { macronutrient distribution of the diet } \\
\text { (i.e., studies that only examine a } \\
\text { single macronutrient in relation to } \\
\text { outcomes) }\end{array}$ \\
\hline
\end{tabular}




\begin{tabular}{lll}
\hline Category Inclusion Criteria & Exclusion Criteria \\
\hline
\end{tabular}

distribution range

$\left(\right.$ AMDR $^{\text {xviii) }}$

Comparator Dietary patterns described by foods and beverages consumed:

- Consumption of and/or adherence to a different dietary pattern

- Different levels of consumption of and/or adherence to a dietary pattern

Diets described by macronutrient distribution:

- Different macronutrient distribution of carbohydrate, fat, and protein

\section{Outcomes}

- Human milk composition assessed in milk collected $\geq 14$ days postpartum

- Macronutrients: Fatty acids, total protein

- Water soluble vitamins: B, $\mathrm{C}$, and choline

- Fat soluble vitamins: A, D, $\mathrm{E}, \mathrm{K}$

- Minerals: lodine and Selenium

- Human milk oligosaccharides

- Bioactive components

- Human milk quantity assessed in milk collected $\geq 14$ days postpartum

xviii Macronutrient percent of energy outside of the AMDR are as follows:

- Carbohydrate for all age groups: $<45$ or $>65$ percentage of energy;

- Protein (age 19 years and older): $<10$ or $>35$ percentage of energy;

- Fat (age 19 years and older): $<20$ or $>35$ percentage of energy.

Institute of Medicine. Dietary Reference Intakes for Energy, Carbohydrate, Fiber, Fat, Fatty Acids, Cholesterol, Protein, and Amino Acids. Washington, DC: The National Academies Press; 2002. 


\section{Category Inclusion Criteria Exclusion Criteria}

\begin{tabular}{llll}
\hline $\begin{array}{l}\text { Date of } \\
\text { publication }\end{array}$ & - January 2000 to November 2019 & $\begin{array}{l}\text { Articles published before January } \\
2000 \text { or after November } 2019\end{array}$ \\
\hline
\end{tabular}

$\begin{array}{lll}\begin{array}{l}\text { Publication } \\ \text { status }\end{array} & \begin{array}{l}\text { Articles published in peer-reviewed } \\ \text { journals }\end{array} & \begin{array}{l}\text { Articles that have not been peer- } \\ \text { reviewed and are not published in } \\ \text { peer-reviewed journals, including } \\ \text { unpublished data, manuscripts, } \\ \text { reports, abstracts, and conference } \\ \text { proceedings }\end{array} \\ & & \\ & \end{array}$

\begin{tabular}{lll}
\hline $\begin{array}{l}\text { Language of } \\
\text { publication }\end{array}$ & Articles published in English & $\begin{array}{l}\text { Articles published in languages other } \\
\text { than English }\end{array}$ \\
\hline
\end{tabular}

\begin{tabular}{lll}
\hline Countryxix & $\begin{array}{l}\text { Studies conducted in Very High or } \\
\text { High Human Development } \\
\text { Countries }\end{array}$ & $\begin{array}{l}\text { Studies conducted in countries } \\
\text { ranked as medium or lower human } \\
\text { development }\end{array}$
\end{tabular}

Study - Human milk composition: Women
participants

- Human milk quantity: Exclusively or predominantly human milk feeding women

- Animal and in vitro models

- Studies that ONLY enroll multiple gestation pregnancies or present ONLY combined analyses of singleton and multiple gestations (human milk quantity outcome only)

\section{Health status of study participants}

- Studies that enroll mothers who are healthy and/or at risk for chronic disease

- Studies that enroll some mothers diagnosed with a disease

- Studies that enroll some mothers who were severely undernourished prior to pregnancy

- Studies that enroll some or all mothers classified as underweight, or obese prior to pregnancy
- Studies that ONLY enroll mothers who gave birth to preterm (gestational age $<37$ weeks and 0/7 days)

- Studies that ONLY enroll mothers diagnosed with a disease, including severe undernutrition, or hospitalized with an illness or injury

\footnotetext{
xix The Human Development classification was based on the Human Development Index (HDI) ranking from the year the study intervention occurred or data were collected (UN Development Program. HDI 1990-2017 HDRO calculations based on data from UNDESA (2017a), UNESCO Institute for Statistics (2018), United Nations Statistics Division (2018b), World Bank (2018b), Barro and Lee (2016) and IMF (2018). Available from:

http://hdr.undp.org/en/data). If the study did not report the year in which the intervention occurred or data were collected, the HDI classification for the year of publication was applied. HDI values are available from 1980, and then from 1990 to present. If a study was conducted prior to 1990, the HDI classification from 1990 was applied. When a country was not included in the HDI ranking, the current country classification from the World Bank was used instead (The World Bank. World Bank country and lending groups. Available from: https://datahelpdesk.worldbank.org/knowledgebase/articles/906519-world- country-and-lending-groups).
} 


\section{Electronic databases and search terms}

\section{PubMed}

- Provider: U.S. National Library of Medicine

- Date(s) Searched: November 13, 2019

- Date range searched: January 1, 2000 - November 13, 2019

- Search Terms:

\#1 - "Lactation"[Mesh] OR lactation[tiab] OR lactating[tiab] OR "Breast Feeding"[Mesh] OR breastfeeding[tiab] OR breast-feeding[tiab] OR breast feed ${ }^{*}$ OR breast-feed [tiab] OR breastfed[tiab] OR breast-fed[tiab] OR breastfeed* OR nursing women[tiab]

\#2 - dietary pattern* OR diet pattern* OR eating pattern* OR food pattern* OR diet quality[tiab] OR eating habit*[tiab] OR dietary habit* OR diet habit* OR food habit* OR "Feeding Behavior"[Mesh] OR feeding behavior*[tiab] OR beverage consumption[tiab] OR beverage habit* [tiab] OR beverage intake*[tiab] OR dietary profile* OR food profile[tiab] OR diet profile* OR eating profile* OR dietary guideline ${ }^{*}$ OR dietary recommendation* ${ }^{*}$ OR dietary intake[tiab] OR food intake[tiab] OR food consumption[tiab] OR dietary consumption[tiab] OR eating frequenc* OR food frequenc ${ }^{*}\left[\right.$ tiab] OR eating style*[tiab] OR dietary change* ${ }^{*}[$ tiab] OR dietary choice*[tiab] OR food choice*[tiab] OR "Diet, Mediterranean"[Mesh] OR Mediterranean Diet*[tiab] OR "Dietary Approaches To Stop Hypertension"[Mesh] OR Dietary Approaches To Stop Hypertension Diet* OR DASH diet* OR "Diet, Gluten-Free"[Mesh] OR Gluten Free diet* OR prudent diet* OR "Diet, Paleolithic"[Mesh] OR Paleolithic Diet" OR "Diet, Vegetarian"[Mesh] OR vegetarian $\operatorname{diet}^{\star}\left[\right.$ tiab] OR vegan $\operatorname{diet}^{*}$ OR "Diet, Healthy"[Mesh] OR plant based diet" OR "Diet, Western"[Mesh] OR western diet* OR "Diet, CarbohydrateRestricted"[Mesh] OR low-carbohydrate diet $^{\star}$ OR high carbohydrate diet $^{\star}$ OR Ketogenic Diet ${ }^{\star}$ OR Nordic Diet* OR "Diet, Fat-Restricted"[Mesh] OR "Diet, High-Fat"[Mesh] OR "Diet, HighProtein"[Mesh] OR high protein $\operatorname{diet}^{\star}\left[\right.$ tiab] OR high-fat diet ${ }^{*}\left[\right.$ tiab] OR low fat $\operatorname{diet}^{*}[$ tiab] OR "Diet, Protein-Restricted"[Mesh] OR low protein diet* OR "Diet, Sodium-Restricted"[Mesh] OR low-sodium diet* OR low salt diet* OR (("Dietary Proteins"[Mesh] OR dietary protein*[tiab] OR "Dietary Carbohydrates"[Mesh] OR dietary carbohydrate*[tiab] OR "Dietary Fats"[Mesh] OR dietary fat*[tiab] OR hypocaloric OR hypo-caloric) AND (diet[tiab] OR diets[tiab] OR consumption[tiab] OR intake[tiab] OR supplement*[tiab])) OR ("Guideline Adherence"[Mesh] AND (diet[tiab] OR dietary[tiab] OR food[tiab] OR beverage[tiab])) OR (diet score* OR diet quality score* OR diet quality index* OR dietary habits score* OR kidmed OR diet index* OR dietary index* OR Food-based Index* OR diet quality index* OR food index* OR food score* OR Mediterranean diet score* OR MedDietScore OR healthy eating index[tiab] OR food frequency questionnaire* OR food frequency survey* OR "Nutrition Surveys"[Mesh] OR nutrition survey*[tiab] OR diet survey*[tiab] OR food survey* OR dietary questionnaire[tiab]) OR ((pattern[tiab] OR patterns[tiab] OR consumption[tiab] OR habit[tiab]) AND ("Diet"[Mesh:NoExp] OR diet[tiab] OR diets[tiab] OR dietary[tiab] OR "Food"[Mesh] OR food[tiab] OR foods[tiab] OR "Beverages"[Mesh] OR beverage[tiab] OR beverages[tiab]))

\#3 - "human milk composition"[tiab] OR "Milk, Human"[Mesh] OR "milk composition"[tiab] OR "Nutrients"[Mesh:NoExp] OR macronutrient*[tiab] OR "Vitamins"[Mesh] OR "Vitamins" [Pharmacological Action] OR vitamin*[tiab] OR "Milk Proteins"[Mesh] OR total protein*[tiab] OR "milk protein"”[tiab] OR lactoferrin*[tiab] OR lactalbumin[tiab] OR casein*[tiab] OR whey protein*[tiab] OR "alpha 1-Antitrypsin"[Mesh] OR alpha 1-antitrypsin*[tiab] OR "alpha 1Antitrypsin Deficiency"[Mesh] OR "alpha 1-Antitrypsin Deficien*"[ tiab] OR 
"Osteopontin"[Mesh] OR osteopontin*[tiab] OR "IgA Deficiency"[Mesh] OR "Immunoglobulin A"[Mesh] OR iga[tiab] OR "iga 1"[tiab] OR "iga 2"[tiab] OR lysozyme*[tiab] OR

"Muramidase"[Mesh]

\#4 - fatty acid*[tiab] OR "Fatty Acids"[Mesh:noexp] OR "Fatty Acids, Unsaturated"[Mesh:noexp] OR Arachidonic acid*[tiab] OR linolenic acid*[tiab] OR linoleic acid $^{*}\left[\right.$ tiab] OR Docosahexaenoic Acid ${ }^{*}\left[\right.$ tiab] OR Eicosapentaenoic Acid ${ }^{*}[$ tiab] OR gammaLinolenic Acid*[tiab] OR "Arachidonic Acids"[Mesh] OR "Fatty Acids, Essential"[Mesh] OR "Fatty Acids, Omega-3"[Mesh] OR "Fatty Acids, Omega-6"[Mesh] OR pufa[tiab] OR pufas[tiab] OR alpha-Linolenic Acid[tiab] OR "Fatty Acids, Essential"[Mesh] OR "Linolenic Acids"[Mesh] OR "Trans Fatty Acids"[Mesh] OR "Fatty Acids, Monounsaturated"[Mesh]

\#5 - "Vitamin B Complex"[Mesh] OR "Vitamin B Complex" [Pharmacological Action] OR "Vitamin B 12"[Mesh] OR "Vitamin B 12"[tiab] OR "Vitamin B12"[tiab] OR "Vitamin B 12 Deficiency"[Mesh] OR "vitamin b"[tiab] OR "vitamin c"[tiab] OR "Ascorbic Acid"[Mesh] OR "ascorbic acid"”ttiab] OR choline[tiab] OR "Choline"[Mesh] OR "vitamin A"[tiab] OR "vitamin E"[tiab] OR "vitamin D"[tiab] OR "vitamin K"[tiab] OR "Vitamin A"[Mesh] OR retinol[tiab] OR "Vitamin A Deficiency"[Mesh] OR "Ascorbic Acid Deficiency"[Mesh] OR "Vitamin E"[Mesh] OR "Vitamin E Deficiency"[Mesh] OR tocopherol*[tiab] OR "Vitamin D"[Mesh] OR "Vitamin D Deficiency"[Mesh] OR "Cholecalciferol"[Mesh] OR cholecalciferol*[tiab] OR "Ergocalciferols"[Mesh] OR ergocalciferol*[tiab] OR "Vitamin K"[Mesh] OR "Vitamin K Deficiency"[Mesh] OR "lodine"[Mesh] OR iodine*[tiab] OR "Selenium"[Mesh] OR selenium[tiab] OR "Oligosaccharides"[Mesh] OR oligosaccharide*[tiab] OR (milk[tiab] AND (amount[tiab] OR quantity[tiab] OR quality[tiab]))

\#6 - \#1 AND \#2

\#7 - \#3 OR \#4 OR \#5

\#8 - \#6 AND \#7

\#9 - \#8 NOT (("Animals"[Mesh] NOT ("Animals"[Mesh] AND "Humans"[Mesh])) NOT (editorial[ptyp] OR comment[ptyp] OR news[ptyp] OR letter[ptyp] OR review[ptyp] OR systematic review[ptyp] OR systematic review[ti] OR meta-analysis[ptyp] OR meta-analysis[ti] OR meta-analyses[ti] OR retracted publication[ptyp] OR retraction of publication[ptyp] OR retraction of publication[tiab] OR retraction notice[ti])

Filters: Publication date from 2000/01/01 to 2019/11/13; English

\section{Cochrane Central Register of Controlled Trials (CENTRAL)}

- Provider: John Wiley \& Sons

- Date(s) Searched: November 14, 2019

- Date range searched: January 1, 2000 - November 14, 2019

- Search Terms:

\#1 - [mh Lactation] OR lactation OR lactating OR [mh "breast feeding"] OR breastfeeding OR "breast feed" OR "breast feeds" OR breast-feed OR breast-feeds OR breastfed OR breast-fed 
\#2 - ("dietary pattern*" OR "diet pattern*" OR "eating pattern*" OR "food pattern*" OR "diet quality" OR "eating habit*" OR "dietary habit*" OR "diet habit*" OR "food habit*" OR [mh "Feeding Behavior"] OR "feeding behavior" OR "beverage consumption" OR "beverage habit" OR "beverage intake*" OR "dietary profile*" OR "food profile" OR "diet profile*" OR "eating profile*" OR "dietary guideline*" OR "dietary recommendation*" OR "dietary intake" OR "food intake" OR "food consumption"):ti,ab OR "dietary consumption" OR "eating frequenc" OR "food frequenc*" OR "eating style*" OR "dietary change*" OR "dietary choice*" OR "food choice*" OR [mh "Diet, Mediterranean"] OR "Mediterranean Diet*" OR [mh "Dietary

Approaches To Stop Hypertension"] OR "Dietary Approaches To Stop Hypertension Diet*" OR "DASH diet"” OR [mh "Diet, Gluten-Free"] OR "Gluten Free diet*" OR "prudent diet" OR [mh "Diet, Paleolithic"] OR "Paleolithic Diet*" OR [mh "Diet, Vegetarian"] OR "vegetarian diet*" OR "vegan diet"” OR [mh "Diet, Healthy"] OR "plant based diet"” OR [mh "Diet, Western"] OR "western diet*" OR [mh "Diet, Carbohydrate-Restricted"] OR "low carbohydrate diet*" OR "high carbohydrate diet*" OR "Ketogenic Diet*" OR "Nordic Diet"” OR [mh "Diet, Fat-

Restricted"] OR [mh "Diet, High-Fat"] OR [mh "Diet, High-Protein"] OR "high protein diet*" OR "high fat diet*" OR "low fat diet*" OR [mh "Diet, Protein-Restricted"] OR "low protein diet*" OR [mh "Diet, Sodium-Restricted"] OR "low sodium diet" OR "low salt diet*" OR (([mh "Dietary Proteins"] OR "dietary protein*" OR [mh "Dietary Carbohydrates"] OR "dietary carbohydrate*" OR [mh "Dietary Fats"] OR "dietary fat*" OR hypocaloric OR hypo-caloric) NEAR (diet OR diets OR consumption OR intake OR supplement*)) OR ("guideline adherence") NEAR (diet OR dietary OR food OR beverage)) OR ("diet score" OR "diet scores" OR "diet quality score" OR "diet quality scores" OR "diet quality index" OR "dietary habits score" OR kidmed OR "diet index" OR "dietary index" OR "Food-based Index" OR "diet quality index" OR "food index" OR "food score" OR "food scores" OR "Mediterranean diet score" OR MedDietScore OR "healthy eating index" OR "food frequency questionnaire" OR "food frequency questionnaires" OR "food frequency survey" OR "food frequency surveys" OR [mh "Nutrition Surveys"] OR "nutrition survey" OR "nutrition surveys" OR "diet survey" OR "diet surveys" OR "food survey" OR "food surveys" OR "dietary questionnaire"):ti,ab,kw OR ((pattern OR patterns OR consumption OR habit*) NEAR ([mh ^ Diet] OR diet OR diets OR dietary OR [mh Food] OR food OR foods OR [mh Beverages] OR beverage OR beverages))):ti,ab,kw

\#3 - ([mh "milk, human"] OR "breast milk" OR "human milk" OR "mother's milk" OR breastmilk OR "human milk" OR "maternal milk" OR (milk NEAR/6 composition) OR [mh "nutrients"] OR macronutrient* OR [mh "vitamins"] OR vitamin* OR [mh "milk proteins"] OR "total protein" OR "total proteins" OR "milk protein*" OR lactoferrin* OR lactalbumin* OR casein* OR "whey protein*" OR "alpha 1 antitrypsin*" OR [mh osteopontin] OR osteopontin* OR [mh "IgA Deficiency"] OR [mh "Immunoglobulin A"] OR iga1 OR iga2 OR iga OR lysozyme* OR [mh muramidase]):ti, ab,kw

\#4 - ("fatty acid*" OR [mh ^"Fatty Acids"] OR [mh ^"Fatty Acids, Unsaturated"] OR "Arachidonic acid*" OR "linolenic acid*" OR "linoleic acid*" OR "Docosahexaenoic Acid*" OR "Eicosapentaenoic Acid*" OR gamma-linolenic acid* OR [mh "Arachidonic Acids"] OR [mh "Fatty Acids, Essential"] OR [mh "Fatty Acids, Omega-3"] OR [mh "Fatty Acids, Omega-6"] OR "omega- 6 fatty acid*" OR "omega-3 fatty acid*" OR "omega 6 fatty acid*" OR "omega 3 fatty acid*" OR pufa OR pufas OR "alpha-linolenic acid*" OR [mh "Fatty Acids, Essential"] OR [mh "Linolenic Acids"] OR [mh "Trans Fatty Acids"] OR [mh "Fatty Acids, 
Monounsaturated"]):ti,ab

\#5 - ([mh "vitamin b complex"] OR [mh "Vitamin B 12"] OR "Vitamin B 12" OR "Vitamin B12" OR [mh "Vitamin B 12 Deficiency"] OR "vitamin b" OR "vitamin c" OR [mh "ascorbic acid"] OR "ascorbic acid"" OR choline OR [mh choline] OR "vitamin A" OR "vitamin E" OR "vitamin D" OR "vitamin K" OR [mh "vitamin A"] OR retinol OR [mh "vitamin A deficiency"] OR [mh "ascorbic acid deficiency"] OR [mh "vitamin E"] OR [mh "vitamin E deficiency"] OR tocopheral ${ }^{\star}$ OR [mh "Vitamin D"] OR [mh "vitamin D deficiency"] OR [mh cholecalciferol] OR

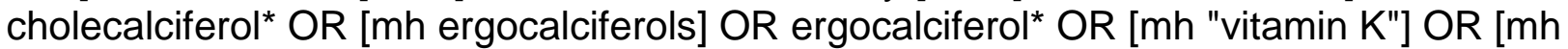
"vitamin K deficiency"] OR [mh iodine] OR iodine* OR [mh selenium] OR selenium OR [mh oligosaccharides] OR oligosaccharide* OR (milk NEAR/5 (amount OR quantity))):ti,ab

\#6 - \#1 AND \#2

\#7 - \#3 OR \#4 OR \#5

\#8 - \#6 AND \#7

Filters: Publication Year from 2000 - 2019, Trials

\section{Embase}

- Provider: Elsevier

- Date(s) Searched: November 13, 2019

- Date range searched: January 1, 2000 - November 13, 2019

- Search Terms:

\#1 - ('breast feeding'/exp OR 'lactation'/exp OR lactation:ti,ab OR lactating:ti,ab OR breastfeeding:ti,ab OR 'breast feed':ti,ab OR breastfed:ti,ab OR 'breast fed':ti,ab OR breastfeed*:ti,ab OR 'nursing women':ti,ab OR 'nursing mother':ti,ab)

\#2 - 'feeding behavior'/exp OR 'mediterranean diet'/de OR 'dash diet'/de OR 'gluten free diet'/exp OR 'paleolithic diet'/de OR 'vegetarian diet'/exp OR 'healthy diet'/de OR 'western diet'/de OR 'low carbohydrate diet'/exp OR 'low fat diet'/de OR 'lipid diet'/exp OR 'protein diet'/exp OR 'protein restriction'/de OR 'sodium restriction'/de OR 'dietary pattern*':ab,ti OR 'diet pattern"':ab,ti OR 'eating pattern': ab,ti OR 'food pattern': ab,ti OR 'diet quality':ab,ti OR 'eating habit'':ab,ti OR 'dietary habit': ab,ti OR 'diet habit"':ab,ti OR 'food habit"':ab,ti OR 'feeding behavior*':ab,ti OR 'beverage consumption':ab,ti OR 'beverage habit': ab,ti OR 'beverage intake ${ }^{\star \prime}: a b, t i$ OR 'dietary profile ${ }^{\star \prime}: a b, t i$ OR 'food profile':ab,ti OR 'diet profile*':ab,ti OR 'eating profile*':ab,ti OR 'dietary guideline ${ }^{* \prime}: a b, t i$ OR 'dietary recommendation':ab,ti OR 'dietary intake':ab,ti OR 'food intake':ab,ti OR 'food consumption':ab,ti OR 'dietary consumption':ab,ti OR 'eating frequenc ${ }^{*}: a b, t i$ OR 'food frequenc ${ }^{\star \prime}: a b$, ti OR 'eating style ${ }^{* \prime}: a b, t i$ OR 'dietary change ${ }^{\star \prime}: a b, t i$ OR 'dietary choice ${ }^{* \prime}: a b, t i$ OR 'food choice ${ }^{\star \prime}: a b, t i$ OR 'mediterranean $\operatorname{diet}^{\star \prime}: a b, t i$ OR 'dietary approaches to stop hypertension diet $^{\star \prime}: a b, t i$ OR 'dash diet $^{\star \prime}: a b, t i$ OR 'gluten free diet' $: a b, t i$ OR 'prudent diet ${ }^{\star \prime}: a b, t i$ OR 'paleolithic diet*':ab,ti OR 'vegetarian

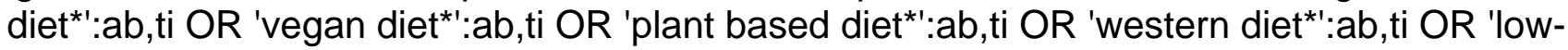
carbohydrate diet $^{\star^{\prime}}: a b$,ti OR 'high carbohydrate diet $^{*^{\prime}}: a b$, ti OR 'ketogenic diet $^{* \prime}: a b, t i$ OR 'nordic

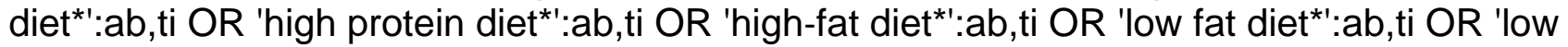


protein diet"':ab,ti OR 'low-sodium diet"':ab,ti OR 'low salt diet' $:$ ab,ti OR ((('dietary protein ${ }^{* \prime}$ OR 'dietary carbohydrate*' OR 'dietary fat*' OR hypocaloric OR 'hypo caloric') NEAR/6 (diet OR diets OR consumption OR intake OR supplement $\left.{ }^{*}\right)$ ):ab,ti) OR (('guideline adherence' NEAR/6 (diet OR dietary OR food OR beverage)):ab,ti) OR 'diet score ${ }^{\star \prime}: a b, t i$ OR 'diet quality score $^{* 1}: a b, t i$ OR 'dietary habits score*':ab,ti OR kidmed:ab,ti OR 'diet index*':ab,ti OR 'dietary index*':ab,ti OR 'food-based index*':ab,ti OR 'diet quality index':ab,ti OR 'food index"':ab,ti OR 'food score ${ }^{* \prime}: a b, t i$ OR 'mediterranean diet score ${ }^{*}: a b, t i$ OR meddietscore:ab,ti OR 'healthy eating index':ab,ti OR 'food frequency questionnaire ${ }^{* 1}: a b, t i$ OR 'food frequency survey"':ab,ti OR 'nutrition survey*':ab,ti OR 'diet survey*':ab,ti OR 'food survey*':ab,ti OR 'dietary questionnaire':ab,ti OR (((pattern OR patterns OR consumption OR habit*) NEAR/6 (diet OR diets OR dietary OR food OR foods OR beverage OR beverages)):ab,ti)

\#3 - ('breast milk'/exp OR 'breast milk':ti,ab OR 'human milk':ti,ab OR 'mothers milk':ti,ab OR breastmilk:ti,ab OR 'maternal milk':ti,ab) OR (milk NEAR/5 composition) OR 'nutrient'/exp OR macronutrient*:ti,ab OR 'vitamin'/exp OR vitamin*:ti,ab OR 'milk protein'/exp OR total) AND protein*:ti,ab OR 'milk protein*':ti,ab OR 'milk protein'/exp OR 'lactoferrin'/exp OR lactoferrin*:ti,ab OR 'lactalbumin'/exp OR lactalbumin:ti,ab OR casein*:ti,ab OR 'whey protein*':ti,ab OR 'alpha 1 antitrypsin"':ti, ab OR 'alpha 1 antitrypsin'/exp OR 'alpha 1 antitrypsin deficiency'/exp OR 'osteopontin'/exp OR osteopontin*:ti,ab OR iga:ti,ab OR 'iga 1':ti,ab OR 'iga 2':ti,ab OR lysozyme*:ti,ab OR 'immunoglobulin a deficiency'/exp OR 'immunoglobulin a'/exp OR 'immunoglobulin a':ti,ab OR 'lysozyme'/exp

\#4 - 'fatty acid"':ti,ab OR 'fatty acid'/de OR 'unsaturated fatty acid'/de OR 'arachidonic acid'/exp OR 'arachidonic acid"':ti,ab OR 'linolenic acid':ti, ab OR 'linoleic acid*':ti,ab OR 'docosahexaenoic acid ${ }^{\star \prime}:$ ti, ab OR 'eicosapentaenoic acid*':ti,ab OR 'gamma linolenic acid"':ti,ab OR 'omega 3 fatty acid'/exp OR 'omega 3 fatty acid"'ti,ab OR 'omega-6 fatty acid'/exp OR 'omega 6 fatty acid': ti, ab OR pufa:ti,ab OR pufas:ti,ab OR 'alpha linolenic $a c^{*}{ }^{*}:$ ti,ab OR 'monounsaturated fatty acid'/exp OR 'essential fatty acid'/exp OR 'linolenic acid'/exp OR 'trans fatty acid'/exp OR 'trans fatty acid"':ti,ab OR 'essential fatty acid' $:$ ti,ab OR 'monounsaturated fatty acid $^{*}:$ ti, ab

\#5 - 'vitamin b 12':ti,ab OR 'vitamin b12':ti,ab OR 'vitamin b':ti,ab OR 'vitamin c':ti,ab OR 'ascorbic acid"':ti,ab OR choline:ti,ab OR 'vitamin a':ti,ab OR 'vitamin e':ti,ab OR 'vitamin d':ti,ab OR 'vitamin k':ti,ab OR retinol:ti,ab OR tocopherol*:ti,ab OR cholecalciferol*:ti,ab OR ergocalciferol*:ti,ab OR iodine*:ti,ab OR selenium:ti,ab OR oligosaccharide*:ti,ab OR (milk NEAR/5 (amount OR quantity OR quality)) OR 'vitamin b complex'/exp OR 'cyanocobalamin'/exp OR 'b12 deficiency'/exp OR 'ascorbic acid'/exp OR 'choline'/exp OR 'retinol'/exp OR 'retinol deficiency'/exp OR 'ascorbic acid deficiency'/exp OR 'alpha tocopherol'/exp OR 'alpha tocopherol deficiency'/exp OR 'vitamin d'/exp OR 'vitamin d deficiency'/exp OR 'colecalciferol'/exp OR 'ergocalciferol'/exp OR 'vitamin k group'/exp OR 'iodine'/exp OR 'selenium'/exp OR 'oligosaccharide'/exp

\#6 - \#1 AND \#2

\#7 - \#3 OR \#4 OR \#5

\#8 - \#6 AND \#7 
\#9 - \#8 AND ([article]/lim OR [article in press]/lim) AND [humans]/lim AND [english]/lim AND [2000-2019]/py NOT ([conference abstract]/lim OR [conference paper]/lim OR [editorial]/lim OR [erratum]/lim OR [letter]/lim OR [note]/lim OR [review]/lim OR [systematic review]/lim OR [meta analysis]/lim)

\section{Cumulative Index of Nursing and Allied Health Literature (CINAHL Plus)}

- Provider: EBSCOhost

- Date(s) Searched: November 14, 2019

- Date range searched: January 1, 2000 - November 14, 2019

- Search Terms:

\#1 - MH "Breast Feeding" OR breastfeeding OR breast-feeding OR MH Lactation OR lactation OR lactating OR breastfeeding OR "breast feed*" OR breast-feed" OR breastfed OR breastfed OR breastfeed* OR "nursing women" OR "nursing mother"

\#2 - "dietary pattern*" OR "diet pattern" OR "eating pattern*" OR "food pattern" OR "diet quality" OR "eating habit" OR "dietary habit*" OR "diet habit"” OR "food habit" OR MH "Eating Behavior+" OR "feeding behavior" OR "beverage consumption" OR "beverage habit" OR "beverage intake" OR "dietary profile*" OR "food profile*" OR "diet profile*" OR "eating profile" OR "dietary guideline *" OR "dietary recommendation*" OR "dietary intake*" OR "food intake" " OR "food consumption" OR "dietary consumption" OR "eating frequenc" OR "food frequenc" OR "eating style*" OR "dietary change *" OR "dietary choice*" OR "food choice*" OR MH "Diet, Mediterranean" OR "Mediterranean Diet*" OR MH "Dietary Approaches To Stop Hypertension" OR "Dietary Approaches To Stop Hypertension Diet"” OR "DASH diet" OR MH "Diet, Gluten-Free" OR "Gluten Free diet" OR "prudent diet" OR MH "Diet, Paleolithic" OR "Paleolithic Diet" OR MH "Diet, Vegetarian" OR "vegetarian diet" OR "vegan diet" $^{*}$ OR MH "Healthy Diet" OR "plant based diet*" OR MH "Diet, Western" OR "western diet"” OR MH "Diet, Carbohydrate-Restricted" OR "low-carbohydrate diet"” OR "high carbohydrate diet"” OR "Ketogenic Diet" OR "Nordic Diet"” OR MH "Diet, Fat-Restricted" OR MH "Diet, High-Fat" OR MH "Diet, High-Protein" OR "high protein diet"” OR "high-fat diet"” OR "low fat diet"” OR MH "Diet, Protein-Restricted" OR "low protein diet" OR MH "Diet, Sodium-Restricted" OR "low-sodium diet*" OR "low salt diet*" OR ((MH "Dietary Proteins" OR "dietary protein*" OR MH "Dietary Carbohydrates" OR "dietary carbohydrate*" OR MH "Dietary Fats" OR "dietary fat"” OR hypocaloric OR hypo-caloric) AND (diet OR diets OR consumption OR intake OR supplementation)) OR (MH "Guideline Adherence" AND (diet OR dietary OR food OR beverage)) OR ("diet score*" OR "diet quality score*" OR "diet quality index" OR "dietary habits score*" OR kidmed OR "diet index" OR "dietary index" OR "Food-based Index" OR "diet quality index" OR "food index" OR "food score*" OR "Mediterranean diet score*" OR MedDietScore OR "healthy eating index" OR "food frequency questionnaire*" OR "food frequency survey*" OR MH "Nutrition Surveys" OR "nutrition survey" OR "diet survey" OR "food survey" OR "dietary questionnaire*") OR ((pattern OR patterns OR consumption OR habit*) AND (MH "Diet" OR diet OR diets OR dietary OR MH "Food" OR food OR foods OR MH "Beverages" OR beverage OR beverages))

\#3 - MH "Milk, Human" OR "breast milk" OR breast-milk OR "human milk" OR "mother's milk" OR "mothers milk" OR "human milk composition" OR (milk n5 composition) OR (MH "Nutrients") OR "macronutrients" OR (MH "Vitamins") OR "vitamin*” OR (MH "milk proteins") OR "total protein" OR "milk protein*” OR lactoferrin* OR lactalbumin* OR casein* OR "whey 
protein*" OR "alpha 1-antitrypsin"” OR osteopontin* OR iga OR "iga 1" OR "iga 2" OR "immunoglobulin a" OR lysozyme* OR muramidase*

\#4 - (MH "Fatty Acids") OR "fatty acid"" OR (MH "Fatty Acids, Omega-6+") OR (MH "Fatty Acids, Omega-3+") OR (MH "Fatty Acids, Unsaturated+") OR (MH "Fatty Acids, Monounsaturated+") OR (MH "Trans Fatty Acids+") OR (MH "Fatty Acids, Essential+") OR "fatty acids" OR "arachidonic acid"” OR "linolenic acid" OR "linoleic acid" OR "linoleic acids" OR "docosahexaenoic acid" OR "Eicosapentaenoic Acid"” OR "gamma-Linolenic Acid" OR (MH "Arachidonic Acids+") OR (MH "Ascorbic Acid Deficiency+") OR pufa OR pufas OR "alpha-linolenic acid"” OR (MH "alpha-Linolenic Acid") OR (MH "Linolenic Acids+")

\#5 - (MH "Vitamins") OR (MH "Vitamin B6 Deficiency") OR (MH "Vitamin B Deficiency") OR (MH "Vitamin B12 Deficiency") OR (MH "Vitamin D Deficiency") OR (MH "Vitamin A Deficiency") OR (MH "Vitamin K Deficiency") OR (MH "Vitamin E Deficiency") OR (MH "Riboflavin Deficiency") OR (MH "Ascorbic Acid Deficiency") OR (MH "Vitamin K") OR (MH "Vitamin B Complex") OR (MH "Vitamin B12") OR (MH "Vitamin A") OR (MH "Ascorbic Acid") OR (MH "Vitamin D") OR (MH "Vitamin E") OR (MH "Vitamin K") OR (MH "Cholecalciferol") OR (MH "Ergocalciferols") OR (MH "lodine") OR (MH "lodine Deficiency") OR (MH "Selenium") OR (MH "Oligosaccharides") OR "Vitamin B Complex" OR "vitamin b12" OR "vitamin b 12" OR "vitamin b" OR "vitamin c" OR "vitamin d" OR "ascorbic acid" OR choline OR "vitamin a" OR "vitamin e" OR "vitamin d" OR "vitamin k" OR retinol* OR tocopherol* OR cholecalciferol $^{*}$ OR ergocalciferol ${ }^{\star}$ OR ergocalciferol* OR iodine OR selenium OR oligosaccharide* OR (milk N5 (amount OR quantity OR quality))

\#6 - \#1 AND \#2

\#7 - \#3 OR \#4 OR \#5

\#8 - \#6 AND \#7

\#9 - \#8 NOT (MH "Literature Review" OR MH "Meta Analysis" OR MH "Systematic Review" OR MH "News" OR MH "Retracted Publication" OR MH "Retraction of Publication )

Filters: Published Date: 20000101 - 20191114, English Language; Human

\section{LITERATURE SEARCH AND SCREENING RESULTS}

The flow chart (Figure 2) below illustrates the literature search and screening results for articles examining the systematic review question. After the initial electronic database search (January 2000-July 2019), an updated search was conducted to also capture macronutrient distribution articles (January 2000-November 2019). The results of both electronic database searches, after removal of duplicates, were screened independently by two NESR analysts using a step-wise process by reviewing titles, abstracts, and full-texts to determine which articles met the inclusion criteria for the systematic review question depicted. Refer to Table 8 for the rationale for exclusion for each excluded full-text article. A manual search was done to find articles that were not identified when searching the electronic databases; all manually identified articles are also screened to determine whether they meet criteria for inclusion. 
Figure 2. Flow chart of literature search and screening results

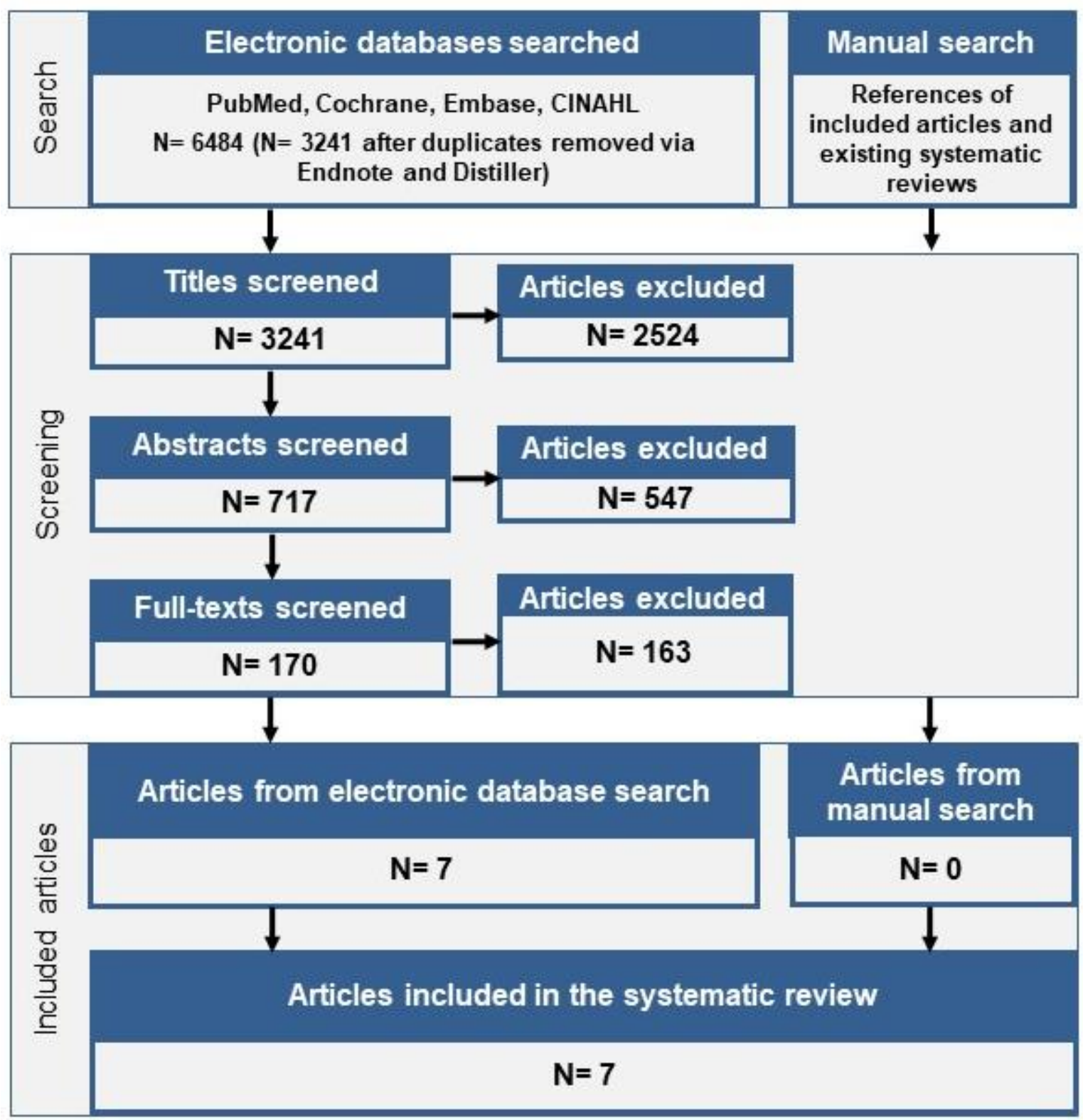




\section{Excluded articles}

The table below lists the articles excluded after full-text screening, and includes rationale for the categories of inclusion and exclusion criteria (see Table 7) that studies were excluded based on. At least one reason for exclusion is provided for each article, though this may not reflect all possible reasons for exclusion. Information about articles excluded after title and abstract screening is available upon request.

\section{Table 8. Articles excluded after full text screening with rationale for exclusion}

\begin{tabular}{|c|c|c|}
\hline & Citation & Rationale \\
\hline 1. & $\begin{array}{l}\text { Agostoni, C, Marangoni, F, Grandi, F, Lammardo, AM, Giovannini, M, Riva, E, Galli, C. Earlier } \\
\text { smoking habits are associated with higher serum lipids and lower milk fat and polyunsaturated fatty } \\
\text { acid content in the first } 6 \text { months of lactation. European Journal of Clinical Nutrition. 2003. 57:1466- } \\
\text { 1472. doi:10.1038/sj.ejcn.1601711. }\end{array}$ & Comparator \\
\hline 2. & $\begin{array}{l}\text { Alberti-Fidanza, A, Burini, G, Perriello, G. Total antioxidant capacity of colostrum, and transitional and } \\
\text { mature human milk. J Matern Fetal Neonatal Med. 2002. 11:275-9. doi:10.1080/jmf.11.4.275.279. }\end{array}$ & Intervention/Exposure \\
\hline 3. & $\begin{array}{l}\text { Ali, MA, Strandvik, B, Palme-Kilander, C, Yngve, A. Lower polyamine levels in breast milk of obese } \\
\text { mothers compared to mothers with normal body weight. J Hum Nutr Diet. } 2013.26 \text { Suppl 1:164-70. } \\
\text { doi:10.1111/jhn.12097. }\end{array}$ & Intervention/Exposure \\
\hline 4. & $\begin{array}{l}\text { Alien, CM, Smith, AM, Clinton, SK, Schwartz, SJ. Tomato consumption increases lycopene isomer } \\
\text { concentrations in breast milk and plasma of lactating women. J Am Diet Assoc. 2002. 102:1257-62. } \\
\text { doi:10.1016/s0002-8223(02)90278-6. }\end{array}$ & Intervention/Exposure \\
\hline 5. & $\begin{array}{l}\text { Andersen, SL. lodine status in pregnant and breastfeeding women: a Danish regional investigation. } \\
\text { Dan Med J. 2015. } 62 .\end{array}$ & Study Design; Intervention/Exposure \\
\hline 6. & $\begin{array}{l}\text { Anderson, NK, Beerman, KA, McGuire, MA, Dasgupta, N, Griinari, JM, Williams, J, McGuire, MK. } \\
\text { Dietary fat type influences total milk fat content in lean women. J Nutr. 2005. 135:416-21. } \\
\text { doi:10.1093/jn/135.3.416. }\end{array}$ & Comparator \\
\hline 7. & $\begin{array}{l}\text { Antonakou, A, Chiou, A, Andrikopoulos, NK, Bakoula, C, Matalas, AL. Breast milk tocopherol content } \\
\text { during the first six months in exclusively breastfeeding Greek women. Eur J Nutr. 2011. 50:195-202. } \\
\text { doi:10.1007/s00394-010-0129-4. }\end{array}$ & Intervention/Exposure \\
\hline 8. & $\begin{array}{l}\text { Antonakou, A, Skenderi, KP, Chiou, A, Anastasiou, CA, Bakoula, C, Matalas, AL. Breast milk fat } \\
\text { concentration and fatty acid pattern during the first six months in exclusively breastfeeding Greek } \\
\text { women. Eur J Nutr. 2013. 52:963-73. doi:10.1007/s00394-012-0403-8. }\end{array}$ & Intervention/Exposure; Comparator \\
\hline 9. & $\begin{array}{l}\text { Arora, M, Ettinger, AS, Peterson, KE, Schwartz, J, Hu, H, Hernández-Avila, M, Tellez-Rojo, MM, } \\
\text { Wright, RO. Maternal dietary intake of polyunsaturated fatty acids modifies the relationship between } \\
\text { lead levels in bone and breast milk. Journal of Nutrition. } 2008.138: 73-79 \text {. }\end{array}$ & Intervention/Exposure \\
\hline
\end{tabular}




\section{Citation}

10. Aumeistere, L, Ciprovica, I, Zavadska, D, Andersons, J, Volkovs, V, Celmalniece, K. Impact of Maternal Diet on Human Milk Composition Among Lactating Women in Latvia. Medicina (Kaunas). 2019. 55. doi:10.3390/medicina55050173

11. Aumeistere, L, Ciproviča, I, Zavadska, D, Volkovs, V. Fish intake reflects on DHA level in breast milk among lactating women in Latvia. International Breastfeeding Journal. 2018. 13:N.PAG-N.PAG. doi:10.1186/s13006-018-0175-8.

12. Azad, MB, Robertson, B, Atakora, F, Becker, AB, Subbarao, P, Moraes, TJ, Mandhane, PJ, Turvey, SE, Lefebvre, DL, Sears, MR, Bode, L. Human Milk Oligosaccharide Concentrations Are Associated with Multiple Fixed and Modifiable Maternal Characteristics, Environmental Factors, and Feeding Practices. J Nutr. 2018. 148:1733-1742. doi:10.1093/jn/nxy175.

13. Baatenburg de Jong, R, Bekhof, J, Roorda, R, Zwart, $P$. Severe nutritional vitamin deficiency in a breast-fed infant of a vegan mother. Eur J Pediatr. 2005. 164:259-60. doi:10.1007/s00431-004-16138.

14. Baheiraei, A, Shamsi, A, Khaghani, S, Shams, S, Chamari, M, Boushehri, H, Khedri, A. The effects of Intervention/Exposure maternal passive smoking on maternal milk lipid. Acta Med Iran. 2014. 52:280-5.

15. Barrera, C, Valenzuela, R, Chamorro, R, Bascunan, K, Sandoval, J, Sabag, N, Valenzuela, F, Valencia, MP, Puigrredon, C, Valenzuela, A. The Impact of Maternal Diet during Pregnancy and Lactation on the Fatty Acid Composition of Erythrocytes and Breast Milk of Chilean Women. Nutrients. 2018. 10. doi:10.3390/nu10070839.

16. Bascunan, KA, Valenzuela, R, Chamorro, R, Valencia, A, Barrera, C, Puigrredon, C, Sandoval, J, Valenzuela, A. Polyunsaturated fatty acid composition of maternal diet and erythrocyte phospholipid status in Chilean pregnant women. Nutrients. 2014. 6:4918-34. doi:10.3390/nu6114918.

17. Bertschi, I, Collomb, M, Rist, L, Eberhard, P, Sieber, R, Bütikofer, U, Wechsler, D, Folkers, G, von Mandach, U. Maternal dietary Alpine butter intake affects human milk: fatty acids and conjugated linoleic acid isomers. Lipids. 2005. 40:581-587.

18. Bobiński, R, Mikulska, M, Mojska, H, Ulman-Włodarz, I, Sodowska, P. Pregnant women's diet composition and transitional milk fatty acids: factor analysis. Ginekologia polska. 2015. 86:113-118.

19. Bode, L. Human Milk Oligosaccharides at the Interface of Maternal-Infant Health. Breastfeed Med. 2018. 13:S7-s8. doi:10.1089/bfm.2018.29073.ljb.

20. Boniglia, C, Carratu, B, Chiarotti, F, Giammarioli, S, Sanzini, E. Influence of maternal protein intake on nitrogen fractions of human milk. Int J Vitam Nutr Res. 2003. 73:447-52. doi:10.1024/03009831.73.6.447

\section{Rationale}

Intervention/Exposure

Intervention/Exposure

Population

Study Design

Intervention/Exposure

Intervention/Exposure; Outcome

Intervention/Exposure

Intervention/Exposure; Outcome

Study Design

Intervention/Exposure 


\section{Citation}

21. Bopp, M, Lovelady, C, Hunter, C, Kinsella, T. Maternal diet and exercise: effects on long-chain polyunsaturated fatty acid concentrations in breast milk. J Am Diet Assoc. 2005. 105:1098-103. doi:10.1016/j.jada.2005.04.004.

22. Buntuchai, G, Pavadhgul, P, Kittipichai, W, Satheannoppakao, W. Traditional Galactagogue Foods and Their Connection to Human Milk Volume in Thai Breastfeeding Mothers. J Hum Lact. 2017. 33:552-559. doi:10.1177/0890334417709432.

23. Burtseva, T, Solodkova, I, Savvina, M, Dranaeva, G, Shadrin, V, Avrusin, S, Sinelnikova, E, Chasnyk, $V$. Dietary intakes of energy and macronutrients by lactating women of different ethnic groups living in Yakutia. Int J Circumpolar Health. 2013. 72. doi:10.3402/ijch.v72i0.21519.

24. Butts, CA, Hedderley, DI, Herath, TD, Paturi, G, Glyn-Jones, S, Wiens, F, Stahl, B, Gopal, P. Human Milk Composition and Dietary Intakes of Breastfeeding Women of Different Ethnicity from the Manawatu-Wanganui Region of New Zealand. Nutrients. 2018. 10. doi:10.3390/nu10091231.

25. Bzikowska-Jura, A, Czerwonogrodzka-Senczyna, A, Jasinska-Melon, E, Mojska, H, Oledzka, G, Wesolowska, A, Szostak-Wegierek, D. The Concentration of Omega-3 Fatty Acids in Human Milk Is Related to Their Habitual but Not Current Intake. Nutrients. 2019. 11. doi:10.3390/nu11071585.

26. Bzikowska-Jura, A, Czerwonogrodzka-Senczyna, A, Oledzka, G, Szostak-Wegierek, D, Weker, H, Wesolowska, A. Maternal Nutrition and Body Composition During Breastfeeding: Association with Human Milk Composition. Nutrients. 2018. 10. doi:10.3390/nu10101379.

27. Cai, X, Duan, Y, Li, Y, Wang, J, Mao, Y, Yang, Z, Zhao, X, Zhao, Y, Guan, Y, Yin, S. Lactoferrin level in breast milk: a study of 248 samples from eight regions in China. Food Funct. 2018. 9:4216-4222. doi:10.1039/c7fo01559c.

28. Canfield, LM, Clandinin, MT, Davies, DP, Fernandez, MC, Jackson, J, Hawkes, J, Goldman, WJ Pramuk, K, Reyes, H, Sablan, B, Sonobe, T, Bo, X. Multinational study of major breast milk carotenoids of healthy mothers. Eur J Nutr. 2003. 42:133-41. doi:10.1007/s00394-003-0403-9.

29. Chapman, DJ, Nommsen-Rivers, L. Impact of maternal nutritional status on human milk quality and infant outcomes: an update on key nutrients. Adv Nutr. 2012. 3:351-2. doi:10.3945/an.111.001123.

30. Chen, GW, Ding, WH, Ku, HY, Chao, HR, Chen, HY, Huang, MC, Wang, SL. Alkylphenols in human milk and their relations to dietary habits in central Taiwan. Food Chem Toxicol. 2010. 48:1939-44. doi:10.1016/j.fct.2010.04.038.

31. Choi, YK, Kim, JM, Lee, JE, Cho, MS, Kang, BS, Choi, H, Kim, Y. Association of Maternal Diet With Zinc, Copper, and Iron Concentrations in Transitional Human Milk Produced by Korean Mothers. Clin Nutr Res. 2016. 5:15-25. doi:10.7762/cnr.2016.5.1.15.

32. Clemens, K, Silvia, R. Physiology of oligosaccharides in lactating women and breast fed infants. Adv Exp Med Biol. 2000. 478:241-50. doi:10.1007/0-306-46830-1_22.

\section{Rationale}

Intervention/Exposure

Intervention/Exposure

Intervention/Exposure

Intervention/Exposure

Intervention/Exposure

Intervention/Exposure

Intervention/Exposure

Intervention/Exposure

\section{Study Design}

Intervention/Exposure; Outcome

Intervention/Exposure

Intervention/Exposure; Publication Status 


\section{Citation}

33. Da Cunha, J, Macedo Da Costa, TH, Ito, MK. Influences of maternal dietary intake and suckling on breast milk lipid and fatty acid composition in low-income women from Brasilia, Brazil. Early Human Development. 2005. 81:303-311. doi:10.1016/j.earlhumdev.2004.08.004.

34. da Silva Ribeiro, KD, de Araujo, KF, de Souza, HH, Soares, FB, da Costa Pereira, M, Dimenstein, R. Nutritional vitamin A status in northeast Brazilian lactating mothers. J Hum Nutr Diet. 2010. 23:15461. doi:10.1111/j.1365-277X.2009.01026.x.

35. da Silva, AGCL, de Sousa Reboucas, A, Mendonca, BMA, Silva, DCNE, Dimenstein, R, Ribeiro, KDDS. Relationship between the dietary intake, serum, and breast milk concentrations of vitamin $A$ and vitamin E in a cohort of women over the course of lactation. Matern Child Nutr. 2019. 15:e12772. doi:10.1111/mcn.12772.

36. Daud, AZ, Mohd-Esa, N, Azlan, A, Chan, YM. The trans fatty acid content in human milk and its association with maternal diet among lactating mothers in Malaysia. Asia Pac J Clin Nutr. 2013. 22:431-42. doi:10.6133/apjcn.2013.22.3.09.

37. de Sousa Reboucas, A, Costa Lemos da Silva, AG, Freitas de Oliveira, A, Thalia Pereira da Silva, L, de Freitas Felgueiras, V, Cruz, MS, Silbiger, VN, da Silva Ribeiro, KD, Dimenstein, R. Factors Associated with Increased Alpha-Tocopherol Content in Milk in Response to Maternal Supplementation with 800 IU of Vitamin E. Nutrients. 2019. 11. doi:10.3390/nu11040900.

38. Del Prado, M, Villalpando, S, Elizondo, A, Rodriguez, M, Demmelmair, H, Koletzko, B. Contribution of dietary and newly formed arachidonic acid to human milk lipids in women eating a low-fat diet. Am J Clin Nutr. 2001. 74:242-7. doi:10.1093/ajcn/74.2.242.

39. Del Prado, M, Villalpando, S, Lance, A, Alfonso, E, Demmelmair, H, Koletzko, B. Contribution of dietary and newly formed arachidonic acid to milk secretion in women on low fat diets. Adv Exp Med Biol. 2000. 478:407-8. doi:10.1007/0-306-46830-1_50.

40. Deng, J, Li, X, Ding, Z, Wu, Y, Chen, $X, X i e, L$. Effect of DHA supplements during pregnancy on the concentration of PUFA in breast milk of Chinese lactating mothers. Journal of Perinatal Medicine. 2017. 45:437-441. doi:10.1515/jpm-2015-0438.

41. Denic, M, Sunaric, S, Gencic, M, Zivkovic, J, Jovanovic, T, Kocic, G, Jonovic, M. Maternal age has more pronounced effect on breast milk retinol and beta-carotene content than maternal dietary pattern. Nutrition. 2019. 65:120-125. doi:10.1016/j.nut.2019.02.019.

42. Ding, M, Li, W, Zhang, Y, Wang, X, Zhao, A, Zhao, X, Wang, P, Sheng, QH. Amino acid composition of lactating mothers' milk and confinement diet in rural North China. Asia Pac J Clin Nutr. 2010. 19:344-9.

\section{Rationale}

Intervention/Exposure

Intervention/Exposure

Intervention/Exposure

Intervention/Exposure

Intervention/Exposure

Intervention/Exposure

Intervention/Exposure; Publication Status

Intervention/Exposure

Intervention/Exposure

Intervention/Exposure; Comparator 


\section{Citation}

43. Dingess, KA, Valentine, CJ, Ollberding, NJ, Davidson, BS, Woo, JG, Summer, S, Peng, YM, Guerrero, ML, Ruiz-Palacios, GM, Ran-Ressler, RR, McMahon, RJ, Brenna, JT, Morrow, AL.

Branched-chain fatty acid composition of human milk and the impact of maternal diet: the Global Exploration of Human Milk (GEHM) Study. Am J Clin Nutr. 2017. 105:177-184. doi:10.3945/ajen.116.132464.

44. Essa, AR, Browne, EP, Punska, EC, Perkins, K, Boudreau, E, Wiggins, H, Anderton, DL, Sibeko, L, Sturgeon, SR, Arcaro, KF. Dietary Intervention to Increase Fruit and Vegetable Consumption in Breastfeeding Women: A Pilot Randomized Trial Measuring Inflammatory Markers in Breast Milk. J Acad Nutr Diet. 2018. 118:2287-2295. doi:10.1016/j.jand.2018.06.015.

45. Fidler, N, Salobir, K, Stibilj, V. Fatty acid composition of human milk in different regions of Slovenia. Annals of Nutrition and Metabolism. 2000. 44:187-193. doi:10.1159/000046682.

46. Fischer, LM, da Costa, KA, Galanko, J, Sha, W, Stephenson, B, Vick, J, Zeisel, SH. Choline intake and genetic polymorphisms influence choline metabolite concentrations in human breast milk and plasma. Am J Clin Nutr. 2010. 92:336-46. doi:10.3945/ajcn.2010.29459.

47. Furman, L. Maternal Vitamin D Supplementation for Breastfeeding Infants: Will it Work?. Pediatrics. 2015. 136:763-4. doi:10.1542/peds.2015-2312.

48. Gao, C, Gibson, RA, McPhee, AJ, Zhou, SJ, Collins, CT, Makrides, M, Miller, J, Liu, G. Comparison of breast milk fatty acid composition from mothers of premature infants of three countries using novel dried milk spot technology. Prostaglandins Leukot Essent Fatty Acids. 2018. 139:3-8. doi:10.1016/j.plefa.2018.08.003.

49. Glew, RH, Wold, RS, Corl, B, Calvin, CD, Vanderjagt, DJ. Low Docosahexaenoic Acid in the Diet and Milk of American Indian Women in New Mexico. Journal of the American Dietetic Association. 2011. 111:744-748. doi:10.1016/j.jada.2011.02.001.

50. Granot, E, Ishay-Gigi, K, Malaach, L, Flidel-Rimon, $O$. Is there a difference in breast milk fatty acid composition of mothers of preterm and term infants?. Journal of Maternal-Fetal and Neonatal Medicine. 2016. 29:832-835. doi:10.3109/14767058.2015.1020785.

51. Guan, P, Tajimi, M, Uehara, R, Watanabe, M, Oki, I, Ojima, T, Nakamura, Y. Associations between dietary intake and breast milk dioxin levels in Tokyo, Japan. Pediatr Int. 2005. 47:560-6. doi:10.1111/j.1442-200x.2005.02121.x.

52. Hairon, N. Improving vitamin D levels in pregnancy and breastfeeding. Nurs Times. 2008. 104:27-8.

53. Hannan, MA, Faraji, B, Tanguma, J, Longoria, N, Rodriguez, RC. Maternal milk concentration of zinc, iron, selenium, and iodine and its relationship to dietary intakes. Biol Trace Elem Res. 2009. 127:615. doi:10.1007/s12011-008-8221-9.

\title{
Rationale
}

Intervention/Exposure

Intervention/Exposure

\section{Outcome}

Intervention/Exposure

Study Design

Intervention/Exposure; Population

Intervention/Exposure

Intervention/Exposure

Intervention/Exposure; Outcome

Study Design

Intervention/Exposure; Comparator

\author{
(n)
}




\section{Citation}

54. Hascoët, JM, Chauvin, M, Pierret, C, Skweres, S, Van Egroo, LD, Rougé, C, Franck, P. Impact of Maternal Nutrition and Perinatal Factors on Breast Milk Composition after Premature Delivery. Nutrients. 2019. 11:366. doi:10.3390/nu11020366.

55. Hoppu, U, Isolauri, E, Laakso, P, Matomaki, J, Laitinen, K. Probiotics and dietary counselling targeting maternal dietary fat intake modifies breast milk fatty acids and cytokines. Eur J Nutr. 2012 51:211-9. doi:10.1007/s00394-011-0209-0.

56. lacovou, M, Craig, SS, Yelland, GW, Barrett, JS, Gibson, PR, Muir, JG. Randomised clinical trial: reducing the intake of dietary FODMAPs of breastfeeding mothers is associated with a greater improvement of the symptoms of infantile colic than for a typical diet. Aliment Pharmacol Ther. 2018. 48:1061-1073. doi:10.1111/apt.15007.

57. lacovou, M, Mulcahy, EC, Truby, H, Barrett, JS, Gibson, PR, Muir, JG. Reducing the maternal dietary intake of indigestible and slowly absorbed short-chain carbohydrates is associated with improved infantile colic: a proof-of-concept study. J Hum Nutr Diet. 2018. 31:256-265. doi:10.1111/jhn.12488.

58. Iranpour, R, Kelishadi, R, Babaie, S, Khosravi-Darani, K, Farajian, S. Comparison of long chain polyunsaturated fatty acid content in human milk in preterm and term deliveries and its correlation with mothers' diet. Journal of Research in Medical Sciences. 2013. 18:1-5.

59. Jarvinen, KM. Variations in Human Milk Composition: Impact on Immune Development and Allergic Disease Susceptibility. Breastfeed Med. 2018. 13:S11-s13. doi:10.1089/bfm.2018.29075.kjs.

60. Jiang, J, Wu, K, Yu, Z, Ren, Y, Zhao, Y, Jiang, Y, Xu, X, Li, W, Jin, Y, Yuan, J, Li, D. Changes in fatty acid composition of human milk over lactation stages and relationship with dietary intake in Chinese women. Food Funct. 2016. 7:3154-62. doi:10.1039/c6fo00304d

61. Jiang, J, Xiao, H, Wu, K, Yu, Z, Ren, Y, Zhao, Y, Li, K, Li, J, Li, D. Retinol and alpha-tocopherol in human milk and their relationship with dietary intake during lactation. Food Funct. 2016. 7:1985-91. doi:10.1039/c5fo01293g.

62. Jin, Y, Coad, J, Weber, JL, Thomson, JS, Brough, L. Selenium Intake in lodine-Deficient Pregnant and Breastfeeding Women in New Zealand. Nutrients. 2019. 11. doi:10.3390/nu11010069.

63. Jirapinyo, $\mathrm{P}$, Densupsoontorn, N, Wiraboonchai, D, Vissavavejam, U, Tangtrakulvachira, T, Chungsomprasong, $\mathrm{P}$, Thamonsiri, N, Wongarn, R. Fatty acid composition in breast milk from 4 regions of Thailand. J Med Assoc Thai. 2008. 91:1833-7.

64. Johansson, S, Wold, AE, Sandberg, AS. Low breast milk levels of long-chain n-3 fatty acids in allergic Intervention/Exposure women, despite frequent fish intake. Clinical and Experimental Allergy. 2011. 41:505-515 doi:10.1111/j.1365-2222.2010.03678.x.

\section{Rationale}

Intervention/Exposure; Health Status

Intervention/Exposure

Intervention/Exposure; Outcome

Study Design; Intervention/Exposure

Intervention/Exposure

Study Design; Intervention/Exposure

Comparator

Intervention/Exposure

Intervention/Exposure

Intervention/Exposure

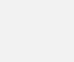




\section{Citation}

65. Jonsson, K, Barman, M, Moberg, S, Sjöberg, A, Brekke, HK, Hesselmar, B, Johansen, S, Wold, AE, Sandberg, AS. Fat intake and breast milk fatty acid composition in farming and nonfarming women and allergy development in the offspring. Pediatric Research. 2016. 79:114-123. doi:10.1038/pr.2015.187.

66. Kankaanpaa, P, Nurmela, K, Erkkila, A, Kalliomaki, M, Holmberg-Marttila, D, Salminen, S, Isolauri, E. Intervention/Exposure Polyunsaturated fatty acids in maternal diet, breast milk, and serum lipid fatty acids of infants in relation to atopy. Allergy. 2001. 56:633-8.

67. Kelishadi, R, Hadi, B, Iranpour, R, Khosravi-Darani, K, Mirmoghtadaee, P, Farajian, S, Poursafa, P. A Intervention/Exposure study on lipid content and fatty acid of breast milk and its association with mother's diet composition. Journal of Research in Medical Sciences. 2012. 17:824-827.

68. Kim, H, Kang, S, Jung, BM, Yi, H, Jung, JA, Chang, N. Breast milk fatty acid composition and fatty acid intake of lactating mothers in South Korea. Br J Nutr. 2017. 117:556-561. doi:10.1017/s0007114517000253.

69. Kim, H, Yi, H, Jung, JA, Chang, N. Association between lutein intake and lutein concentrations in human milk samples from lactating mothers in South Korea. Eur J Nutr. 2018. 57:417-421. doi:10.1007/s00394-017-1414-2.

70. Kim, YH, Kim, KW, Lee, SY, Koo, KO, Kwon, SO, Seo, JH, Suh, DI, Shin, YH, Ahn, K, Oh, SY, Lee, S, Outcome; Dissertation Sohn, MH, Hong, SJ. Maternal Perinatal Dietary Patterns Affect Food Allergy Development in Susceptible Infants. Journal of Allergy and Clinical Immunology: In Practice. 2019. doi:10.1016/j.jaip.2019.03.026.

71. Kocaadam, B, Köksal, E, Türkyllmaz, C. Are breast milk adipokines affected by maternal dietary factors?. Journal of Pediatric Endocrinology and Metabolism. 2018. 31:1099-1104. doi:10.1515/jpem2018-0196.

72. Lauritzen, L, Halkjær, LB, Mikkelsen, TB, Olsen, SF, Michaelsen, KF, Loland, L, Bisgaard, H. Fatty acid composition of human milk in atopic Danish mothers. American Journal of Clinical Nutrition. 2006. 84:190-196.

73. Lauritzen, L, Jørgensen, MH, Mikkelsen, TB, Skovgaard, IM, Straarup, EM, Olsen, SF, Høy, CE, Michaelsen, KF. Maternal fish oil supplementation in lactation: effect on visual acuity and n-3 fatty acid content of infant erythrocytes. Lipids. 2004. 39:195-206.

74. Leotsinidis, M, Alexopoulos, A, Kostopoulou-Farri, E. Toxic and essential trace elements in human milk from Greek lactating women: association with dietary habits and other factors. Chemosphere. 2005. 61:238-47. doi:10.1016/j.chemosphere.2005.01.084.

75. Li, K, Jiang, J, Xiao, H, Wu, K, Qi, C, Sun, J, Li, D. Changes in the metabolite profile of breast milk over lactation stages and their relationship with dietary intake in Chinese women: HPLC-QTOFMS based metabolomic analysis. Food Funct. 2018. 9:5189-5197. doi:10.1039/c8fo01005f.

\section{Rationale}

Intervention/Exposure

Intervention/Exposure

Intervention/Exposure

Intervention/Exposure; Outcome

Study Design; Intervention/Exposure

Intervention/Exposure

Intervention/Exposure; Outcome

Intervention/Exposure 


\section{Citation}

76. Liao, KY, Wu, TC, Huang, CF, Lin, CC, Huang, IF, Wu, L. Profile of nucleotides and nucleosides in Taiwanese human milk. Pediatr Neonatol. 2011. 52:93-7. doi:10.1016/j.pedneo.2011.02.012.

77. Lipkie, TE, Morrow, AL, Jouni, ZE, McMahon, RJ, Ferruzzi, MG. Longitudinal Survey of Carotenoids in Human Milk from Urban Cohorts in China, Mexico, and the USA. PLoS One. 2015. 10:e0127729. doi:10.1371/journal.pone.0127729.

78. Liu, G, Ding, Z, Li, X, Chen, $X, \mathrm{Wu}, \mathrm{Y}, \mathrm{Xie}, \mathrm{L}$. Relationship between polyunsaturated fatty acid levels in maternal diets and human milk in the first month post-partum. J Hum Nutr Diet. 2016. 29:405-10. doi:10.1111/jhn.12337.

79. Liu, MJ, Li, HT, Yu, LX, Xu, GS, Ge, H, Wang, LL, Zhang, YL, Zhou, YB, Li, Y, Bai, MX, Liu, JM. A Correlation Study of DHA Dietary Intake and Plasma, Erythrocyte and Breast Milk DHA

Concentrations in Lactating Women from Coastland, Lakeland, and Inland Areas of China. Nutrients. 2016. 8. doi:10.3390/nu8050312.

80. Liu, Y, Liu, X, Wang, L. The investigation of fatty acid composition of breast milk and its relationship with dietary fatty acid intake in 5 regions of China. Medicine (Baltimore). 2019. 98:e15855. doi:10.1097/md.0000000000015855.

81. Lu, M, Xiao, H, Li, K, Jiang, J, Wu, K, Li, D. Concentrations of estrogen and progesterone in breast milk and their relationship with the mother's diet. Food Funct. 2017. 8:3306-3310. doi:10.1039/c7fo00324b.

82. Lubetzky, R, Sever, O, Mimouni, FB, Mandel, D. Human Milk Macronutrients Content: Effect of Advanced Maternal Age. Breastfeed Med. 2015. 10:433-6. doi:10.1089/bfm.2015.0072.

83. Luoto, R, Laitinen, $\mathrm{K}$, Nermes, M, Isolauri, E. Impact of maternal probiotic-supplemented dietary counseling during pregnancy on colostrum adiponectin concentration: a prospective, randomized, placebo-controlled study. Early Hum Dev. 2012. 88:339-44. doi:10.1016/j.earlhumdev.2011.09.006.

84. Machado, MR, Kamp, F, Nunes, JC, El-Bacha, T, Torres, AG. Breast Milk Content of Vitamin A and E Intervention/Exposure from Early- to Mid-Lactation Is Affected by Inadequate Dietary Intake in Brazilian Adult Women. Nutrients. 2019. 11. doi:10.3390/nu11092025.

85. Mahdavi, R, Nikniaz, L, Arefhosseini, SR, Vahed Jabbari, M. Determination of aflatoxin M(1) in breast milk samples in Tabriz-Iran. Matern Child Health J. 2010. 14:141-5. doi:10.1007/s10995-008-0439-9.

86. Mahdavi, R, Taghipour, S, Ostadrahimi, A, Nikniaz, L, Hezaveh, SJ. A pilot study of synbiotic supplementation on breast milk mineral concentrations and growth of exclusively breast fed infants. Journal of trace elements in medicine and biology : organ of the Society for Minerals and Trace Elements (GMS). 2015. 30:25-29. doi:10.1016/j.jtemb.2015.01.007.

\section{Rationale}

Outcome; Missing data on dietary pattern

Intervention/Exposure

Intervention/Exposure

Intervention/Exposure

Intervention/Exposure

Intervention/Exposure; Outcome

Intervention/Exposure

Intervention/Exposure; Outcome

Intervention/Exposure

Intervention/Exposure 


\section{Citation}

87. Makela, J, Linderborg, K, Niinikoski, H, Yang, B, Lagstrom, H. Breast milk fatty acid composition differs between overweight and normal weight women: the STEPS Study. Eur J Nutr. 2013. 52:72735. doi:10.1007/s00394-012-0378-5.

88. Malek L, Makrides, M. 28 Nutrition in pregnancy and lactation. World Rev Nutr Diet. 2015.113:12733. doi:10.1159/000367872.

89. Mandel, D, Lubetzky, R, Dollberg, S, Barak, S, Mimouni, FB. Fat and energy contents of expressed human breast milk in prolonged lactation. Pediatrics. 2005. 116:e432-5. doi:10.1542/peds.2005-0313.

90. Martin, MA, Lassek, WD, Gaulin, SJ, Evans, RW, Woo, JG, Geraghty, SR, Davidson, BS, Morrow, AL, Intervention/Exposure; Country Kaplan, HS, Gurven, MD. Fatty acid composition in the mature milk of Bolivian foragerhorticulturalists: controlled comparisons with a US sample. Matern Child Nutr. 2012. 8:404-18. doi:10.1111/j.1740-8709.2012.00412.x.

91. Martysiak-Żurowska, D, Kiełbratowska, B, Szlagatys-Sidorkiewicz, A. The content of conjugated linoleic acid and vaccenic acid in the breast milk of women from Gdansk and the surrounding district, as well as in, infant formulas and follow-up formulas. nutritional recommendation for nursing women. Developmental period medicine. 2018. 22:128-134.

92. Martysiak-Zurowska, D, Szlagatys-Sidorkiewicz, A, Zagierski, M. Concentrations of alpha- and gamma-tocopherols in human breast milk during the first months of lactation and in infant formulas. Matern Child Nutr. 2013. 9:473-82. doi:10.1111/j.1740-8709.2012.00401.x.

93. Mastorakou, D, Ruark, A, Weenen, $H$, Stahl, B, Stieger, M. Sensory characteristics of human milk: Association between mothers' diet and milk for bitter taste. J Dairy Sci. 2019. 102:1116-1130. doi:10.3168/jds.2018-15339.

94. Matamoros, N, Visentin, S, Ferrari, G, Falivene, M, Fasano, V, Gonzalez, HF. Vitamin A content in mature breast milk and its adequacy to the nutritional recommendations for infants. Arch Argent Pediatr. 2018. 116:146-148. doi:10.5546/aap.2018.eng.146.

95. Mekrungcharas, T, Kasemsup, R. Breast milk iodine concentrations in lactating mothers at Queen Sirikit National Institute of Child Health. J Med Assoc Thai. 2014. 97 Suppl 6:S115-9.

96. Meneses, F, Torres, AG, Trugo, NM. Influence of recent dietary intake on plasma and human milk levels of carotenoids and retinol in Brazilian nursing women. Adv Exp Med Biol. 2004. 554:351-4. doi:10.1007/978-1-4757-4242-8 39.

97. Metcalfe, JR, Marsh, JA, D'Vaz, N, Geddes, DT, Lai, CT, Prescott, SL, Palmer, DJ. Effects of maternal dietary egg intake during early lactation on human milk ovalbumin concentration: a randomized controlled trial. Clin Exp Allergy. 2016. 46:1605-1613. doi:10.1111/cea.12806.

\section{Rationale}

Population

Study Design

Intervention/Exposure; Outcome

Intervention/Exposure

Intervention/Exposure

Intervention/Exposure; Outcome

Intervention/Exposure

Intervention/Exposure; Outcome; Publication Status

Intervention/Exposure

Intervention/Exposure 


\section{Citation}

98. Meyer, KM, Mohammad, M, Bode, L, Chu, DM, Ma, J, Haymond, M, Aagaard, K. Maternal diet structures the breast milk microbiome in association with human milk oligosaccharides and gutassociated bacteria. American journal of obstetrics and gynecology. Conference: 37 th annual meeting of the society for maternal-fetal medicine: the pregnancy meeting. United states. Conference start: 20170123. Conference end: 20170128. 2017. 216:S15.

99. Meyer, KM, Mohammad, M, Ma, J, Chu, D, Haymond, M, Aagaard, K. Maternal diet alters the breast milk microbiome and microbial gene content. American journal of obstetrics and gynecology. 2016. 214:S47-S48.

100. Minato, T, Nomura, $K$, Asakura, $H$, Aihara, A, Hiraike, $H$, Hino, $Y$, Isojima, T, Kodama, $H$. Maternal Undernutrition and Breast Milk Macronutrient Content Are Not Associated with Weight in Breastfed Infants at 1 and 3 Months after Delivery. Int J Environ Res Public Health. 2019. 16. doi:10.3390/ijerph16183315.

101. Modification of docosahexaenoic acid composition of milk from women who received DHA from a milk formula during the pregnancy and breastfeeding period. Annals of nutrition \& metabolism. 2017. Conference: 21st International Congress of Nutrition, ICN 2017. Argentina. 71:506. doi:10.1159/000480486.

102. Mojska, H, Socha, P, Socha, J, Soplinska, E, Jaroszewska-Balicka, W, Szponar, L. Trans fatty acids in human milk in Poland and their association with breastfeeding mothers' diets. Acta Paediatr. 2003. 92:1381-7.

103. Moltó-Puigmartí, C, Plat, J, Mensink, RP, Müller, A, Jansen, E, Zeegers, MP, Thijs, C. FADS1 FADS2 gene variants modify the association between fish intake and the docosahexaenoic acid proportions in human milk. American Journal of Clinical Nutrition. 2010. 91:1368-1376. doi:10.3945/ajcn.2009.28789.

104. Moro, GE, Bertino, E, Bravi, F, Tonetto, P, Gatta, A, Quitadamo, PA, Salvatori, G, Profeti, C, Di Nicola, P, Decarli, A, Ferraroni, M, Tavani, A, Stahl, B, Wiens, F. Adherence to the Traditional Mediterranean Diet and Human Milk Composition: Rationale, Design, and Subject Characteristics of the MEDIDIET Study. Front Pediatr. 2019. 7:66. doi:10.3389/fped.2019.00066.

105. Mueller, A, Steinhart, H, Thijs, C, Rist, L, Simões-Wüst, AP, Huber, M. Trans fatty acids in human milk are an indicator of different maternal dietary sources containing trans fatty acids. Lipids. 2010. 45:245-251. doi:10.1007/s11745-010-3390-7.

106. Nct, . Does a Diet With the Recommended Amount of Polyunsaturated Fatty Acids, Increase Their Proportion in Maternal Milk?. Https://clinicaltrials.gov/show/nct03805997. 2019.

107. Nct, . Effect of n-3 Polyunsaturated Fatty Acids Supplementation on Human Milk Composition of Lactating Women. Https://clinicaltrials.gov/show/nct01288313. 2011.

\section{Rationale}

Study Design; Publication Status

Study Design

Intervention/Exposure

Study Design; Conference

Intervention/Exposure

Intervention/Exposure

Study Design; Intervention/Exposure

Intervention/Exposure; Population

Study Design; Clinical Trial Registry

Study Design; Clinical Trial Registry 


\section{Citation}

108. Nct, . Is Dietary Manipulation of Human Milk Total Fat and Caloric Content Feasible? Https://clinicaltrials.gov/show/nct00408980. 2006.

109. Nct, . The Mediterranean Diet and Lactation Study: a Diet Study in Lactating Women. Https://clinicaltrials.gov/show/nct01459991. 2011. doi:10.1038/pr.2014.24.

111. Nikniaz, L, Jr, Mahdavi, R, Arefhoesseini, SR, Sowti Khiabani, M. Association between fat content of breast milk and maternal nutritional status and infants' weight in tabriz, iran. Malays J Nutr. 2009. 15:37-44.

112. Nikniaz, L, Mahdavi, R, Ostadrahimi, A, Hejazi, MA, Vatankhah, AM. Effects of synbiotic supplementation on total antioxidant capacity of human breastmilk. Breastfeed Med. 2013. 8:217-22. doi:10.1089/bfm.2012.0078.

113. Nikniaz, L, Mahdavi, R, Ostadrahimi, A, Nikniaz, Z, Aliasgharzadeh, S. Does Maternal Synbiotic Supplementation Affect Conjugated Linoleic Acid Level in Breast Milk? A Randomized PlaceboControlled Clinical Trial. Breastfeeding Medicine. 2018. 13:81-84. doi:10.1089/bfm.2017.0053.

114. Nishimura, RY, Barbieiri, P, Castro, GS, Jordao, AA, Jr, Perdona GD, S, Sartorelli, DS. Dietary polyunsaturated fatty acid intake during late pregnancy affects fatty acid composition of mature breast milk. Nutrition. 2014. 30:685-9. doi:10.1016/j.nut.2013.11.002.

115. Ohta, S, Ishizuka, D, Nishimura, H, Nakao, T, Aozasa, O, Shimidzu, $Y$, Ochiai, F, Kida, T, Nishi, M, Miyata, $\mathrm{H}$. Comparison of polybrominated diphenyl ethers in fish, vegetables, and meats and levels in human milk of nursing women in Japan. Chemosphere. 2002. 46:689-96. doi:10.1016/s00456535(01)00233-8.

116. Olafsdottir, AS, Thorsdottir, I, Wagner, KH, Elmadfa, I. Polyunsaturated fatty acids in the diet and breast milk of lactating icelandic women with traditional fish and cod liver oil consumption. Ann Nutr Metab. 2006. 50:270-6. doi:10.1159/000091685.

117. Olafsdottir, AS, Wagner, $\mathrm{KH}$, Thorsdottir, I, Elmadfa, I. Fat-soluble vitamins in the maternal diet, influence of cod liver oil supplementation and impact of the maternal diet on human milk composition. Ann Nutr Metab. 2001. 45:265-72. doi:10.1159/000046737.

118. Otto, SJ, Van Houwelingen, AC, Badart-Smook, A, Hornstra, G. Comparison of the peripartum and postpartum phospholipid polyunsaturated fatty acid profiles of lactating and nonlactating women. American Journal of Clinical Nutrition. 2001. 73:1074-1079.

119. Paronen, J, Bjorksten, B, Hattevig, G, Akerblom, HK, Vaarala, O. Effect of maternal diet during lactation on development of bovine insulin-binding antibodies in children at risk for allergy. J Allergy Clin Immunol. 2000. 106:302-6. doi:10.1067/mai.2000.108110.

\section{Rationale}

Study Design; Clinical Trial Registry

Study Design; Publication Status

Study Design

Intervention/Exposure; Comparator

Intervention/Exposure

Intervention/Exposure

Intervention/Exposure

Intervention/Exposure

Comparator

Intervention/Exposure

Intervention/Exposure

Intervention/Exposure 


\section{Citation}

120. Pawlak, R. To vegan or not to vegan when pregnant, lactating or feeding young children. Eur $\mathrm{J}$ Clin Nutr. 2017. 71:1259-1262. doi:10.1038/ejcn.2017.111.

121. Peng, $Y$, Zhou, $T$, Wang, $Q$, Liu, $P$, Zhang, $T$, Zetterström, $R$, Strandvik, B. Fatty acid composition of diet, cord blood and breast milk in Chinese mothers with different dietary habits. Prostaglandins Leukotrienes and Essential Fatty Acids. 2009. 81:325-330. doi:10.1016/j.plefa.2009.07.004.

122. Qian, J, Chen, $T, L u, W, W u, S, Z$ hu, J. Breast milk macro- and micronutrient composition in lactating Outcome mothers from suburban and urban Shanghai. J Paediatr Child Health. 2010. 46:115-20. doi:10.1111/j.1440-1754.2009.01648.x.

123. Quinn, E, Kuzawa, C. A dose-response relationship between fish consumption and human milk DHA Intervention/Exposure content among Filipino women in Cebu City, Philippines. Acta Paediatrica. 2012. 101:e439-45. doi:10.1111/j.1651-2227.2012.02777.x.

124. Quinn, EA, Largado, F, Power, M, Kuzawa, CW. Predictors of breast milk macronutrient composition Intervention/Exposure in Filipino mothers. Am J Hum Biol. 2012. 24:533-40. doi:10.1002/ajhb.22266.

125. Rachmel, A, Steinberg, T, Ashkenazi, S, Sela, BA. Cobalamin deficiency in a breast-fed infant of a Study Design vegetarian mother. Isr Med Assoc J. 2003. 5:534-6.

126. Ramani, S. Multidisciplinary Studies on Rotavirus-Human Milk Oligosaccharide Interactions. Breastfeed Med. 2018. 13:S9-s10. doi:10.1089/bfm.2018.29074.sjr.

127. Reghu, A, Hosdurga, S, Sandhu, B, Spray, C. Vitamin B12 deficiency presenting as oedema in infants of vegetarian mothers. Eur J Pediatr. 2005. 164:257-8. doi:10.1007/s00431-004-1616-5.

128. Rist, L, Mueller, A, Barthel, C, Snijders, B, Jansen, M, Simoes-Wust, AP, Huber, M, Kummeling, I, von Intervention/Exposure Mandach, U, Steinhart, H, Thijs, C. Influence of organic diet on the amount of conjugated linoleic acids in breast milk of lactating women in the Netherlands. Br J Nutr. 2007. 97:735-43. doi:10.1017/s0007114507433074.

129. Sabel, KG, Lundqvist-Persson, C, Bona, E, Petzold, M, Strandvik, B. Fatty acid patterns early after premature birth, simultaneously analysed in mothers' food, breast milk and serum phospholipids of mothers and infants. Lipids in Health and Disease. 2009. 8. doi:10.1186/1476-511X-8-20.

130. Samur, G, Topcu, A, Turan, S. Trans fatty acids and fatty acid composition of mature breast milk in turkish women and their association with maternal diet's. Lipids. 2009. 44:405-13. doi:10.1007/s11745-009-3293-7.

131. Sartorelli, DS, Nishimura, RY, Castro, GSF, Barbieri, P, Jordão, AA. Validation of a FFQ for estimating $\omega-3, \omega-6$ and trans fatty acid intake during pregnancy using mature breast milk and food recalls. European Journal of Clinical Nutrition. 2012. 66:1259-1264. doi:10.1038/ejcn.2012.127.

\section{Rationale}

Study Design

Population; Outcome

Study Design

Study Design

Intervention/Exposure; Population

Intervention/Exposure; Comparator

Intervention/Exposure 


\section{Citation}

\section{Rationale}

132. Scopesi, F, Ciangherotti, S, Lantieri, PB, Risso, D, Bertini, I, Campone, F, Pedrotti, A, Bonacci, W,

Intervention/Exposure; Comparator Serra, G. Maternal dietary PUFAs intake and human milk content relationships during the first month of lactation. Clin Nutr. 2001. 20:393-7. doi:10.1054/clnu.2001.0464.

133. Shoff, SM, Lai, HJ. Essential fatty acid content appears low in breast milk and diet of mothers of infants with CF. Pediatric pulmonology. 2016. Conference: 30th Annual North American Cystic Fibrosis Conference. United States. Conference Start: 20161027. Conference End: 20161029. 51:430. doi:10.1002/ppul.23576.

134. Silva, MA, Soares, MM, Fonseca, PCA, Vieira, SA, Carvalho, CA, Amaral, RM, Franceschini, SDCC, Novaes, JF. Relationship between breastfeeding patterns and intake of vitamin A and iron in children 6-12 months. Cien Saude Colet. 2019. 24:4009-4018. doi:10.1590/1413-812320182411.05782018.

135. Silva, MHL, Silva, MTC, Brandão, SCC, Gomes, JC, Peternelli, LA, Franceschini, SDCC. Fatty acid composition of mature breast milk in Brazilian women. Food Chemistry. 2005. 93:297-303. doi:10.1016/j.foodchem.2004.09.026.

136. Snoj Tratnik, J, Falnoga, I, Mazej, D, Kocman, D, Fajon, V, Jagodic, M, Stajnko, A, Trdin, A, Slejkovec, Z, Jeran, Z, Osredkar, J, Sesek-Briski, A, Krsnik, M, Kobal, AB, Kononenko, L, Horvat, M. Results of the first national human biomonitoring in Slovenia: Trace elements in men and lactating women, predictors of exposure and reference values. Int J Hyg Environ Health. 2019. 222:563-582. doi:10.1016/j.ijheh.2019.02.008.

137. Stendell-Hollis, NR, Thompson, PA, West, JL, Wertheim, BC, Thomson, CA. A comparison of mediterranean-style and mypyramid diets on weight loss and inflammatory biomarkers in postpartum breastfeeding women. Journal of Women's Health. 2013. 22:48-57. doi:10.1089/jwh.2012.3707.

138. Storck Lindholm, E, Strandvik, B, Altman, D, Möller, A, Palme Kilander, C. Different fatty acid pattern in breast milk of obese compared to normal-weight mothers. Prostaglandins Leukotrienes and Essential Fatty Acids. 2013. 88:211-217. doi:10.1016/j.plefa.2012.11.007.

139. Stoutjesdijk, E, Schaafsma, A, Dijck-Brouwer, DAJ, Muskiet, FAJ. lodine status during pregnancy and Intervention/Exposure lactation: a pilot study in the Netherlands. Neth J Med. 2018. 76:210-217.

140. Su, LL, Sk, TC, Lim, SL, Chen, Y, Tan, EA, Pai, NN, Gong, YH, Foo, J, Rauff, M, Chong, YS. The influence of maternal ethnic group and diet on breast milk fatty acid composition. Ann Acad Med Singapore. 2010. 39:675-5.

141. Taghipour, S, Nikniaz, L, Mahavi, R, Ostadrahimi, A, Nikniaz, Z. Synbiotic supplementation is not effective on breast milk selenium concentrations and growth of exclusively breast fed infants: a pilot study. Int J Vitam Nutr Res. 2019. doi:10.1024/0300-9831/a000549.

142. Tavares, MP, Devincenzi, MU, Sachs, A, de Vilhena Abrão, ACF. Nutritional status and diet quality of Outcome nursing mothers on exclusive breastfeeding. Acta Paulista de Enfermagem. 2013. 26:294-298.

Study Design; Conference/poster

Intervention/Exposure; Population

Intervention/Exposure

Intervention/Exposure

\section{Outcome}

Intervention/Exposure

Intervention/Exposure

Intervention/Exposure 


\section{Citation}

143. Tawfeek, $\mathrm{HI}$, Muhyaddin, OM, al-Sanwi, $\mathrm{HI}$, al-Baety, $\mathrm{N}$. Effect of maternal dietary vitamin $\mathrm{C}$ intake on the level of vitamin C in breastmilk among nursing mothers in Baghdad, Iraq. Food Nutr Bull. 2002. 23:244-7. doi:10.1177/156482650202300302.

144. Tiangson, CLP, Gavino, VC, Gavino, G, Panlasigui, LN. Docosahexaenoic acid level of the breast milk of some Filipino women. International Journal of Food Sciences and Nutrition. 2003. 54:379-386. doi:10.1080/0963748031000092152.

145. Urwin, HJ, Miles, EA, Noakes, PS, Kremmyda, LS, Vlachava, M, Diaper, ND, Perez-Cano, FJ, Godfrey, KM, Calder, PC, Yaqoob, P. Salmon consumption during pregnancy alters fatty acid composition and secretory lgA concentration in human breast milk. J Nutr. 2012. 142:1603-10. doi:10.3945/jn.112.160804.

146. Urwin, HJ, Zhang, J, Gao, Y, Wang, C, Li, L, Song, P, Man, Q, Meng, L, Froyland, L, Miles, EA, Calder, PC, Yaqoob, P. Immune factors and fatty acid composition in human milk from river/lake, coastal and inland regions of China. Br J Nutr. 2013. 109:1949-61. doi:10.1017/s0007114512004084.

147. Vähämiko, S, Isolauri, E, Poussa, T, Laitinen, K. The impact of dietary counselling during pregnancy on vitamin intake and status of women and their children. International Journal of Food Sciences and Nutrition. 2013. 64:551-560. doi:10.3109/09637486.2013.766153.

148. Valent, F, Horvat, M, Mazej, D, Stibilj, V, Barbone, F. Maternal diet and selenium concentration in human milk from an Italian population. J Epidemiol. 2011. 21:285-92. doi:10.2188/jea.je20100183.

149. Vaysse, C, Simon, N, Tressou, J, Pasteau, S, Buaud, B, Guesnet, P, Couedelo, L, Billeaud, C. Polyunsaturated fatty acids consumption in lactating women in France: The INCA 2 study and evolution of essential fatty acids composition in breast milk from 1997 to 2014. Cahiers de Nutrition et de Dietetique. 2019. 54:35-43. doi:10.1016/j.cnd.2018.11.004.

150. Wan, ZX, Wang, XL, Xu, L, Geng, Q, Zhang, Y. Lipid content and fatty acids composition of mature human milk in rural North China. Br J Nutr. 2010. 103:913-6. doi:10.1017/s0007114509992455.

151. Williams, JE, Carrothers, JM, Lackey, KA, Beatty, NF, York, MA, Brooker, SL, Shafii, B, Price, WJ, Settles, ML, McGuire, MA, McGuire, MK. Human Milk Microbial Community Structure Is Relatively Stable and Related to Variations in Macronutrient and Micronutrient Intakes in Healthy Lactating Women. J Nutr. 2017. 147:1739-1748. doi:10.3945/jn.117.248864.

152. Wong, VW, Ng, YF, Chan, SM, Su, YX, Kwok, KW, Chan, HM, Cheung, CL, Lee, HW, Pak, WY, Li, SY, Wong, MS. Positive relationship between consumption of specific fish type and omega-3 polyunsaturated fatty acids in milk of Hong Kong lactating mothers. Br J Nutr. 2019. doi:10.1017/s0007114519000801.

153. Wu, TC, Lau, BH, Chen, PH, Wu, LT, Tang, RB. Fatty acid composition of Taiwanese human milk. J Chin Med Assoc. 2010. 73:581-8. doi:10.1016/s1726-4901(10)70127-1.

\section{Rationale}

Intervention/Exposure; Country

Intervention/Exposure

Intervention/Exposure

Population

Intervention/Exposure

Intervention/Exposure

Not English

Intervention/Exposure; Outcome

Intervention/Exposure

Intervention/Exposure

Intervention/Exposure 


\section{Citation}

154. Xiang, M, Alfven, G, Blennow, M, Trygg, M, Zetterstrom, R. Long-chain polyunsaturated fatty acids in human milk and brain growth during early infancy. Acta Paediatr. 2000. 89:142-7.

155. Xiang, M, Harbige, LS, Zetterström, R. Breast milk levels of zinc and $\omega-6$ polyunsaturated fatty acids and growth of healthy Chinese infants. Acta Paediatrica, International Journal of Paediatrics. 2007. 96:387-390. doi:10.1111/j.1651-2227.2006.00140.x.

156. Xiang, M, Harbige, LS, Zetterstrom, R. Long-chain polyunsaturated fatty acids in Chinese and Swedish mothers: diet, breast milk and infant growth. Acta Paediatr. 2005. 94:1543-9. doi:10.1080/08035250500251601.

157. Xue, Y, Campos-Gimenez, E, Redeuil, KM, Leveques, A, Actis-Goretta, L, Vinyes-Pares, G, Zhang, Y, Intervention/Exposure Wang, $P$, Thakkar, SK. Concentrations of Carotenoids and Tocopherols in Breast Milk from Urban Chinese Mothers and Their Associations with Maternal Characteristics: A Cross-Sectional Study. Nutrients. 2017. 9. doi:10.3390/nu9111229.

158. Yalcin, SS, Yurdakok, K, Yalcin, S, Engur-Karasimav, D, Coskun, T. Maternal and environmental determinants of breast-milk mercury concentrations. Turk J Pediatr. 2010. 52:1-9.

159. Yang, T, Zhang, Y, Ning, Y, You, L, Ma, D, Zheng, Y, Yang, X, Li, W, Wang, J, Wang, P. Breast milk macronutrient composition and the associated factors in urban Chinese mothers. Chin Med $\mathrm{J}$ (Engl). 2014. 127:1721-5.

160. Yang, Z, Jiang, R, Chen, Q, Wang, J, Duan, Y, Pang, X, Jiang, S, Bi, Y, Zhang, H, Lonnerdal, B, Lai, $\mathrm{J}$, Yin, S. Concentration of Lactoferrin in Human Milk and Its Variation during Lactation in Different Chinese Populations. Nutrients. 2018. 10. doi:10.3390/nu10091235.

161. Yu, Y, Tao, S, Liu, W, Lu, X, Wang, X, Wong, M. Dietary intake and human milk residues of hexachlorocyclohexane isomers in two Chinese cities. Environ Sci Technol. 2009. 43:4830-5. doi:10.1021/es900082v.

162. Zhao, A, Ning, Y, Zhang, Y, Yang, X, Wang, J, Li, W, Wang, P. Mineral compositions in breast milk of healthy Chinese lactating women in urban areas and its associated factors. Chin Med J (Engl). 2014. 127:2643-8.

163. Zielinska, MA, Hamulka, J, Wesolowska, A. Carotenoid content in breastmilk in the 3rd and 6th month of lactation and its associations with maternal dietary intake and anthropometric characteristics. Nutrients. 2019. 11. doi:10.3390/nu11010193.

\section{Rationale}

Intervention/Exposure

Intervention/Exposure

Intervention/Exposure; Country

Intervention/Exposure

Intervention/Exposure; Comparator

Intervention/Exposure

Intervention/Exposure; Outcome

Intervention/Exposure

I

Intervention/Exposure; Comparator 